\title{
THE RELATIONSHIP OF HIGH SCHOOL CURRICULUM TRACKS TO DEGREE ATTAINMENT AND OCCUPATIONAL EARNINGS
}

\section{DISSERTATION}

Presented in Partial Fulfillment of the Requirements for

the Degree Doctor of Philosophy in the Graduate

School of The Ohio State University

By

Edward Charles Fletcher Jr., M.Ed.

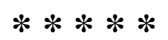

The Ohio State University

2009

Dissertation Committee:

Approved by

Professor Chris Zirkle, Adviser

Professor Joseph Gliem

Professor Robert Hite

Adviser

College of Education \& Human

Ecology 


\section{Copyright by}

Edward Charles Fletcher Jr. 


\begin{abstract}
The scope and direction of career and technical education (CTE) has been reconceptualized based on federal legislation objectives, particularly the Carl D. Perkins Vocational and Applied Technology Education Act of 1990. Consequently, CTE’s historical focus on preparing students solely for the workforce is no longer adequate. Thus, a new emphasis on preparing students for the workforce and for postsecondary education is now on the agenda. In the midst of heightened accountability standards set forth by the No Child Left Behind (NCLB) Act, it is essential to evaluate long-term CTE student outcomes. Hence, the purpose of this study was to investigate the relationship between high school curriculum tracks and student achievement outcomes through the consideration of degree attainment and occupational earnings. Data on graduates from the 1996-1997 academic school year cohort were analyzed through the National Longitudinal Survey of Youth (NLSY) 1997 dataset. This study investigated the linkage between participation in high school curriculum tracks, degree attainment and occupational earnings. Findings of this research study indicated that the Carl D. Perkins Vocational and Applied Technology Education Act of 1990 may not be meeting its objectives in terms of CTE students earning postsecondary degrees. However, this study found that CTE students were indeed outperforming the general, dual, and college preparatory tracks in terms of occupational earnings. More promising was the dual track that was
\end{abstract}


more likely to earn associate's degrees than their general tracked counterparts. As expected, the college preparatory track outperformed all tracks in terms of degree attainment, particularly in earning bachelor's degrees. This study also found that general track students were not as likely to earn degrees and higher earnings as those in the college preparatory, CTE, or dual tracks. In terms of participation rates, Blacks were much more likely to participate in the CTE track, Hispanics were more likely to participate in the general track, and non-Black/non-Hispanics were more likely to participate in the college preparatory track. In addition, this research study provided several implications for CTE programs, teachers, administrators, guidance counselors, parents, as well as for students choosing to enroll in CTE, college preparatory, general, or dual tracks. Future directions for further research that include additional variables that predict participation in high school curriculum tracks, degree attainment, and earnings were provided. Further, the need for longitudinal studies regarding student outcomes of tracking, as well as student outcomes on high school reform initiatives were suggested. 
Dedicated to my parents,

Edward and Ramona Fletcher 


\section{ACKNOWLEDGMENTS}

First and foremost, I would like to express my sincere gratitude to my parents, Edward and Mona Fletcher Sr., for providing me with the most precious gift of life. My parents have continually supported and encouraged me through the sometimes rough terrain and constant hurdles of the Ph.D. process. Moreover, they have always believed in me, particularly through the high demanding road leading to the Ph.D. My parents taught me the meaning of dedication and perseverance, which carried me through the Ph.D. process, as well as all of my other successes and accomplishments in my life. I am constantly reminded of the old adage that my dad would say to me, "If it is to be, it is up to me".

I also would like to give special thanks to my adviser, Dr. Chris Zirkle. I will never forget that it is he that advocated for me and was instrumental in my acceptance to the Workforce Development and Education (WDE) Ph.D. program. When I first met my adviser, I shook his hand and indicated to him that I was so grateful for his affirmative response in terms of my acceptance into the Ph.D. program, and expressed my excitement to be a part of The Ohio State University. At that moment, I could tell that he believed in me and was ready to take on the charge of developing me as a scholar. I also knew that I had to ensure that I did not let him down. Further, I knew I had my work cut out for me. In addition to the many publications Dr. Zirkle and I co-authored, he has introduced me to the Career and Technical Education (CTE) community of scholars and made sure that 
his colleagues knew me and my accomplishments. Further, I really appreciate his willingness to help me when I ran into difficulties with my car and other life challenges. I look forward to furthering our collegial relationship and future collaboration on research projects.

I owe many thanks and much gratitude to my committee members. Dr. Robert Hite has not only been a committee member, but has also inspired me to be the best teacher educator that I can be. He has equipped me with the knowledge, skills, and dispositions I will need for my role as a teacher educator. He has also modeled to me what it is like to genuinely care for others. I will always remember the dinner gatherings him and his wife would provide for his students. Dr. Hite's practices should be studied by all.

Further, I would like to thank Dr. Joe Gliem. He has equipped me with the most valuable knowledge and skills that a doctoral student would need. The content that I learned in his research courses will surely serve me well in the professoriate. Further, I would like to express my appreciation for Dr. Jill Ellingson. She was willing to serve on my candidacy exam committee and challenged me to understand the Human Resources/Organizational Behavior body of knowledge.

It is also essential that I acknowledge my invisible advisor and committee member, Dr. Michael Mobley. Dr. Mobley has been a mentor to me since my undergraduate days. I am forever indebted to Dr. Mobley, for he was critical in me graduating from the University of Missouri and receiving honors for my bachelor's degree. He has counseled and consulted me on many issues and challenges I experienced. Further, he has reviewed my work and has given me substantive feedback, sometimes in 
a very short notice. I also owe much of the credit for landing my new position at Illinois State University to Dr. Mobley. He has been a great friend and mentor.

The challenges and issues that I experienced in my pursuit of the Ph.D. was certainly lessened by the many colleagues that I met in the WDE community. Special thanks are in line for soon-to-be Dr. Susan Johnston. She has been one of my cheerleaders and has counseled me through many of my difficult times. On many occasions, we cried together and celebrated our successes together. I look forward to our continuing friendship.

I would also like to express my sincere appreciation for two other cheerleaders of mine, soon-to-be Drs. Mona Simons and Ruth Ann Harris. I will always remember our dinner gatherings and discussions. I have been able to share my stories and life issues with Mona. She has listened and always given me good advice. In addition, Ruth Ann has been an inspiration to me and has encouraged me throughout the Ph.D. process. These individuals have certainly made the road much more manageable. I look forward to our continuing friendship.

It was certainly a pleasure working with Charles Saunders as a fellow graduate teaching associate in WDE. I have never met an individual that had such a caring disposition and concern for the well-being of others. Many thanks to Dr. Constance Wanstreet for her wisdom, insight, and patience in helping me build knowledge in conducting research.

Last, but not least, I would like to extend many thanks to the WDE faculty, students, and staff. I would like to thank Dr. Josh Hawley for his encouragement throughout my program. He took out the time in his busy schedule to listen to me and 
provide me with advice on many occasions. One of the most inspiring moments for me was when Dr. Hawley awarded me the WDE Ph.D. award and showed me the plaque with all of the past recipients' names inscribed on it. He told me that all of those individuals have gone on to do great things and that was the expectation for me as well. At that moment, I knew that I had to step up to the plate and not let Dr. Hawley or the WDE community down. In addition, I would like to thank Dr. Ruth Dohner for listening to my issues and giving me advice. Her work and dedication was certainly inspiring to me. Further, I would like to thank Dr. Jim Pinchak for taking the time to show me how to conduct field supervision visits for teacher candidates and taking an interest in me.

I have had so many people that are responsible for my success. Some of my colleagues that have touched my life, encouraged me, and collaborated with me on scholarly projects include the following: Dr. Jacobs, Dr. Jane Briggs, Kris Sander, Younghee Kong, Dr.Yoonhee Park, Woojae Choi, Joohee Chang, Kathy Lechman, MeiLin Chang, Maria Gies, Dr. Samuel Hodge, Dr. James Moore, Dr. Rod Githens, Bonita Williams, and Dolly Curry. I deeply regret not mentioning those individuals that I have left out of this discussion that were a part of my success. Please do know that I am very much appreciative of your support. 
VITA

April $29,1980 \ldots$ B.

Research Publications

1. Fletcher, E. \& Zirkle, C. (2009). Career and technical education in light of the No Child Left Behind legislation. In V. Wang (Ed.), The Handbook of Research on E-Learning Applications for Career and Technical Education: Technologies for Vocational Training. IGI Global.

2. Zirkle, C., \& Fletcher, E. (2009). Access barriers experienced by adults in distance education courses and programs. In V. Wang (Ed.), The Handbook of Research on E-Learning Applications for Career and Technical Education: Technologies for Vocational Training. IGI Global.

3. Zirkle, C., \& Fletcher, E. (2009). Utilization of distance education in career and technical education teacher education. In V. Wang (Ed.), The Handbook of Research on E-Learning Applications for Career and Technical Education: Technologies for Vocational Training. IGI Global. 
4. Hite, R., Fletcher, E., Bruening, P., Durr, A., Yontz, B., Zatezalo, R., et al.(2009). The preparation, roles, and responsibilities of teacher educators. In A. Selkirk \& M. Tichenor (Eds.), Teacher Education: Policy, Practice, and Research. Hauppage, NY: Nova Publishers.

5. Fletcher, E. (2006). The Effects of the No Child Left Behind legislation on career and technical education. Career and Technical Education Research, 30(3), 1-20.

\section{FIELDS OF STUDY}

Major Field: Education

Career and Technical Education

Chris Zirkle, Ph.D.

Research Methods

Joseph Gliem, Ph.D.

Doctoral Study in Teacher Education Policy and Leadership

Robert Hite, Ph.D.

Human Resources and Organizational Behavior

Jill Ellingson, Ph.D. 


\section{TABLE OF CONTENTS}

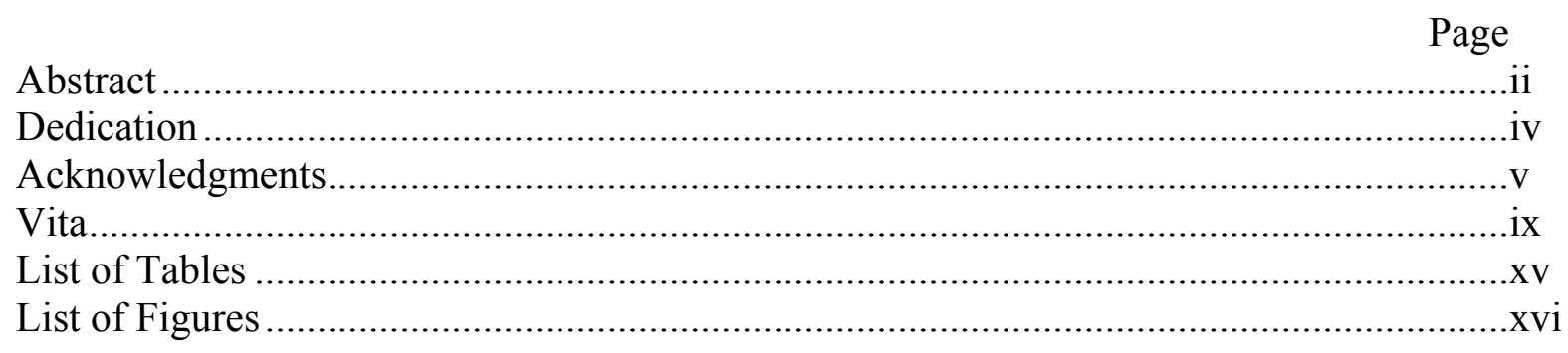

Chapters:

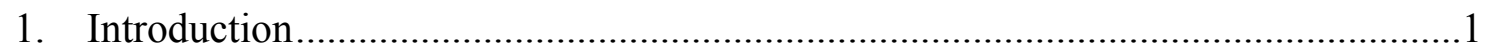

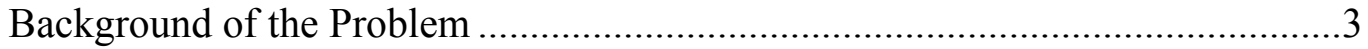

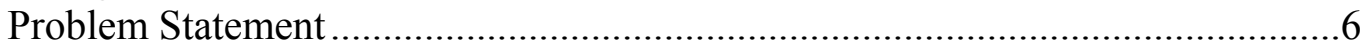

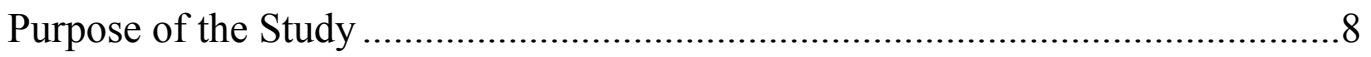

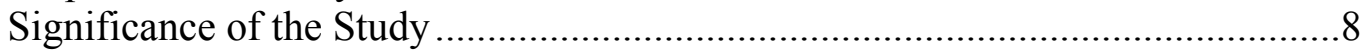

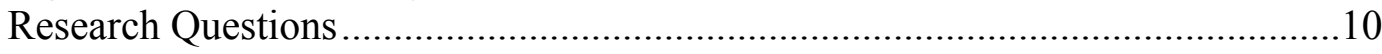

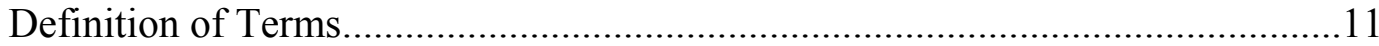

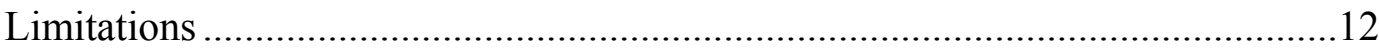

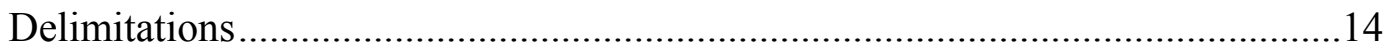

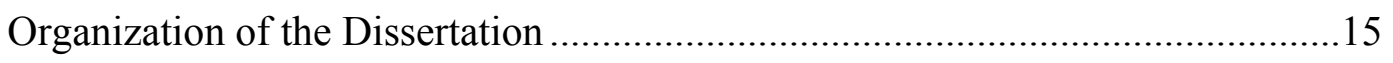

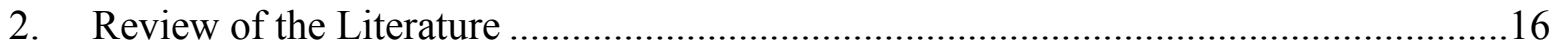

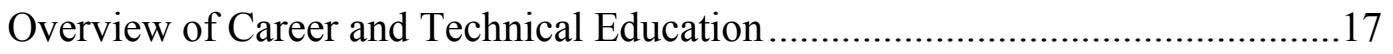

A Brief Historical Account of CTE ........................................................... 17

Current Conceptions of CTE ............................................................... 17

The Separation of CTE and Core Academic Curricula .................................19

Current CTE Teachers' Perceptions of Integrating Academic and CTE

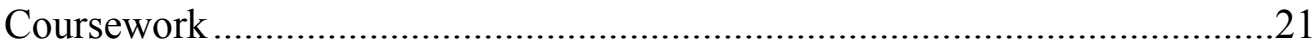

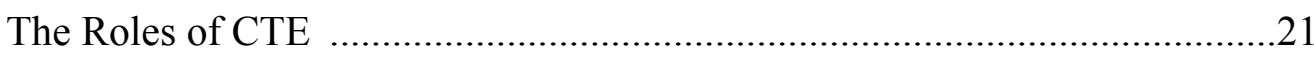

Students' Long-Term Decision-Making .......................................................22

Social Learning Theory of Career Decision-Making...................................22

Social Cognitive Theory of Career and Academic Interest, Choice, and

Performance ...................................................................................23

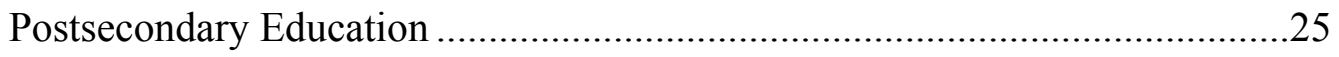

Research on Factors Contributing to Decisions to Enroll in Postsecondary

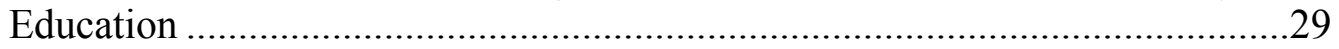


Factors Influencing Postsecondary Education Attainment for Core

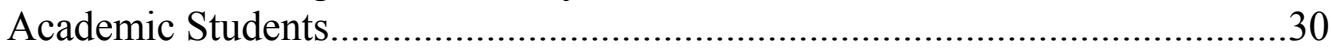

Factors Influencing Postsecondary Education Attainment for CTE Students ..31 Summary of Research Findings on Factors Influencing Postsecondary

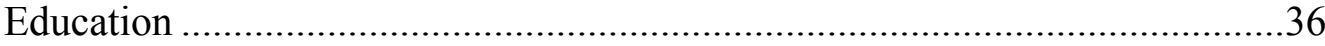

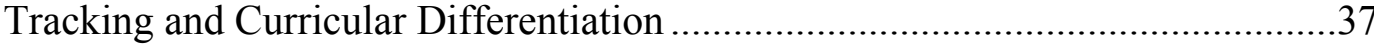

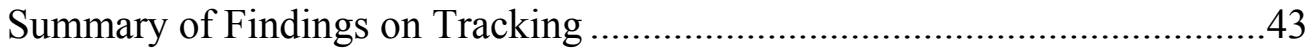

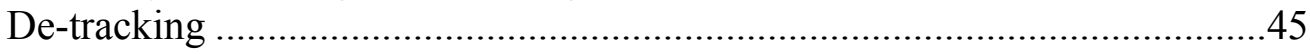

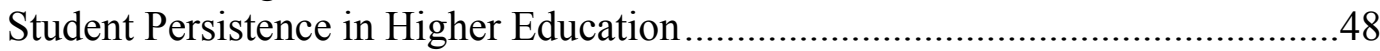

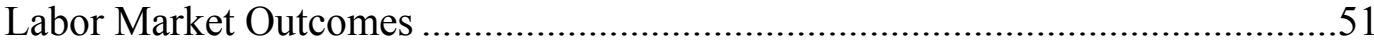

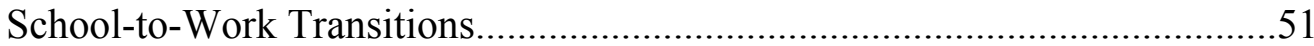

The Impact of CTE on Long-Term Earnings..........................................54

The Impact of CTE on Occupational Choices ...........................................56

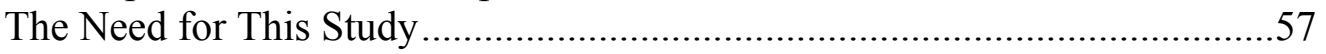

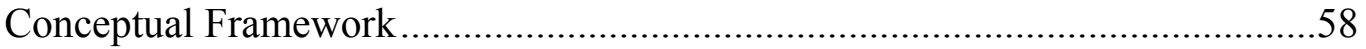

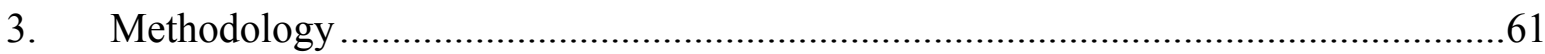

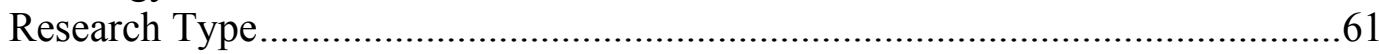

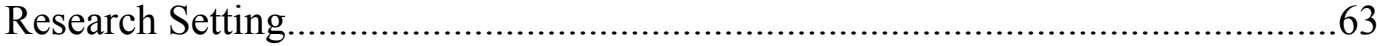

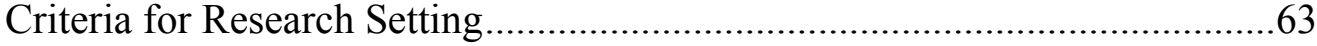

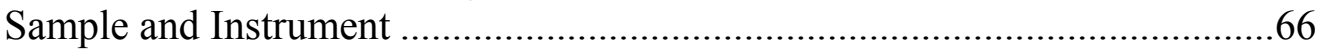

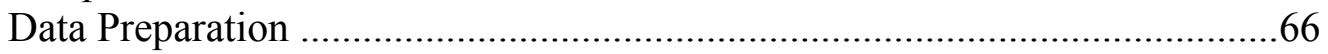

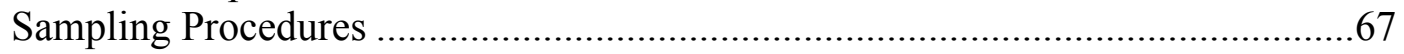

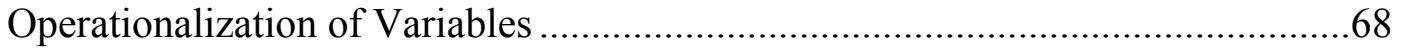

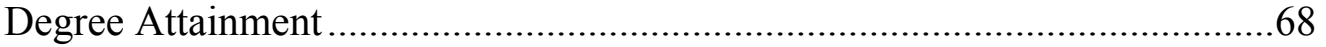

Fathers with a College Education ........................................................69

Fathers with a High School Education...................................................69

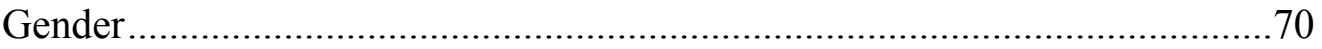

High School Curriculum Tracks ......................................................... 70

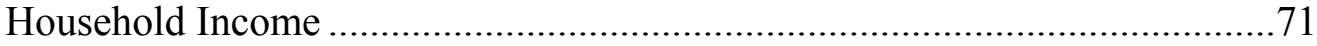

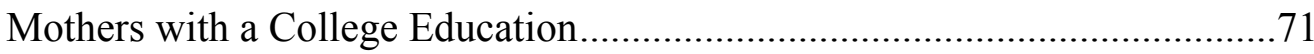

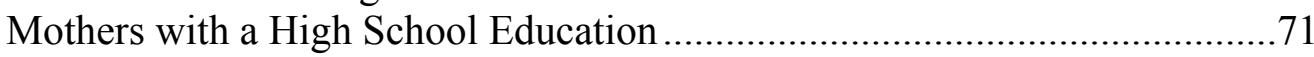

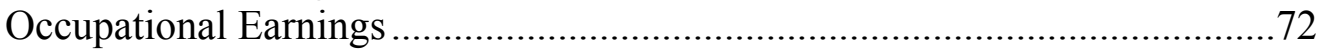

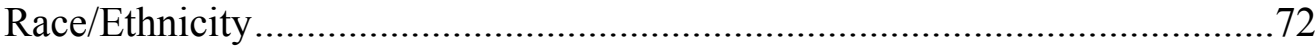

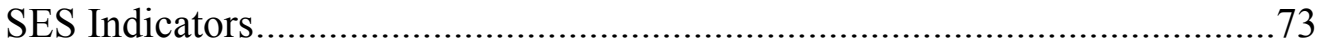

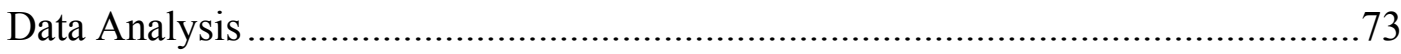

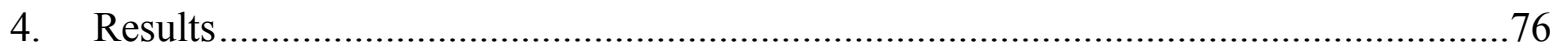

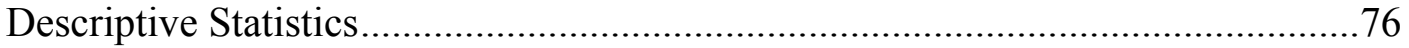

Assessing the Assumptions for Research Question One and Research

Question Two......................................................................................79

Response to Research Question One: To what extend do demographic

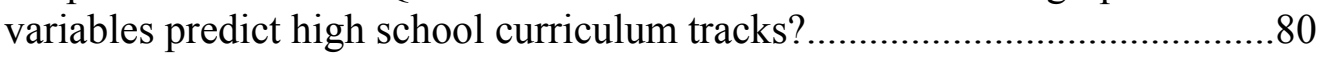

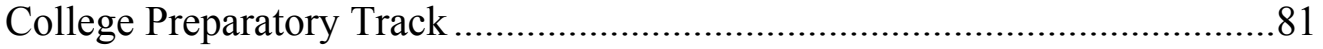


CTE Track

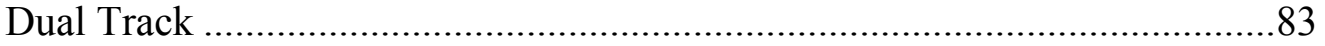

Response to Research Question Two: To what extent do demographic variables and high school curriculum tracks predict degree attainment? ........83

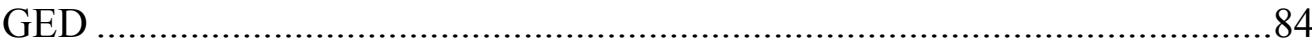

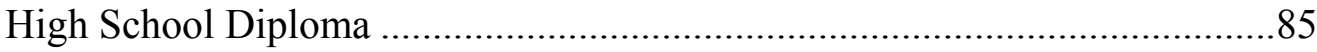

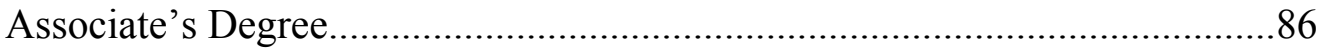

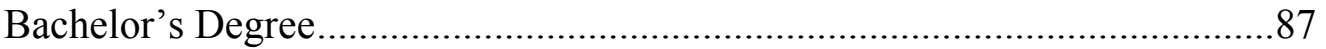

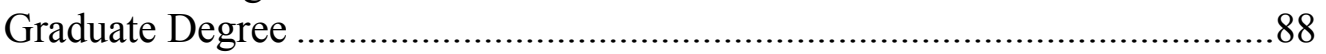

Assumptions of Research Question Three....................................................89

Assessing Multicollinearity Issues................................................................90

Response to Research Question Three: To what extent do demographic variables, degree attainment, and high school curriculum tracks predict

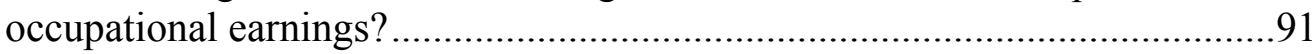

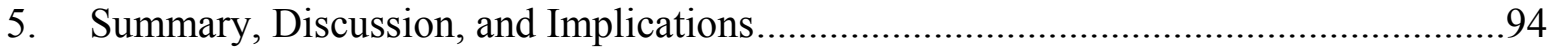

A Summary of Results from this Research Study ....................................................94

Summary of Results for Research Question One: To what extent do demographic variables predict high school curriculum tracks?..............................95

Summary of Results for Research Question Two: To what extent do demographic variables and high school curriculum tracks predict degree attainment?

Summary of Results for Research Question Three: To what extent do demographic variables, degree attainment, and high school curriculum tracks

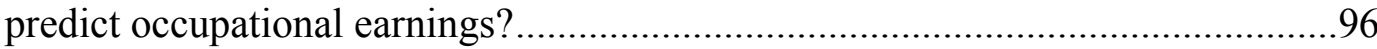

A Discussion of the Results of this Study ...............................................................97

Participation in High School Curriculum Tracks................................................97

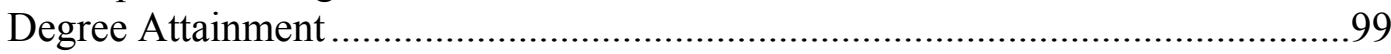

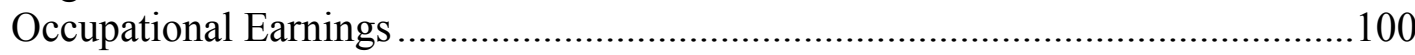

Implications for Further Research .......................................................................101

Participation in High School Curriculum Tracks.................................................101

Degree Attainment ........................................................................................102

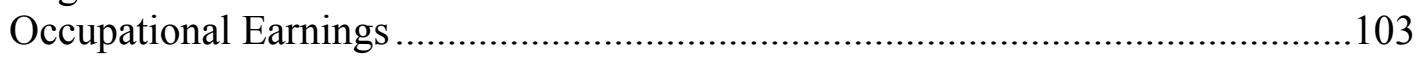

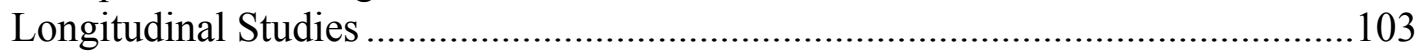

Future Research on CTE High School Reform Initiatives.......................................104

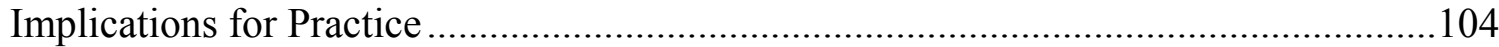

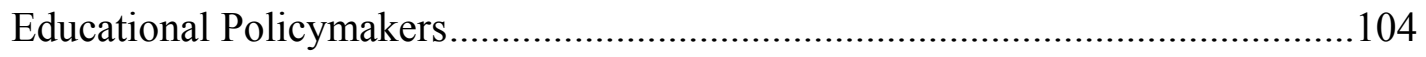

Implications for Administrators, Guidance Counselors, Parents, Teacher

Education, Teachers, and Students ..................................................................106

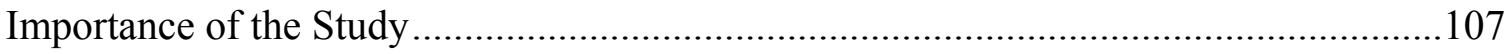

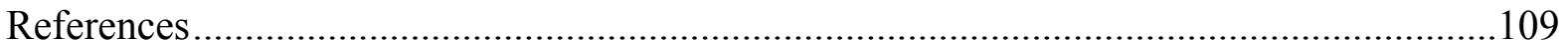


Appendices

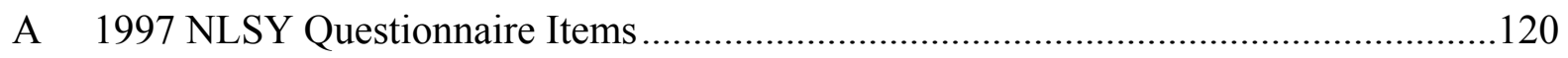

B Participation based on High School Curriculum Tracks ...........................................129

C Degree Attainment based on High School Curriculum Tracks..................................133

D Histogram of Residuals and Normal Probability Plot.............................................139

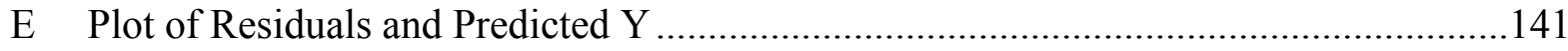

F Predictors of Occupational Earnings …......................................................... 143 


\section{LIST OF TABLES}

Table

PAGE

4.1 Race/Ethnicity Participation Rates based on High School Curriculum Tracks ...... 77

4.2 Degree Attainment in 2006 by High School Curriculum Track based on NLSY

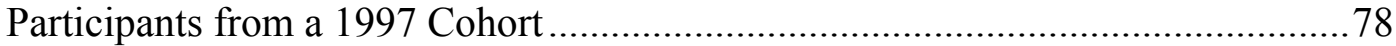

4.3 2005 Average Earned Income based on High School Curriculum Track..............79 


\section{LIST OF FIGURES}

Figure

PAGE

2.1 Conceptual framework for examining status attainment effects of high school

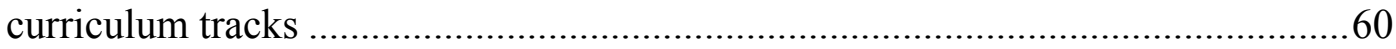




\section{CHAPTER 1}

\section{INTRODUCTION}

Secondary education is increasingly being scrutinized for not properly preparing students for entry into the workforce or for postsecondary education attainment (Fletcher, 2006). In response to schools not meeting public expectations, there has been an increase in accountability measures for high schools. The most comprehensive accountability measure for schools throughout the nation is the No Child Left Behind (NCLB) legislation mandating that all schools be held accountable for students' academic achievement (Fletcher, 2006; Fletcher \& Zirkle, 2009; King, Schexnayder, \& Gourgey, 2005; NCLB, 2001). Coupled with the recent reauthorization of the Carl D. Perkins Vocational and Technical Education Act of 1998 (currently known as the Carl D. Perkins Career and Technical Education Improvement Act of 2006), one of the more recent objectives for career and technical education (CTE) is to increase student achievement through the integration of CTE and traditional academic content (Carl D. Perkins Career \& Technical Education Act; 2006; Dare, 2006; Elliott, 2006; Gordon, 2008; Park \& Osborne, 2007; Scott \& Sarkees-Wircenski, 2008).

In fact, the integration of $\mathrm{CTE}$ and academic education is a fairly recent

phenomenon and has caused educators, administrators, researchers, and policymakers to 
re-think how the traditional educational curriculum is organized for students. This phenomenon has been sparked by several contemporary events such as the technological revolution, the increasing presence of women and minorities due to globalization in the workforce, and the increased competition among countries (Castellano, Stringfield, \& Stone, 2003). These factors serve as impetus for educators, administrators, researchers, and policymakers to create a more seamless integration of career development and college preparatory curricula for all students in order to increase students' options upon graduation, decrease high youth unemployment, and increase international competitiveness (Plank, 2002; Rojewski, 2002; Rojewski \& Kim, 2003). In concert with increasing students' options upon graduation, the epistemological structure of integrating a college preparatory curriculum and applying it through CTE courses is an innovative concept undergirded in the pedagogical platform of theory to practice, applied learning, and contextual teaching and learning.

Despite efforts at integrating academic and CTE courses, little is known of its effects on student achievement or long-term student outcomes (Castellano et al., 2003; DeLuca, Plank, \& Estacion, 2006; Hudson \& Hurst, 1999). Furthermore, Castellano et al. (2003) found that research on long-term outcomes of students attending schools with integrated curricula such as the High Schools That Work (HSTW) model is critically warranted, especially outcomes indicating performance on standardized assessments, graduation rates, postsecondary education attainment rates, and participation in the labor market. 


\section{Background of the Problem}

With the establishment of public schools in the last quarter of the nineteenth century (during the industrial age), philosophical debates proliferated around the issue of classical and practical education programs (Gordon, 2008; Scott \& Sarkees-Wircenski, 2008). Soon after, the enactment of the Smith-Hughes Act of 1917 was instituted. This legislation was the first time the federal government supported and provided funding for vocational education (Jacobs \& Grubb, 2003; Stasz \& Bodilly, 2004), thus making the initiation of ongoing involvement in vocational programs. It called for the separation of vocational education from all other curricula in a comprehensive high school. Accordingly, the legislation mandated that vocational education have a separate state board distinguished from the State Board of Education. According to Gordon (2008), "The impact of this separation has been felt through subsequent decades in the development of separate training programs, separate teacher organizations, and separate student organizations" (p. 88). The objective of vocational education was to prepare youth and adults for the work force.

The federal government has had a tremendous role in enacting educational legislation since the 1950s (Umpstead, 2008). During the Civil Rights era of the 1950s, legislative initiatives centered around the issue of providing all students with educational opportunities regardless of race, ability, or gender (Hardman \& Dawson, 2008). In fact, the 1954 Brown v. Board of Education Supreme Court case was pivotal in setting the precedent for equal educational rights for all citizens and marked the end of segregated schools (Blanchett, Mumford, \& Beachum, 2005); therefore, this case overturned the 
Plessy v. Ferguson separate but equal policy. In 1965, the Elementary and Secondary Education Act (ESEA) was enacted to encourage states and local school districts to provide supplementary educational services to schools with high percentages of economically and educationally disadvantaged students (McDonnell, 2005). In addition, the Individuals with Disabilities Education Act (IDEA) of 1997 mandated that all students have access to the general education curriculum (Courtade \& Ludlow, 2008).

Vocational education legislation in the 1960 s responded to societal concerns as well. In 1963, the Vocational Education Act was passed. This piece of legislation was in alignment with the ESEA of 1965, in that it designated programs for economically and educationally disadvantaged students (Scott \& Sarkees-Wircenski, 2008). The objective of the legislation was to ensure that individuals of all ages and of all backgrounds would have access to vocational preparation.

In response to the lack of quality in education, a number of reports and educational legislation initiatives have been implemented since the 1980s. A Nation at Risk, a report written by The National Commission on Excellence in Education (NCEE, 1983), was written to address the heightened concern for educational quality and articulated the need for transformation in education (Hardman \& Dawson, 2008). Concomitantly, the U.S. was experiencing increased pressure due to high unemployment, high inflation, and concern for international competitiveness (Harris \& Herrington, 2006). As a result, the NCEE (1983) recommended that: (a) schools increase graduation requirements; (b) that schools administer more rigorous and measurable standards with heightened expectations for student performance and conduct; (c) that schools spend 
more time with students to learn the basics; (d) that postsecondary education institutions improve the preparation of teachers; and (e) that teachers and elected officials ensure the implementation of the new standards.

Meanwhile, the Carl D. Perkins Vocational and Applied Technology Education Act of 1990 was enacted ([an amendment to the Carl D. Perkins Vocational Act of 1984], Gordon, 2008). This name change was significant in that it was the first legislation that emphasized the integration of traditional academic and vocational content needed to equip students with the skills to compete in a technologically advanced global society (Jacobs \& Grubb, 2003; King et al., 2005; Lewis \& Cheng, 2006; Silverberg, Warner, Fong, \& Goodman, 2004). Thus, the Carl D. Perkins Vocational and Applied Technology Education Act had a new vision that promoted CTE as a vehicle that not only equipped students with the skills to enter the workforce, but also provided academic rigor to prepare them for postsecondary education (Hudson \& Hurst, 1999; Rojewski, 2002).

The recommendations of the NCEE led to fundamental changes in the educational arena with many efforts to reform education. The most recent and comprehensive reform initiative is the NCLB legislation signed into effect by President George W. Bush in 2001, which is an eighth amendment to the earlier ESEA of 1965 (Fletcher, 2006; Fletcher \& Zirkle, in press; NCLB, 2001). The main objectives of the legislation are to increase academic achievement of all students and to close the achievement gap between students of all races, socioeconomic statuses (SES), and backgrounds (Fletcher, 2006; Mantel, 2005; NCLB, 2001). 
Current CTE legislation objectives coincide with the accountability era for education. President George W. Bush reauthorized the Carl D. Perkins Vocational and Technical Education Act of 1998 (which historically was the Vocational Education Act of 1963) and named it the Carl D. Perkins Career and Technical Education Improvement Act of 2006 (Gordon, 2008; Scott \& Sarkees-Wircenski, 2008). As appropriate, the new legislation reflects the name transformation from vocational education to CTE. In addition, it communicates the new goals of CTE as a vehicle for preparing students for the workforce and for postsecondary education attainment. The main additions to the legislation included the following: (a) accountability and continued improvement of CTE programs; (b) a more seamless transition between secondary and postsecondary education for students; (c) and an increased focus on the knowledge, skills, and dispositions expected from business and industry.

\section{Problem Statement}

Vocational education and academic education had traditionally constituted two separate trajectories stratifying students with low academic promise into vocational education and students with strong academic promise into academic education, along with administering distinct curricula (Castellano et al., 2003; Gordon, 2008; Lewis, 1998; Lynch, 2000; Plank, 2001; Scott \& Sarkees-Wircenski, 2008). According to Lewis (1998),

The practice of dividing the curriculum into academic and vocational aspects, and treating the latter as a default for and those deemed to be ill-suited to the former, has been an enduring staple of educational systems across the globe...those who pursue the vocational route thereby effectively forfeit the opportunity to go on to the university and then on to high-status jobs (p. 284-5) 
As a result, vocational education and academic education had separate funding sources and had different objectives (Bragg, 1999; Castellano et al., 2003; Gordon, 2008; Gray, 1999; Gray \& Herr, 1998; Lynch, 2000; Plank, 2001; Scott \& Sarkees-Wircenski, 2008).

However, current educational legislation and comprehensive school reform (CSR) efforts are attempting to re-structure entire schools to promote an increasingly integrated system of CTE and traditional academic education (Castellano et al., 2003; DeLuca et al., 2006; Gordon, 2008; Hudson \& Hurst, 1999; Scott \& Sarkees-Wircenski, 2008). As a result, the objectives of the once segregated programs have attempted to merge, becoming more of a mutual one of preparing students for college and careers (Association for Career and Technical Education [ACTE], 2006; DeLuca et al., 2006; Gordon, 2008; Hudson \& Hurst, 1999; Scott \& Sarkees-Wircenski, 2008; Stone \& Aliaga, 2005). Despite this recent phenomenon, little research has been rendered examining CTE’s impact on students' educational outcomes (Kulik, 1998).

If the curricula of vocational education and academic education have historically been separate (focusing on students with different objectives), and if the two programs have recently merged in a time where the accountability of schools is of increased focus and the attainment of postsecondary education is increasingly valued, then more research is needed to investigate the effect of engaging in CTE curricula on student outcomes such as postsecondary education attainment and occupational earnings (Bailey, Alfonso, Scott, \& Leinbach, 2004a; Bishop \& Mane, 2004; Hudson \& Hurst, 1999; Kulik, 1998). Kulik (1998) indicated the need to study CTE student outcomes:

To decide whether vocational education shortchanges students, we must first know what its results are and whether they differ from results of other programs. 
How results are produced is also important to know, but it is not the first consideration. ( 9 7)

Purpose of the Study

The purpose of this study was to investigate the relationship of high school curriculum tracks and outcomes of schooling (degree attainment and occupational earnings).

\section{Significance of the Study}

Education is designed to prepare students for contemporary roles; therefore, education equips students with skills so that individuals may fulfill their job requirements and become productive citizens of society (Walters, 2004). In human capital theory, the ability of students to acquire relevant skills, knowledge, and dispositions serves as a form of capital (Schultz, 1961). This capital contributes to the earnings of employees. Thus, the more education an individual obtains, the higher the likelihood that individual will earn more in the long-term. Those individuals with limited learning capacities that enter the workforce are likely to lack the skills needed to advance (Walters, 2004). Currently, organizations are demanding greater skills of their employees, even for entry-level positions. Consequently, these organizations are requiring employees to have postsecondary credentials.

Due to the increased societal awareness of the need for human capital, education legislation (such as the NCLB Act and the Carl D. Perkins Career and Technical Education Act) has emphasized the critical nature in which schooling should provide students with the knowledge, skills, and dispositions to earn postsecondary credentials, as 
well as seek employment in high-skilled, high-wage professions. In fact, according to Jacobs and Grubb (2003),

Employees need to have both higher levels of education - in most cases education beyond high school - and different forms of education, with a new focus on such higher-order competencies as problem-solving abilities, communication, and critical thinking skills. (p. 1)

In response, CTE has transformed its curricula, which may be evident by declining enrollments in auto mechanics and materials production as countered with higher enrollments in courses such as health occupations and computer technology (Bishop \& Mane, 2004). Consistent with human capital theory, proponents of CTE programs contend that this type of curriculum promotes appropriate skills and dispositions needed for high-wage, high-skilled positions, which reduce the likelihood of them being unemployed or in low-wage, low-skilled positions (Arum \& Shavit, 1995). Thus, it is vital that important student outcomes such as postsecondary education attainment and occupational earnings are assessed, particularly now when CTE is attempting to revamp its curricula to better meet the needs of students as well as societal needs in increasing human capital. This is evident through the Carl D. Perkins Career and Technical Education Act objectives, the re-conceptualization of broadened career pathways and the integration of traditional academic and CTE concepts. However, Silverberg et al. (2004) noted in their National Assessment of Vocational Education report that it is of critical importance that CTE programs concentrate on increasing teacher quality in order to impact CTE student achievement.

Therefore, an investigation of the relationship of high school curriculum tracks to degree attainment and occupational earnings may lead to a better understanding of how 
CTE contributes to student outcomes and societal expectations. This information could be useful for parents, CTE practicing teachers and teacher candidates, students, and guidance counselors in advising high school students in selecting the various curriculum tracks, as well as providing them with insight regarding their likely destinations in terms of degree attainment and occupational earnings. In addition, longitudinal analyses enhance national and state education agencies and schools' abilities to identify and respond to achievement gaps between programs of study, as well as groups of students (King et al., 2005). Furthermore, the outcomes of this research study may contribute to enhancing education policy. Data on graduates from the 1996-1997 academic school year cohort were analyzed through the National Longitudinal Survey of Youth (NLSY) 1997 dataset. This study utilized the NLSY 1997 dataset particularly to assess the outcomes of students under the Carl D. Perkins Vocational and Applied Technology Education Act of 1990. In addition, the findings of this study may suggest benefits of students engaging in certain programs of study.

\section{Research Questions}

The following research questions were examined in this research study:

1) To what extent do demographic variables (independent variables) predict high school curriculum tracks (dependent variables)?

2) To what extent do demographic variables and high school curriculum tracks (independent variables) predict degree attainment (dependent variable)? 
3) To what extent do demographic variables, high school curriculum tracks, and degree attainment (independent variables), predict occupational earnings (dependent variable)?

A conceptual framework denoting the variables studied as well as their interrelationships is presented at the end of chapter two.

\section{Definitions of Terms}

Major terms in this research study are constitutively defined as follows:

Career and Technical Education Track: A high school curriculum track in which students must earn three credits or more in a CTE occupational pathway (Silverberg et al., 2004). College Preparatory Track: A high school curriculum track in which students earn an appropriate amount of credits in math, science, English, and foreign language that is consistent with college entrance requirements at private and public-four year colleges and universities.

Degree Attainment: The postsecondary educational credential an individual earns; these credentials include the following: no degree/diploma, GED, diploma, associate's degree, bachelor's degree, and graduate degree.

Dual Track: A high school curriculum track in which students earn three or more credits in CTE and take appropriate coursework aligned with a college preparatory track. Fathers with a College Education: Participants who had fathers whose highest grade completed was at the sixteenth grade.

Fathers with a High School Education: Participants who had fathers whose highest grade completed was twelfth grade. 
Gender: Differences based on individuals identifying as male or female.

General Track: A high school curriculum track in which students take the minimum amount of state-mandated credits and courses required to graduate.

High School Curriculum Tracks: The course of study in which a participant participates during high school. High school curriculum tracks include: general, college preparatory, CTE, and a dual track (a combination of CTE and college preparatory).

Household Income: Participants' families' annual income in 1996.

Mothers with a College Education: Participants who had mothers whose highest grade completed was sixteenth grade.

Mothers with a High School Education: Participants who had mothers whose highest grade completed was twelfth grade.

Occupational Earnings: The annual earned income (wages and/or salary) in 2005 of an individual from his or her job.

Race/Ethnicity: An individual's cultural/racial background and sub-group that he or she identifies; this group typically has shared origins and traditions. These include: Black; Hispanic; Mixed Race (Non-Hispanic); or Non-Black/Non-Hispanic.

Socioeconomic Status Indicators: Sociological and economic factors that indicate a person's status relative to other individuals or families. These include father's highest grade completed, mother's highest grade completed, and household income.

\section{Limitations}

A primary concern in utilizing ex post facto methods is the inability to control for confounding variables that may account for the reasons why students earned a degree and 
for their current occupational earnings. Hence, a myriad of explanations may account for these long-term outcomes that may not solely be related to demographic variables or the type of high school curriculum track they participated in during high school.

A second concern is that the data were a result of the instruments utilized and were self-reported. It is likely that some participants did not have adequate knowledge to respond accurately and the information gained was based solely on participants' perceptions. In particular, respondents reported their respective high school curriculum track in which they participated. As a result, it is not certain that all participants responded accurately to this question.

Limitations may have also included mortality (the loss of research participants), location, instrumentation, and the maturation of participants (Fraenkel \& Wallen, 2006). Mortality occurs when the number of research participants at the initiation of the data collection is different than at the end of the data collection; this is particularly an issue when more research participants are missing from one group than the other. The NLSY dataset did have respondents who could not be reached after the initial round of data collection. Location is a threat when the data collected is administered under different conditions, or different researchers collect data. The NLSY dataset did have multiple researchers collecting data, which indicates that location is a plausible concern. Maturation is an issue when research is conducted over time and the differences among the groups may be attributed to growth and development of the participants. This threat may be plausible in that data from this study was collected over eight years and respondents transitioned from adolescence to adulthood. However, this study employed 
random sampling and this type of sampling is the best method for supporting generalizations from the findings. Hence, results of this study may be generalized to former students across the nation that graduated from 1997 to 2006 in the following high school curriculum tracks: general, college preparatory, CTE, and dual.

\section{Delimitations}

Several other variables are likely to have the capacity to predict high school curriculum tracks, besides the demographic variables investigated in this research study such as variables that are not fixed. First, geographical variables such as whether the participants resided in a rural, suburban, or urban environment is likely to assist in the prediction of choosing a high school curriculum track. Second, college and career aspirations may also influence a student's likelihood of participating in a high school curriculum track. Third, academic measures such as G.P.A., high school grades, and standardized achievement scores (i.e., ACT and SAT) are likely to influence participation rates as well. However, this research study did not include these variables in the analysis.

In addition, variables that may be relevant to degree attainment might also include parents' influence as well as students' connectedness to their schools, parents, and teachers. Self-efficacy in school related tasks could also significantly influence their degree attainment (Lent et al., 1994). Moreover, institutional factors related to the institutes of higher education such as academic and social integration within the fabric of college life may also have a considerable influence on student's persistence (Tinto, 1993). These factors were not included in the scope of this research study. 
In terms of occupational earnings, variables that may be of interest include career aspirations, experience in the workforce, employment history, major in college, and participation in CTE school reform initiatives such as Tech Prep, school-to-work, and work-based learning programs. However, these variables were not examined in this study.

\section{Organization of the Dissertation}

The subsequent order of this dissertation includes an extensive review of the literature related to factors associated with long-term student outcomes in chapter two. A detailed account of the research methods for this study will be explicated in chapter three. The results of data analyses of this research study will be presented in chapter four. A discussion will be provided linking the research findings to theoretical, practical, and policy interpretations and implications for educational constituents. 


\section{CHAPTER 2}

\section{REVIEW OF THE LITERATURE}

Chapter two of this dissertation is a result of an extensive review of literature on factors influencing high school students' long-term outcomes. The scope and sequence of chapter two is as follows. First, an overview of CTE is provided to review the contemporary presence of the field in the United States. Second, theories describing students' career and academic decision-making are explained. Third, a discussion is provided regarding perspectives on the need for students to pursue postsecondary education in current society. Fourth, research on factors influencing students' decisions to enroll as well as factors contributing to degree attainment is described. Fifth, the issues of tracking and de-tracking on long-term student outcomes and achievement are investigated. Sixth, Tinto's theory of student persistence in higher education is articulated. Seventh, issues of occupational factors are explored, including school-towork transitions, long-term earnings of high school graduates, and occupational decisions. Lastly, a conceptual framework is explained that illustrates the variables of interest for this research study. 
Overview of Career and Technical Education

\section{A Brief Historical Account of CTE}

Since the earliest times, parents have attempted to prepare their children for the responsibilities of the real world and to be independent. One of the earliest developments of more formal types of vocational education came in the form of apprenticeships in colonial America (Scott \& Sarkees-Wircenski, 2008). However, this was not considered to be a component of the curriculum. The apprenticeship was a formal agreement between an employer and an employee that provided the employee with training and the employer with labor. It is important to note the two types of apprenticeship programs.

One type was voluntary and the other was involuntary. The involuntary apprenticeships consisted primarily of economically disadvantaged children and orphans (Gordon, 2008). Current Conceptions of CTE

Despite the ancient historical presence of vocational education, the vocational education that mirrors more of what is seen today was established in the late nineteenth century as trade schools, private business schools, and some agriculture programs (Gordon, 2008). Contemporary CTE, formerly referred to as vocational education, programs constitute a tremendously large educational system in the United States through which adolescents and adults explore career areas and learn valuable skills for the workforce and for further educational pursuits (Scott \& Sarkees-Wircenski, 2008). CTE has a presence in K-12 schooling as well as institutes of higher education, particularly within community/technical colleges. At the postsecondary and secondary education levels, CTE is known for coursework and cooperative educational experiences that often 
lead to industry-recognized credentials, certificates, or articulation agreements (enabling the transfer of secondary course credits to postsecondary education credits). Thus, high school CTE participants may earn credits leading to associates' degrees through an initiative typically referred to as Tech Prep.

The largest component of CTE is through curriculum programs provided for students at the high school level. In fact, almost every student (96.6\%) in the country has taken at least one CTE credit throughout their K-12 schooling experiences (Silverberg et al., 2004). Further, 11,000 high schools, which is two-thirds of high schools currently in the United States, offer at least one CTE program. Despite the large enrollments in CTE coursework, CTE remains an option/elective for students. CTE program areas cover a vast array of occupational pathways and includes disciplines such as agriculture education, business education, family and consumer sciences education (formerly called home economics), health occupations education, marketing education (formerly called distributive education), differentiated content areas in technical and industrial education (T\&I), and technical/communications education. According to Scott and SarkeesWircenski (2008), 50\% of students participating in CTE are enrolled in a business course, while $33 \%$ take T\&I classes.

CTE instruction at the secondary level is largely provided through comprehensive high schools offering core academic subjects as well. However, other settings for CTE at the secondary level include CTE (also called vocational-technical) high schools and CTE centers. The CTE schools and centers usually offer half-day instruction for students that are bussed from their home comprehensive high schools. However, some CTE schools 
and centers offer instruction for the entire school day. The likelihood of a student enrolling in a CTE school/center is predicated on its availability and approval by students' parents or guardians. Regardless of the CTE high school configuration, students take core academic classes in addition to their CTE coursework. Increasingly, students participating in CTE are earning higher numbers of credits in core academic subjects (Silverberg et al., 2004). Nonetheless, students earn more credits in CTE (4.0) than in math (3.4) or science (3.0). However, the researchers did not report a rationale for this finding.

A certain portion of the high school student population chooses to take a coherent set of CTE courses and some even declare a career major. Individuals earning three or more credits in CTE are considered CTE concentrators, which typically consists of three year-long courses. According to Silverberg et al. (2004), CTE concentrators are likely to be of certain demographics, including the following: (a) attending lower-income rural schools; (b) white; (c) male; and (d) identified as special needs' students. Based on focus group interviews, Silverberg et al. (2004) noted that students chose to participate in CTE courses for a variety of reasons, including the following:

to gain career exposure, to help them select or prepare for a college major, to use as a fallback if college or other career plans fail to materialize, to pursue a leisure interest, or to take courses that present less of an intellectual challenge than do other courses. (p. 29)

\section{The Separation of CTE and Core Academic Curricula}

In the latter 1800's schools were primarily focused on the core academic areas. However, many believed that vocational education was a way to establish more equality in the schools due to the few opportunities afforded for students to pursue postsecondary 
degrees. Two influential Black educational philosophers, Booker T. Washington and W.E.B. Du Bois, debated the purposes of education, particularly for Blacks. Washington believed in the pedagogical concept of learning by doing. On the contrary, W.E.B. Du Bois argued for a more academic education for Blacks to release them from the oppressive social and economic inequalities of pursuing a more vocationally focused education (Gordon, 2008). According to Gordon (2008), "Washington and Du Bois were trailblazers for the pattern of philosophical distinction between vocational and academic education" (p. 25).

In the early twentieth century, a newer philosophical approach was emerging that was concerned with students' interests. The philosophy of idealism was moving towards pragmatism and experimentalism. The educational leaders of this philosophy were John Dewey and Charles Prosser. The ideas of Charles Prosser merged into the creation of the Smith-Hughes Act of 1917. Similar to the debates of Washington and Du Bois, Dewey and Prosser also had distinct views of vocational and academic education. Prosser emphasized the need for students to gain practical experiences and have financial rewards. He also believed that the learning space be highly similar to the workplace. John Dewey, on the other hand, proclaimed that education be democratic. Dewey wanted education to include vocational exploration to assist students in gaining more practical knowledge. Thus, he supported the integration of vocational and academic content. $\mathrm{He}$ advocated for vocational education as a means for transforming the social inequalities that existed (Gordon, 2008). 
Dewey's vision of academic and vocational integration was transcendental. In fact, the Carl D. Perkins Vocational and Applied Technology Education Act of 1990 was the first time federal legislation stressed the need to integrate academic and vocational content. This legislation was transformational and set out new objectives for vocational education. These new objectives included the charge for vocational education to prepare students not only for the demands of the workplace, but also to pursue postsecondary degrees. However, individuals' perspectives regarding the purposes and nature of vocational education have been difficult to change. The difficulty of transforming perspectives may be closely related to the historical nature of vocational education and its separation from the core academic curriculum that had been in place since the SmithHughes Act of 1917.

Current CTE Teachers' Perceptions of Integrating Academic and CTE Coursework

According to Silverberg et al. (2004) CTE teachers believed that basic fundamental courses such as math, science, and reading are strongly needed for students' achievement in CTE courses and for the workforce. However, the majority of CTE teachers also believed they should not be held responsible for providing instruction on core academic content and held accountable for student achievement in core academic areas. Hence, CTE teachers typically do not report that the attainment of academic concepts is reflected in students' grades in CTE courses.

The Roles of CTE

Scott and Sarkees-Wircenski (2008) described the various roles that CTE plays in preparing students for citizenship. They reported four seminal roles for CTE. These roles 
are as follows: (a) to prepare students for postsecondary education opportunities; (b) providing students with opportunities for career exploration and linking students to employers through work-based programs such as internships, job shadowing, practicums, cooperative education, and apprenticeships; (c) establishing positive student-teacher relationships through relevant instruction and career and technical student organizations (CTSOs); and (d) facilitating valuable work experience.

\section{Students' Long-Term Decision-Making}

Students in high school are faced with an array of pathways that, often unbeknownst to them, strongly contribute to their long-term trajectories. Thus, empirical research investigating issues impacting students' decision-making processes are of extreme value. Accordingly, a variety of long-standing and more recent theories have been examined to better understand the factors that influence individuals' long-term achievements, particularly associated with career decisions and academic engagement.

\section{Social Learning Theory of Career Decision-Making}

The social learning theory of career decision making explores sociological indicators that influence students' decisions to pursue postsecondary education (Hossler $\&$ Stage, 1992). Factors included in the social psychological model are occupational attainment, educational attainment, occupational aspiration, educational aspiration (Stage \& Hossler, 1989), significant others' influence (Sewell \& Shah, 1968), high school performance, socioeconomic status ([SES)], Hearn, 1984; Rumberger, 1983; Sewell \& Shah, 1968; Stone \& Aliaga, 2005), and high school cognitive ability (Fuller, Manski, \& Wise, 1982; Hause, 1982; Sewell, Haller, \& Portes, 1969; Sewell \& Shah, 1968). 
In contrast to socialization models of status attainment, Kerckhoff (1976) presented an allocation model of status attainment. This model lessens the significance of factors associated with socialization (such as the impact of interpersonal and internal influences on goal construction) and highlights the impact of societal factors that predestine individuals for certain pathways and preclude them from others. Factors that would be considered under the allocation model rubric would include characteristics of the institution.

According to Kerckhoff (1976), "an allocation model views the individual as relatively constrained by the social structure, his attainments being determined by what he is to do" (p. 369). The difference in the socialization and attainment models are primarily found in whether individuals want something and expect something. Utilizing the allocation model, expectations are closely associated with attainments and adolescents typically have the knowledge to determine the likelihood of obtaining various outcomes. Thus, the majority of individuals have similar wants in terms of outcomes; however, individuals in different social stratifications expect different outcomes. In addition, individuals' observance of others like themselves shapes their own expectations of themselves. Research has also demonstrated that adolescents' expectations become more in sync with the real world. Therefore, expectations of future attainment are strongly influenced by observed structural limitations.

Social Cognitive Theory of Career and Academic Interest, Choice, and Performance

Drawing on Bandura's social cognitive theory, Lent, Brown, and Hackett (1994) presented an integrative theoretical framework of career development that outlines three 
phenomena. These phenomena include the following: (a) the development of career and academic interests; (b) how career decisions are carried out; and (c) how performance outcomes are obtained.

In regard to the factors that impact individuals' career and academic interests, Lent et al. (1994) posited that during childhood and adolescent stages, individuals are exposed (directly or vicariously) to a wide variety of events that might be meaningful and relevant to each individual. Further, they are reinforced by the actions they take in pursuit of those events as well as their achievement in them. Through this, individuals develop their skills, set personal performance objectives and standards, gain a sense of efficacy, and acquire expectations regarding the outcomes of their actions. When individuals become self-efficacious regarding an event, they form an interest in that activity. Thus, this forms the fruition of academic and career interests.

Career decisions are then carried out by personal objectives that are impacted by the interaction of self-efficacy, beliefs about one's outcomes when engaging in the activity, and whether or not the goal is of interest or value to the individual (Lent et al., 1994). This interplay incites agency within an individual. However, choices are dynamic - in that, choices are often adjusted based on the individual's actual performance outcomes. Lent et al. (1994) illustrated this point by stating, For example, after declaring an engineering major, a student may have serious difficulty passing required physics courses. Such compelling performance data may force a revision of perceived capabilities, ultimately prompting a change in goals (e.g., selection of a new major). (p. 94)

Last, past performance builds individuals' perceptions regarding their self-efficacy and outcomes. This, then, helps strengthen individuals' interests and goals. 


\section{Postsecondary Education}

Students graduating from high school have two primary options; these options typically include pursuing postsecondary education (community college, technical college, or four-year university) or entering into the workforce (King et al., 2005). Many of these individuals participate in the workforce while pursing higher education to offset the costs of participating in postsecondary education. However, if individuals are provided with funding incentives, they are more likely to delay participation in the workforce.

Societal views of higher education historically have been conceptualized as a high priority for individuals (Swail, Perna, \& Redd, 2003; Venezia \& Kirst, 2005), a vehicle for socioeconomic mobility (Kulik, 1998) and social stability (Corazzini, Dugan, \& Grabowski, 1972; Lewis, 1998). Furthermore, higher education has also been known to decrease the large inequities that exist in earnings potential between ethnic minorities and Caucasians (Bailey, Kienzl, \& Marcotte, 2004b). Currently, 70\% of the approximately 2.5 million public high school graduates in the United States pursue postsecondary education within a two-year span of graduation (Venezia \& Kirst, 2005). Further, 50\% aspire to earn a bachelor's degree.

Particularly within the last two decades, an increased emphasis has been placed on postsecondary education attainment, which is then utilized to determine one's economic well-being. Accordingly, Tinto (1987) contended that,

It is commonly recognized that a college degree, especially a four-year degree, is an important certificate for occupational entry without which access to prestigious positions in society becomes measurably more difficult. (p. 2) 
Further, Scott and Sarkees-Wircenski (2008) posited,

In nearly every high school in the nation, the push is on to prepare students to enter college. Parents want their children to go to college and they sacrifice financially to meet the high cost of enrolling their children in colleges and universities. They want their children to prepare for and enter a career or wellpaying job so that their children can live satisfying and productive lives. (p. 7)

Illustrating the ever-transforming nature of societal expectations, Venezia and Kirst (2005) further substantiated this claim by stating,

Where once a high school diploma was all that was necessary for an individual to obtain a job that could guarantee entrance in the middle class, today at least a coherent program of postsecondary training, if not a college degree, is typically necessary to achieve the same economic status. (p. 285)

In fact, one major objective of education is to prepare and equip students with the knowledge, skills, and dispositions needed to be successful and to be productive citizens of society (King et al., 2005). Moreover, higher education demands a premium in the workforce, partially due to the extensive opportunities that unfold in regards to jobs and careers. Those without higher education credentials are typically not afforded those same opportunities presently or in the future. Despite the increasing awareness of this phenomenon, a substantial number of college-bound and non-college-bound students are completing secondary education without the skills, knowledge, and dispositions needed to complete postsecondary work or without the appropriate resources to take advantage of this type of an opportunity. As a result, many two-year colleges are forced to emphasize remedial courses to address the situation. Furthermore, many students exiting high schools are not prepared with the occupational skills and career readiness to participate in high-wage, high-skilled jobs. Thus, it is critical that schools become better informed of 
how they may better prepare their students for postsecondary education as well as in the labor market.

Despite the large amount of students deciding not to obtain postsecondary education, there still is an increasingly growing trend of students pursuing postsecondary education and earning degrees. Based on the Current Population Survey of labor force and demographic information, individuals earning degrees that are 16 years of age and over have doubled within the last three decades (Liming \& Wolf, 2008). Utilizing data from the Bureau of Labor Statistics (BLS) as well as the U.S. Census Bureau, Liming and Wolf (2008) charted average earnings and unemployment rates, for employed individuals from 25 to 44 years old, according to educational attainment. They found the following: (a) individuals with less than a high school diploma earned $\$ 419$ per week and had a 6.8\% unemployment rate; (b) high school graduates earned $\$ 595$ per week and had a 4.3\% unemployment rate; (c) individuals with some college and no degree earned $\$ 674$ per week and had a 3.9\% unemployment rate; (d) individuals with an associates degree earned \$721 per week and had a 3\% unemployment rate; (e) individuals with a bachelor's degree earned $\$ 961$ per week and had a 2.3\% unemployment rate; (f) individuals with a master's degree earned $\$ 1140$ per week and had a 1.7\% unemployment rate; (g) individuals with a professional degree earned $\$ 1474$ per week and had a 1.1\% unemployment rate; and (h) individuals with a doctorate degree earned $\$ 1441$ per week and had a $1.4 \%$ unemployment rate. Thus, by and large, earnings increase and unemployment rates decrease for each degree an individual earns. This finding has been 
substantiated in a multitude of other empirical research studies as well (Bailey et al., 2004b).

In fact, Bailey et al. (2004b) utilized the National Educational Longitudinal Study (NELS), the High School and Beyond (HS\&B), and the Beginning Postsecondary Students (BPS) Longitudinal Survey to explore the economic benefits of postsecondary education degree attainment. First, they found that high school students without college credentials are less likely to be employed full-time and have higher earnings than those with associate's degrees. Second, they also found that those with a bachelor's degree earned substantially higher (approximately $67 \%$ higher for females and $37 \%$ higher for males) earnings than their non-degreed counterparts. Third, they found that even those individuals with some postsecondary education (without actually earning a degree) had higher economic earnings than those with no postsecondary education experience. Fourth, they found that students participating in CTE coursework during high school were not significantly different than those without CTE experiences. As a result of their findings, Bailey et al. (2004) concluded that students do indeed benefit from subbaccalaureate programs as well as CTE programs. They further recommended that Congress implement initiatives to encourage students to participate in postsecondary education, even at the sub-baccalaureate levels.

The rise in earnings for students earning degrees has indeed sparked the growth of students aspiring to pursue postsecondary education (Mane, 1999). According to Mane (1999), this has logically resulted in more students completing college-preparatory coursework and has likely been the source of declining enrollments in CTE programs. 
Correspondingly, he further contended that states are increasingly requiring students to earn more academic course credits, which have reduced the number of elective credits students may earn; thereby, reducing the number of CTE courses taken. On the contrary, Silverberg et al. (2004) in their NAVE findings indicated that CTE course enrollments and credits are not declining.

\section{Research on Factors Contributing to Decisions to Enroll in Postsecondary Education}

Research has demonstrated that factors influencing students' decision to enroll in postsecondary education is complex and nuanced (Esters, 2007; Hossler \& Stage, 1992); some influential factors suggested by research findings include family background such as socioeconomic status ([SES] Kao \& Tienda, 1998), family encouragement (Alfeld, Hansen, Aragon, \& Stone, 2006; Kao \& Tienda, 1998; Legutko, 2008; Sewell \& Shah, 1968; Stage \& Hossler, 1989), financial aid (Fuller et al., 1982; Jackson, 1978) peer encouragement (Alfeld et al., 2006; Harnish \& Lynch, 2005; Spady, 1970), extracurricular involvement (Spady, 1970), school environments (Alfeld et al., 2006; Hearn, 1984; Konstantopoulos, 2006), and curricula tracking (Akos, Lambie, Milsom, \& Gilbert, 2007). Postsecondary aspirations are central in that they substantially influence involvement in certain types of activities in high school that may promote postsecondary education attainment, an individual's ability to attain a high wage job, and future career possibilities (Rojewski, 1997).

Hossler and Stage (1992) discussed the predisposition stage of students' college choices. This stage is characteristic of the time when the student decides whether or not to continue formal education beyond their high school studies. A host of factors at this 
stage influence their decisions include the following: "socioeconomic status, student achievement, ethnicity, gender, parental educational expectations and encouragement, high school quality, high school curriculum track, and student involvement in high school activities" (Hossler \& Stage, 1992, p. 428).

Factors Influencing Postsecondary Education Attainment for Core Academic Students

Legutko (2008) studied the impact of family influence on high school seniors in Pennsylvania by utilizing chi-square tests to compare a group in 1995 and 2005. They found an 11\% statistically significant increase between the 1995 and 2005 groups in regard to students' decisions to enroll in postsecondary education (54\% in 1995 and 65\% in 2005). The researchers also found that students deciding to enroll in postsecondary education whose parents did not attend college had a statistically significant increase by $28 \%$ (38\% in 1995 to $66 \%$ in 2005$)$. Further, those students that did not have parents that pursued college and were undecided or did not plan to attend college had a statistically significant decrease by $23 \%$ (35\% in 1995 to $12 \%$ in 2005$)$. In addition, those students whom perceived that they were lower-middle class that had plans to pursue postsecondary education showed a statistically significant increase by $21 \%(55 \%$ in 1995 and $76 \%$ in 2005$)$. Those students whom perceived that they were lower-middle class and did not have plans to attend college or were undecided had a statistically significant decrease by $18 \%$ (25\% in 1995 and 7\%). However, the influence of siblings' education was not statistically significant. The researchers concluded that rural families are encouraging their children to become more educated and to become more upwardly mobile. 
Hossler and Stage (1992) crafted a model of student college choice and tested their model utilizing 2,497 ninth grade Indiana high school students and their parents from 21 high schools. They used structural equation modeling to test students' predispositions to college enrollment. Their dependent variables included parents' expectations, G.P.A., students' activities in high school, and students' aspirations. They found that parents' educational levels and gender contributed significantly and positively to the dependent variables. In addition, parental influence and high school experience factors (grades and activities) was significantly related to students' aspirations. The model explained $36 \%$ of the variance in students' plans to enroll in postsecondary education. The researchers recommended that an emphasis be placed on parents as well as students in attempting to affect students' college plans.

\section{Factors Influencing Postsecondary Education Attainment for CTE Students}

The pathways of CTE concentrators and college-preparatory concentrators are markedly different (Kulik, 1998). Kulik (1998) estimated that 75\% of college-preparatory students do indeed continue on to pursue postsecondary educational opportunities; however, only $20 \%$ of CTE students decide to further their education subsequent to earning their high school diplomas. Some research has ensued that focused on the impact of students participating in CTE on postsecondary education aspirations (Alfeld et al., 2006; Harnish \& Lynch, 2005; Rojewski, 1997; Stone \& Aliaga, 2005), attainment (Silverberg et al., 2004), and degree completion (Esters, 2007).

Findings from the 2004 National Assessment of Vocational Education (NAVE) indicated that CTE concentrators have increasingly higher postsecondary education 
participation rates (Silverberg et al., 2004). However, these students still enroll in postsecondary education at a much lower rate than other students. Nevertheless, CTE students are much more likely to earn an associate's degree or complete a certificate program than a bachelor's degree.

In comparison to students with a curriculum specialization in CTE solely, Hudson and Hurst (1999) reported that 1992 high school graduates that participated in CTE and college preparatory courses enrolled in college at a higher rate two years subsequent to graduating high school and were almost as likely to enroll compared to their college preparatory counterparts. The researchers suggested that the findings indicated that students with a curriculum specialization in CTE and college preparatory are benefiting from the increased integration of CTE and academic learning in their courses

Stone and Aliaga (2005) utilized the NLSY 1997 dataset to investigate participation rates of CTE concentrators, career majors, tech prep, cooperative education, job shadowing, mentoring, school-based enterprises, and internship and apprenticeships. In addition, they described students' characteristics in terms of family background, community, and school achievement. Lastly, the researchers examined the relationship among curriculum participation, students' characteristics, indicators of academic rigor, and college aspirations. As a result of their analyses, the researchers found that $6.6 \%$ of students nationwide indicated that they were CTE concentrators. A third of students reported to have chosen a career major at some point in their education; a fifth indicated they participated in job shadowing; and, a fourth stated they participated in cooperative education or an internship or apprenticeship. Parents' education level had a statistically 
significant negative relationship with a student being a CTE concentrator. CTE

concentrators completed high school at a higher rate than general education

concentrators. However, CTE concentrators had the lowest college aspirations and had a tremendously lower (71\%) likelihood of completing high school in comparison with academic concentrators. The researchers concluded that CTE accounts for a large portion of students' high school experiences; while, race, gender, ethnicity, and SES are strong influencers of CTE concentration.

Esters (2007), utilizing discriminant analysis, examined factors that influenced 88 agricultural education urban high school graduates' decisions of enrolling in postsecondary education. These graduates were from a school in the Midwest and earned their high school diplomas between the years of 1992 and 1995. Fifty-four percent of the participants were Caucasian, $40 \%$ were African-American, $4 \%$ were Hispanic, and 2\% indicated "other". The respondents that had completed a bachelor's degree were as follows: (a) eight percent were in agricultural; (b) seven percent were in the liberal arts; and (c) five percent were in education. The researchers did not report the percentage of students earning a master's degree; however, they did indicate that students completed master's degrees in agriculture, education, and liberal arts. None of the respondents had earned a doctoral degree.

In addition, respondents reported that their mothers or female guardians had the most impact $(M=4.07)$ on their decisions to pursue a postsecondary degree. The second highest influence came from their fathers $(M=3.64)$. Further, respondents indicated that their interest in agriculture was the most significant factor in deciding to enroll in 
postsecondary education. Students' high school grade point average (GPA) and mother's or female guardians' influence only explained eight percent of the variance in their decisions' to enroll in postsecondary education. The researchers acknowledged readers to take caution when interpreting their findings because of the small sample size and because this study was limited to only one school. They recommended that parents and/or guardians should be encouraged to be involved in students' college decision processes. The researchers further stated that there are many contributing factors in students' decisions to enroll in postsecondary education.

In a four group pre-test/post-test, longitudinal research design, Alfeld et al. (2006) utilized hierarchical linear modeling to examine whether students' participation in career and technical student organizations (CTSOs) affected outcomes such as achievement, transition to postsecondary education and training, and employability. The study included a sample of 1,797 high school students in general classes, CTE classes, and CTE classes with CTSOs. When comparing students in CTE classes and students in CTE classes with CTSOs, findings revealed that students in CTE classes with CTSOs had significantly higher academic motivation, academic engagement, civic engagement, and career selfefficacy initially. However, students in CTE courses had gained higher increases than students in CTE classes with CTSOs. When comparing CTE classes with CTSOs and general classes, findings indicated that CTE classes with CTSOs initially had significantly higher career self-efficacy. However, general classes had a higher and significant increase in career self-efficacy. Additional findings concluded that the amount of CTSO participation did not significantly impact any of the dependent variables. The 
researchers concluded that CTSOs are of value to students' high school experiences. They further mentioned that despite the finding that students in CTE classes have less college aspirations than students in the general classes, they still aspire to earn bachelors' and masters' degrees.

One approach utilized to increase the likelihood of high school students to pursue postsecondary education is through dual enrollment programs. Dual enrollment programs enable students to earn college credit by taking high school courses. In a longitudinal mixed methods' study of Georgia's dual enrollment programs, Harnish and Lynch (2005) explored students' transitions from high school to technical colleges. By analyzing focus group interviews of 43 high school students from six different schools, the researchers found two major incentives for participating in dual enrollment courses; these incentives included gaining college credit and increasing their earning potential. The high school students reported that friends were the most significant factor influencing their decisions to enroll in dual credit courses. A barrier identified as inhibiting enrollment in dual credit classes was the admission test. Dual enrollment students also reported that benefits to participating included exposure to college, increased options, and helping them to make choices regarding their careers. Lastly, administrators reported that enrollment increased by $10 \%$ as a result of more students participating in dual enrollment. The researchers suggested that administrators should attempt to focus on those students that are not intending on pursuing college immediately following high school.

Rojewski (1997) utilized the 1988 to 1994 NELS dataset to investigate disadvantaged high school CTE students' participation rates in CTE, work experiences, 
and postsecondary aspirations. He found that the CTE rate of participation for disadvantaged students was more than twice that of non-disadvantaged students. Students that enrolled in a CTE program had higher employment rates regardless of disadvantaged status. One-third of students reported working at fast food restaurants, particularly for disadvantaged students. On the contrary, many of the non-disadvantaged students worked in sales-related occupations. CTE students were more likely to work in mechanical or general repair occupations. Three-fourths of all students reported earning slightly above the minimum wage (which was $\$ 4.25$ at the time). Unexpectedly, the more disadvantaged students were involved in CTE, the higher the likelihood of them receiving less than minimum wage. In regards to educational and occupational aspirations, CTE students had the lowest educational and occupational aspirations regardless of disadvantaged status. The researcher concluded that CTE practitioners should attempt to deal with concerns of tracking disadvantaged youth into CTE programs. Rojewski (1997) further indicated that more research should determine whether CTE students participate because of their own decisions or because of systemic approaches.

\section{Summary of Research Findings on Factors Influencing Postsecondary Education}

Based on the studies reviewed, the majority of studies provide evidence for the assertion that increasing the attainment of higher education credentials is positively related to earnings and employment (Bailey et al., 2004b; Liming \& Wolf, 2008). Therefore, the argument for increasing students' opportunities for postsecondary education attainment is warranted. 
Further, important factors influencing students' postsecondary education decisionmaking are family influence (Legutko, 2008), parents' educational levels (Hossler \& Stage, 1992), and gender (Hossler \& Stage, 1992). In regards to students' participation in specific types of high school curriculum, research findings have found that CTE concentrators are more likely to be disadvantaged (Rojewski, 1997), have the lowest college aspirations (Rojewski, 1997; Stone \& Aliaga, 2005) and have the lowest occupational aspirations (Rojewski, 1997) compared to their general and college preparatory concentrating counterparts. Nevertheless, CTE concentrators have demonstrated higher employment rates (Rojewski, 1997). As a result of these research outcomes, more research is warranted on CTE concentrators' actual degree attainment and earnings in relation to their general and college preparatory counterparts.

\section{Tracking and Curricular Differentiation}

American high schools structure educational opportunities for students by providing them with differentiated curricular programs based on their purported interests and talents (Gamoran, 1987; Gamoran \& Weinstein, 1998; Hallinan, 1994). This sorting process results in stratified learning opportunities of students within the same school. Thus, the learning opportunities and instruction that schools expose students to (i.e., advanced placement courses) often set the boundaries for student experiences and achievement (Gamoran, 1987; Gamoran \& Nystrand, 1991).

A wealth of long-standing knowledge and research has matriculated within the last few decades based on the phenomenon of tracking in U.S. schools, which has been well-documented in the literature (Gamoran, 1989; Lewis, 2007; Oakes \& Guiton, 1995) 
and highly contentious (Hallinan, 1994) among educators, administrators, researchers, and parents. Tracking, which is the separation of students into distinct curricula tracks based on perceived or measured cognitive ability, has been cited as a vehicle that provides students with an unequal education (Alvarez \& Mehan, 2007; Gamoran, 1986; Hallinan, 1991, 1994; Rubin, 2006); long-term social inequalities (Arum \& Shavit, 1995; Ayalon \& Gamoran, 2000; Biafora, \& Ansalone, 2008; Gamoran, 1989; Gamoran \& Mare, 1989; Kelly, 2007; Page, 1990; Rojewski, 1997; Rubin, 2006); unequal status attainment (Ayalon \& Gamoran, 2000; LeTendre, Hofer, \& Shimizu, 2003; Lewis, 2007; Oakes \& Guiton, 1995; Rubin, 2006; Vanfossen, Jones, \& Spade, 1987); and lower selfesteem, motivation to learn, and academic status (Hallinan, 1994). Researchers have also indicated that ability (Alexander \& McDill, 1976; Biafora \& Ansalone, 2008; Gamoran \& Mare, 1989; Hallinan, 1991; Kelly, 2007; Lee \& Bryk, 1988; Vanfossen et al., 1987; Yonezawa, Wells, \& Serna, 2002), past performance/achievement (Gamoran, 1989; Lee \& Byrk, 1988; Rubin, 2006), teacher and counselor recommendations (Hallinan, 1991), college and career aspirations (Akos et al., 2007; Gamoran, 1989; Lee \& Byrk, 1988; Rojewski, 1997; Vanfossen et al., 1987), interests (Lee \& Bryk, 1988), race/ethnicity (Akos et al., 2007; Alvarez \& Mehan, 2007; Burris, \& Welner, 2005; Hallinan, 1991; Kelly, 2007; Lee \& Byrk, 1988; Lewis, 2007; Lewis \& Cheng, 2006; Oakes \& Guiton, 1995; Rubin, 2006; Welner \& Oakes, 1996; Yonezawa et al., 2002), SES (Akos et al., 2007; Alvarez \& Mehan, 2007; Gamoran, 1989; Kelly, 2007; Kilgore, 1991; Lee \& Byrk, 1988; Lewis, 2007; Lewis \& Cheng, 2006; Oakes \& Guiton; Rojewski, 1997; Rubin, 2006; Vanfossen et al., 1987; Yonezawa et al., 2002), structural/institutional constraints 
(Gamoran, 1986; Oakes \& Guiton, 1995), and family backgrounds (Kelly, 2007) are all determinants in the placement of students in different curriculum tracks. Thus, research examining and explanations describing the antecedents and effects of tracking are quite complex (Oakes \& Guiton, 1995).

The distinct curricula tracks include: (a) a college preparatory curriculum; (b) a CTE curriculum; and (c) a general curriculum. However, recent initiatives have developed an integrated curriculum combining college preparatory and CTE coursework. This new phenomenon has been referred to as the new vocationalism and includes programs such as Tech- Prep, Career Academies, and HSTW. These curriculum reform models have attempted to increase college preparatory coursework in CTE programs as well as provide pathways for postsecondary education participation. In addition, tracking in schools may also take the form of differentiated levels of courses such as "advanced placement, honors, regular, and basic" (Hallinan, 1994, 1 1). Thus, the conceptualization of separate tracks is widely varied among American schools (McPartland \& Schneider, 1996).

The phenomenon of tracking students may be traced back as early as 1940 (Mayer, 2008). Tracking has been shown to be a mechanism that strongly influences students' perceptions of the types of post-high school opportunities that are available (Akos et al., 2007). In fact, tracking has been a source of much litigation and has been contested in many court cases (Welner \& Oakes, 1996). Research on the effects of tracking has shown to lead to long-term negative outcomes such as an academic achievement gap between college preparatory and non-college preparatory students. 
Despite the negative long-term effects of tracking, the primary rationale for tracking in schools is pedagogical - in that, students vary greatly in their academic ambitions, prior knowledge, and the environment in which learning is optimal (Gamoran \& Mare, 1989; Lucas \& Berends, 2002; McPartland \& Schneider, 1996) and tracking provides teachers with an opportunity to tailor their instruction in order to meet the varied student learning needs (Gamoran, Nystrand, Berends, \& LePore, 1995; Hallinan, 1991; Page, 1990). Nevertheless, research has shown that high-ability tracks often engage in much higher quality discourse than their low-tracked counterparts, which typically involves the emphasis of lower-order cognitive skills (Lee \& Byrk, 1988).

Akos et al. (2007) studied 522 eighth grade students from four middle schools in North Carolina to determine the relationship between curriculum track choices and achievement indicators such as G.P.A., behavior, attendance, ability classification, as well as student characteristics such as gender, SES, and race. The researchers found statistically significant positive relationships between students choosing a college and university track as well as a career track. Achievement indicators were also found to be significant with track and G.P.A. Additional significant negative relationships were found between curriculum track choices and attendance and behavior referrals. Therefore, students that chose a college and university track had fewer absences and behavior referrals than those students that were in a College-Tech track. Lastly, a statistically significant difference was found in curriculum track choices and ability classifications. More special education students chose the Career and Occupational track; more gifted students chose the College and University track; and, students in regular education chose 
College-Tech. The researchers contended that approximately $95 \%$ of students in North Carolina may be prepared for postsecondary education. They also discussed the instrumentality of tracking on students' career and educational aspirations, as well as pointed out the need for school counselors to advocate against curriculum tracking. In a study investigating the perceptions of 272 principals of New York City schools regarding tracking, Biafora and Ansalone (2008) found that 56.5\% believed that their teachers were supportive of tracking in their schools. Further analyses revealed that principals in lower SES schools were more favorable of tracking. In addition, $65.5 \%$ agreed to the statement that tracking promotes inequalities. Principals in higher SES schools $(70.7 \%)$ agreed with this statement at a statistically significant higher rate than their lower SES counterparts (50.5\%). Furthermore, $64.9 \%$ of principals in higher SES schools supported the eradication of tracking. The researchers concluded that principals' perceptions of tracking was strongly influenced by political, SES, and academic concerns.

Lewis and Cheng (2006) explored the perceptions of 665 high school principals on whether race and SES are contributing factors influencing tracking. Findings demonstrated that a statistically significant difference was found in the percentage of free/reduced priced lunches to determine whether a CTE track or college preparatory track was predominant. In addition, principals' expectations of students' likelihood of attending a four-year college or university compared to directly pursuing work was statistically significant with income and free/reduced priced lunches. Similar to the selffulfilling prophecy, the researchers contended that principals' expectations of students' 
status attainment may significantly influence school policies and the occurrence of tracking in their schools.

In a qualitative study of six teachers, Watanabe (2007) revealed that five of the six teachers perceived the proliferation of tracking in schools as diminishing because of the focus on student choice. The researcher argued that because these teachers emphasized student choice and accountability when defining tracking, structural and institutional inequalities were not considered.

Oakes and Guiton (1995) conducted qualitative and quantitative analyses of three high schools to determine how teachers conceive of tracking. Findings demonstrated that teachers utilized junior high school teachers' opinions of students' abilities and motivation to determine their track placements. Second, teachers believed that students' track placements were accommodations that were in alignment with students' abilities and motivation and they did not attempt to alter students' abilities or motivation. Third, race/ethnicity and social class were determining factors for track placements. Fourth, structural issues (such as policies regulating course offerings) impacted curriculum decisions, as well as reduced resources and transformations in demographics. In addition, students in high-status curriculum tracks were more positively benefited when structural changes, resources, and shifting demographics occurred. Correspondingly, the researchers suggested that a complex interplay of structural, cultural, and political dynamics accounted for decision-making in the placement of students in differentiated tracks. 
To determine how tracking was administered, Kelly (2007) analyzed curriculum guides of 92 North Carolina high schools from 1997 to 1998. He found that all of the North Carolina high schools in the study had the same course requirements for graduation. However, course-taking in English and mathematics courses were highly differentiated. The findings indicated that most students were tracked based on ability and age. Kelly (2007) further stated that tracking was intensified by school policies such as co-requisite regulations that link placements in academic courses. This, he described as, "Track placements in English and math often determine placement in social studies and science respectively" (Kelly, 2007, p. 29).

Vanfossen et al. (1987) utilized the HS\&B dataset to assess the influence of curriculum tracking over a two-year period. They found that one-third of the students participated in a college preparatory curriculum, approximately one-half were in the general track, and one-fifth was in a CTE track. Students scoring in the upper quartile were in the college preparatory track. Findings also indicated that students that were in the college preparatory and general tracks were statistically significant predictors of postsecondary education attainment. The researchers concluded that students in general and CTE tracks are not given adequate opportunities to increase their academic performance as well as educational and occupational aspirations.

\section{Summary of Findings on Tracking}

An earlier summarization of findings resulting from tracking studies was rendered by Kulik's (1998) review entitled, Curricular tracks and high school vocational education. Kulik (1998) concluded that ethnographic studies on tracking have 
demonstrated that there are varying degrees of time on-task between upper- and lowertracks, differences in teachers, in student-teacher relationships, and instruction. In addition, Kulik (1998) reported that the majority of regression studies have explored factors influencing students' decisions to enroll in particular tracks as well as how the different tracks impact students. The majority of findings pointed to students' personal preferences as the primary factor influencing their decisions to enroll in a curriculum track, whereas factors such as gender, race, and SES show lesser roles in students' placement in tracks. Moreover, the overwhelming majority of studies have shown that students in college-preparatory tracks enroll in postsecondary education after high school, at a higher rate than any other curriculum track. Study findings are inconclusive regarding students' track placement and student achievement (i.e., test scores). Last, Kulik (1998) concluded that experimental studies have shown that students of different ability groups that are placed in the same curriculum track achieve at a lower rate than those students tracked according to their ability levels. Students in the lower tracks suffer from much lower self-esteem.

Kulik (1998) further commented that tracking studies typically do not examine academic and vocational tracks. In addition, little attention has been given to comparing student outcomes of general and vocational tracks. In fact, according to Kulik (1998),

The overwhelming impression that one gets from literature reviews on grouping and tracking, in fact, is neglect of vocational education. Reviewers of survey research usually fail to distinguish between general and vocational tracks. Instead, they lump general and vocational classes together into a single category of nonacademic classes. Reviewers of ethnographic studies examine instruction in upper- and lower-track academic classes, but not in vocational courses. Reviewers of the experimental literature cite relatively few studies of ability grouping at the senior-high level and seldom mention the topic of vocational education. (đ 58) 
Based on the literature on tracking reviewed in this dissertation, findings have demonstrated that tracking has a negative impact on achievement in the CTE and general tracks (Akos et al., 2007). In addition, tracking has been shown to be influenced by ability (Kelly, 2007), age (Kelly, 2007), and institutional factors of the school (Kelly, 2007). Furthermore, tracking has been associated with impacting students' postsecondary education attainment (Vanfossen et al., 1987).

Similarly, teachers' perceptions of tracking have shown that SES, race, ethnicity, perceptions of students, institutional factors, and school resources are factors associated with the placement of students in tracks. In regards to perceptions of principals, principals' perceptions of students have been found to influence tracking placements (Lewis \& Cheng, 2006). In addition, research findings have indicated that tracking has had a negative impact on low SES students (Biafora \& Ansalone, 2008), which has been shown to promote inequalities (Biafora \& Ansalone, 2008). Thus, many researchers have called for the abolishment of tracking (Biafora \& Ansalone, 2008).

\section{De-tracking}

Within the last decade, some schools in the U.S. have been implementing reform initiatives to "detrack" curricula in an attempt to fix the negative effects associated with tracking (Alvarez \& Mehan, 2007; Rubin, 2006) and improve the likelihood of underserved students participating in postsecondary education (Alvarez \& Mehan, 2007). These schools use academic and racially heterogeneous grouping (Rubin, 2003, 2006) and place all students in a college preparatory program regardless of ability level (Lewis, 2007); this new unified curriculum is deemed to be highly challenging with increasing 
standards (McPartland \& Schneider, 1996). However, some scholars argue for an integrated curriculum for all students that includes study in the core academic areas as well as in CTE (Lewis, 1998; Lewis \& Cheng, 2006). This perspective of schooling is the primary objective and result of the new vocationalism, making CTE more attractive and relevant to students. To illustrate, Rubin (2006) described the wide spectrum of school structural reform efforts as follows:

Schools and school districts have taken widely divergent approaches to detracking. Of one end of the spectrum are deep restructuring efforts, such as the complete elimination of ability grouping in all subject areas throughout an entire school district. On the other end are changes that do not directly affect a school's track structure, such as providing more access to high-track classes for students formerly in lower tracks. (p. 7)

Despite the attempts to improve the academic achievement of all students, detracking reform efforts have been quite controversial (Rubin, 2003). The implementation of de-tracking in schools have been fraught with challenges and tremendously complex, not only with the logistics, but particularly with the attempt to transform parents' and students' long-held, deeply-ingrained dispositions regarding the acquisition of knowledge and privilege that is rooted in years of tracking (Oakes, Wells, Jones, \& Datnow, 1997). In addition, the varying methods of de-tracking in different schools makes the evaluation of these efforts difficult and quite problematic (Rubin, 2003, 2006). Thus, findings of quantitative and qualitative research that have been conducted on de-tracking are inconclusive (Rubin, 2003, 2006; Yonezawa et al., 2002), with some studies showing positive outcomes (Alvarez \& Mehan, 2007; Cohen \& Lotan, 1995) and others showing little to no gains (Gamoran \& Weinstein, 1998; Yonezawa et al., 2002). 
In a qualitative study of four middle schools and six high schools, Yonezawa et al. (2002) found that schools engaged in implementing de-tracking were ineffective at enabling students to have "freedom of choice" in the selection of courses (p. 38). It is important to note that the schools had varied methods of de-tracking [in that some schools enabled their students to choose honors courses, while other schools permitted students to select courses across curricula]. The researchers suggested that these schools were unsuccessful primarily due to long-standing, imbedded school structures and cultural dynamics of schools and student relationships. The researchers found three main themes in their study. These themes included institutional barriers, tracked aspirations, and choosing respect. Institutional barriers such as the amount of information that was provided to some students were limited, having an impact on students' known options in regards to course-taking. Tracked aspirations were a significant factor because students held on to long-standing aspirations and identities of prior schooling experiences and reduced the likelihood of choosing alternative courses. Lastly, "choosing respect" referred to the phenomenon of low to middle income students choosing lower tracks based on supportive environments with courses that was comprised of many students of similar races, and peers and teachers that valued their cultures.

Another qualitative research study utilizing focus group interviews from 12 schools, Yonezawa and Jones (2006) found that students perceived tracking as unjust. They described instances in where their friends and relatives were placed in inappropriate tracks based on prior performance/achievement and work habits, as well as how those students were viewed as unintelligent by their teachers. These students believed that 
education should be equitable and enable all students to gain equal access to a rigorous curriculum. The researchers concluded that educational constituents should follow the same reasoning of the students when implementing de-tracking in their schools.

\section{Student Persistence in Higher Education}

Some students are unfamiliar with the expectations of higher education. Correspondingly, some students were not well equipped with high school courses aimed at preparing them for academic success in college (Venezia \& Kirst, 2005). The transition from high school to postsecondary education is often problematic for first-generation college students. These students typically rely almost solely on high school resources in their preparations for postsecondary education. Nevertheless, students that enroll in postsecondary education and never complete a college degree may in fact benefit from their experiences and may grow socially and intellectually as a result (Tinto, 1987).

Spanning four decades, research on student persistence in higher education is one of the most prevalent studied subject matter (Metz, 2005; Tinto, 1987, 2006). In fact, according to Tinto (2006), "In addition to the extensive body of research literature that now spans more than four decades, there are books and edited volumes, a journal, and a variety of conferences dedicated solely to student retention" (p. 1). This surge in research regarding student persistence in higher education is warranted, mainly due to the fact that the majority of students entering institutions of higher education leave prior to completing a degree (Tinto, 1987). According to Tinto (1987),

In many respects departure is a highly idiosyncratic event, one that can be fully understood only by referring to the understandings and experiences of each and every person who departs. Nevertheless, there does emerge among the diversity of behaviors reported in research on this question a number of common themes as to 
the primary causes of individual withdrawal from institutions of higher education. (p. 39)

Similar to research on factors associated with students' decisions to enroll in higher education, research on student persistence in higher education has indicated that ability (Tinto, 1987), race (Swail et al., 2003; Tinto, 1987), SES (Wells, 2008), student dispositions (Tinto, 1987), parental education (Wells, 2008), curriculum in high school (Swail et al., 2003), level of involvement, either socially or academically (Metz, 2005; Tinto, 1993; Tinto, 2006), academic performance (Metz, 2005), interactions with faculty members, residence on campus, tuition, financial aid (Fike \& Fike, 2008; Metz, 2005), housing, working while in school, type of institution enrolled in ([two-year or four-year institution] Tinto, 1987), and institutional selectivity (Tinto, 1987) are all determinants of student retention. Other predictors such as institutional factors (i.e., institutional size) may contribute to student persistence, but have not been substantiated with unequivocal findings of empirical studies (Wells, 2008). Despite the progress that research has made in shedding light on the complexity of factors contributing to student persistence, much is still not known about the reasons for student departure (Tinto, 1987).

Many models of student departure have been devised including examining student attrition from psychological, societal (often referred to as educational and social attainment), structural-functional, and economic perspectives (Tinto, 1987). Tinto (1987) developed a theory of student persistence in institutions of higher education that draws from the field of social anthropology and research on the tribal rites of passage, which is concerned with the issues that individuals encounter throughout their lives. 
Similarly, Tinto examined the longitudinal process of student persistence in institutes of higher education through describing various stages students go through. Tinto (1987) noted, "By extension, it further suggests that the process of student departure reflects the difficulties individuals face in seeking to successfully navigate those passages" (p. 94). Thus, in the first stage, new college students must deal with the issues arising from transitioning from their families and local high schools to a highly differentiated community with new values and norms, as well as behavioral, intellectual, and cultural expectations of college life. This stage focuses on the separation that exists when students must disassociate with their past community. The second stage deals with students' transitions from high school to college and marks the doing away with the old and accepting the new norms and expectations of college. Lastly, students are faced with the issue of whether to become integrated into their new college communities. This integration is primarily dependent on formal and informal relationships with members of the institution. Further, the make-up of institutes of higher education consists of academic and social facets. Inadequate social and academic integration are two main ingredients that perpetuate students' departure from institutions.

Community colleges are often an attractive option for students who believe they might not be ready to enroll in a four-year institution. Consequently, community colleges often enroll students that are under-prepared for studies at higher education institutions (Fike \& Fike, 2008). However, many colleges and universities have selective or highly selective admissions policies limiting the number of under-prepared students entering their institutions (Fike \& Fike, 2008). On the contrary, community colleges often have 
open-door policies. According to Fike and Fike (2008), "Because of the open-door policy, under-prepared students are encouraged to enroll in a community college, where they can take advantage of developmental education, or remedial, courses" (p. 70).

Fike and Fike (2008) investigated 9,200 first-generation community college students to find predictors of their persistence. They found developmental education (such as completion of a developmental reading course), enrolling in an online course, participating in Student Support Services (a federally funded program for disadvantaged students), financial aid, and the number of course hours enrolled in a semester were all predictors in students' persistence at a community college. The researchers recommended that institutions utilize data on their students to better understand what programs are effective in enhancing student retention.

\section{Labor Market Outcomes}

Despite the acknowledgement that obtaining a bachelor's degree has many benefits and provides access to increased opportunities, according to the Bureau of Labor Statistics data, projections of job opportunities for individuals without a bachelor's degree indicated that approximately 42 million positions will be available between 2002 and 2012 (Moncarz \& Crosby, 2004). This projection outweighs the number of expected positions available for those with bachelor's degrees by three-fold.

\section{School- to-Work Transitions}

The school-to-work network includes collaborative relationships among three parties, including students, employers, and schools (Rosenbaum, Kariya, Settersten, \& Maier, 1990). This relationship is often problematic - in that, the needs of the workforce 
are constantly transforming while communication oftentimes is lacking between the employers and schools. Further, schools sometimes fail to adapt to the dynamic needs of the workforce. This sometimes is due to the lack of communication and other times might be due to lack of resources or teachers' professional development.

Unlike college graduates whom might have more insight into the labor market within their disciplines and have gained greater field relevant knowledge and skills, adolescents that do not participate in postsecondary education encounter varied experiences in their transitions from school to the workforce with some employed in several jobs as contingent workers, some landing permanent long-term careers, and others finding themselves unemployed (Yates, 2005). Educators and policymakers share varied perspectives in relation to the phenomenon of adolescents working in multiple jobs. One perspective is that these individuals, by experiencing and accumulating a wide variety of work opportunities, gain valuable work experience in the process - work experience that might be substantially valuable to increasing their knowledge, skills, and interests as well as increasing their prospects of earning a higher wage. On the contrary, another perspective is that the unnecessary time these adolescents take by transitioning into multiple jobs is unproductive and increases their opportunity costs (Rosenbaum et al., 1990).

Yet another group of adolescents do not earn a high school diploma and are oftentimes disadvantaged in comparison with their high school graduate counterparts. Yates (2005) described their likely outlook: "they lack both general and job-specific skills, and they face employers who have low expectations and little incentive to invest in 
their matches" (p. 21). Kulik (1998) estimated the number of students dropping out of high school to be an astounding 450,000 in non-academic curricula tracks. This large number of students dropping out of high school tends to be equated with high societal costs in terms of placing these individuals in social welfare programs for housing, healthcare, and employment (Kulik, 1998). Furthermore, it is unfortunate that the majority of individuals that comprise this category are minorities and economically disadvantaged. Proponents of CTE have long perceived CTE to be a preventative component in students dropping out of high school due to students' interest in the curriculum, relevance to students, and because students find it rewarding (Kulik, 1998). And, researchers have supported this assertion (Kulik, 1998; Rasinski \& Pedlow, 1998). Thus, students' educational experiences are strongly associated with employment prospects - for that is the time where students should learn about hard (i.e., literacy and mathematical) and soft (i.e., employability) skills (Yates, 2005).

Utilizing the 1979 NLSY dataset, Yates (2005) investigated the school-to-work transitions of high school graduates of the period in which they graduated to the time they reached 35 years of age. She found that $17 \%$ of students dropped out of high school approximately at the age of $17 ; 55 \%$ graduated, but did not attend college; $22 \%$ graduated from high school and went to college, but did not earn a bachelor's degree; and 11\% earned a college degree. In regards to demographics, men were both more likely to dropout of high school as well as earn a college degree; whites were more likely than students of color to earn a high school diploma as well as a college degree. 
Further, Yates (2005) found that high school student dropouts' employment was not stable. In fact, these students, on average, had positions lasting no longer than two years in duration. Yates (2005) noted,

At age 20, 14 percent of dropouts have never held a job and 58 percent had yet to hold a job for more than one year... Only 36 percent of high school dropouts had held a job for 5 years or more by age 35. (p. 24)

Those findings are in stark contrast to college-goers whom by age 30, approximately $86 \%$ held positions for at least two years and $82 \%$ of college degree holders held a job for at least two years. The percentage increased to $95 \%$ by age 35 . Lastly, Yates found that college graduates had steady, long-lasting employment relationships in contrast to high school dropouts whom had multiple short-term positions 15 years subsequent to leaving high school. Therefore, Yates concluded that increases in education positively impacts school-to-work transitions.

In a review of research findings, Kulik (1998) concluded that CTE students were more satisfied with their jobs than students in the general education track ( $44 \%$ of CTE students compared to $37 \%$ of general students). However, he further stated that future studies should explore what may account for attributions of students' job satisfaction.

\section{The Impact of CTE on Long-Term Earnings}

Meer (2007) contested the research that demonstrated lower earnings potential for CTE students because of the contextual factors that are omitted from the findings. He commented,

After all, it is just as plausible that these students earn less because of unobservable characteristics that are correlated with track choice as it is that vocational education is somehow diminishing their earnings potential. Simply because those who are currently on the academic or general track earn more than 
vocational students does not mean that shifting vocational students to those tracks would increase their income (p. 560).

Therefore, based on analyzing NELS 1988 dataset, Meer (2007) examined students in the general, academic, technical, and business tracks instead of the more common three-track system (general, academic, and CTE) that is often studied. They found that students in the technical track are not more likely to have higher incomes if they had chosen another track. Those individuals in a general track were more likely to have benefited from a technical track. Further, those individuals that were in a technical or an academic track benefited greatly from their choices in terms of earnings potential. Unexpectedly, those individuals in the business track were more likely to have gained from choosing a general track. The researcher concluded that CTE has been wrongly stigmatized as an inferior curriculum track and encourages CTE constituents to prepare its students for the current high-technology workforce.

Mane (1999) utilized the NLSY of 1972, the HS\&B survey of 1980, and the NELS of 1988 to examine the short and medium term outcomes of non-college bound students in academic and CTE high school courses. He found that non-college bound students in CTE earned a higher wage than their academic counterparts for those graduating in 1980 and 1992, but not graduates of 1972. The researcher concluded that the findings argue against those that propose closing CTE programs. He further supported the advancement of articulation agreements with institutes of higher education, stating "While the return to high school vocational education is substantial, the return to post secondary study is larger still. Consequently, high school students should always be encouraged to plan on getting further education after high school” (Mane, 1999, p. 434). 


\section{The Impact of CTE on Occupational Choices}

Prior research has indicated that work experience opportunities provided by CTE programs promote and extend students understanding in CTE courses (Rojewski, 1997). Research has demonstrated that curriculum tracking (Akos et al., 2007) is an indicator of career aspirations.

Current CTE objectives not only emphasize postsecondary education attainment, but also promote student exploration and focus on occupational goals through initiatives such as Tech Prep, school-to-work, and work-based learning (Ryken, 2006; Stone \& Aliaga, 2005).

Ryken (2006) utilized a case study method to determine three African-American female students' perceptions of their challenges in transitioning from high school to college. These participants were former CTE work-based learning students. The study revealed that career decisions are associated with work experiences. In addition, longterm career experiences and education are needed to shape an individual's occupational focus, instead of solely participating in a short-term program in high school. The researcher concluded that CTE programs may limit students' career decision-making; thus, CTE programs might consider providing students with varied career experiences. Arum and Shavit (1995) studied school-to-work transitions of high school CTE students. Utilizing the HS\&B dataset of students from 1980 to 1986 , they examined the impact of CTE on the probabilities of students' occupational attainment and employment status. For males, findings indicated that the CTE track had a statistically significant positive relationship with being employed and being a skilled employee, in comparison to 
those in the general track. Further, it was found that an integrated curriculum with academic and CTE courses was the most beneficial. The researchers concluded that their findings support educational reformers in restoring CTE programs.

Bishop and Mane (2004) analyzed longitudinal data to assess the impact of students' participation in CTE courses on high school completion rates and post high school earnings. They found students engaging in CTE courses one-sixth of their time in high school earned $12 \%$ more earnings after one year of graduating high school and $8 \%$ more seven years later.

\section{The Need for This Study}

As a result of an extensive review of the literature on the factors influencing students' long-term student outcomes, it is evident that the type of high school curriculum a student participates in significantly impacts their long-term opportunities. Coupled with the changing nature of the workplace and the growing awareness for the need of postsecondary education credentials, more research is needed on the type of high school curriculum a student is exposed to and their actual long-term outcomes. This need is further explicated in the new legislation guiding the objectives of CTE. In fact, CTE too has recognized the need for the changing needs of its students and in 1990 incited the charge for CTE programs to ensure their students are not only prepared for the workforce, but are also prepared to pursue postsecondary educational experiences.

The pressing nature of research investigating CTE student long-term outcomes is explicated in the following quote:

The neglect of vocational education in research reviews is distressing because important questions are being raised today about the effectiveness of vocational 
education. Are disproportionate numbers of minorities and poor children shunted into the vocational track? Do these students receive an inferior education there? Are they taught low-status subjects from low-status teachers? Would everyone's needs be better met in one-track schools? These questions need to be answered, and the answers to the questions need to be based on careful analyses of evidence not hearsay and stereotyping. (Gamoran, Kulik, Lynch, Rasinski, \& Pedlow, 1998, व 2).

\section{Conceptual Framework}

As illustrated in Figure 2.1, the conceptual framework underlying this research study outlines the relationships among demographic variables, high school curriculum tracks, degree attainment, and occupational earnings. Essential relationships critical to this study are shown through the conceptual framework for examining status attainment effects of high school curriculum tracks. First, the relationship between demographic variables (namely - gender, race/ethnicity, and SES) and high school curriculum tracks will be examined. Prior research has indicated that gender, race/ethnicity, and SES are strong influencers of CTE concentration (Stone \& Aliaga, 2005). Second, the relationship among demographic variables, high school curriculum track, and students' degree attainment will be explored. Other research has suggested that demographic variables such as SES (Kao \& Tienda, 1998) and gender (Hossler \& Stage, 1992) are factors influencing postsecondary education enrollment; further, curricula tracking (Esters, 2007) has also been shown to influence postsecondary education enrollment. In addition, findings from a study by Hudson and Hurst (1992) found that dual concentrators were

more likely to enroll in college than their CTE and general counterparts, but not as likely as college preparatory concentrators. Third, the relationships among demographic variables, degree attainment, high school curriculum track, and occupational earnings 
will be assessed. A substantial number of studies have supported the positive relationship between degree attainment and occupational earnings (Bailey et al., 2004b; Liming \& Wolf, 2008). Research by Rojewski (1997), Mane (1999), and Bishop and Mane (2004) has demonstrated that CTE concentrators often have higher wages than their college preparatory and general counterparts. On the contrary, Meer (2007) found evidence that the college preparatory track yielded higher earnings. Thus, this study will investigate the relationship of high school curriculum tracks and postsecondary education attainment, as well as occupational earnings. Chapter three focuses on the research methods guiding this study. 


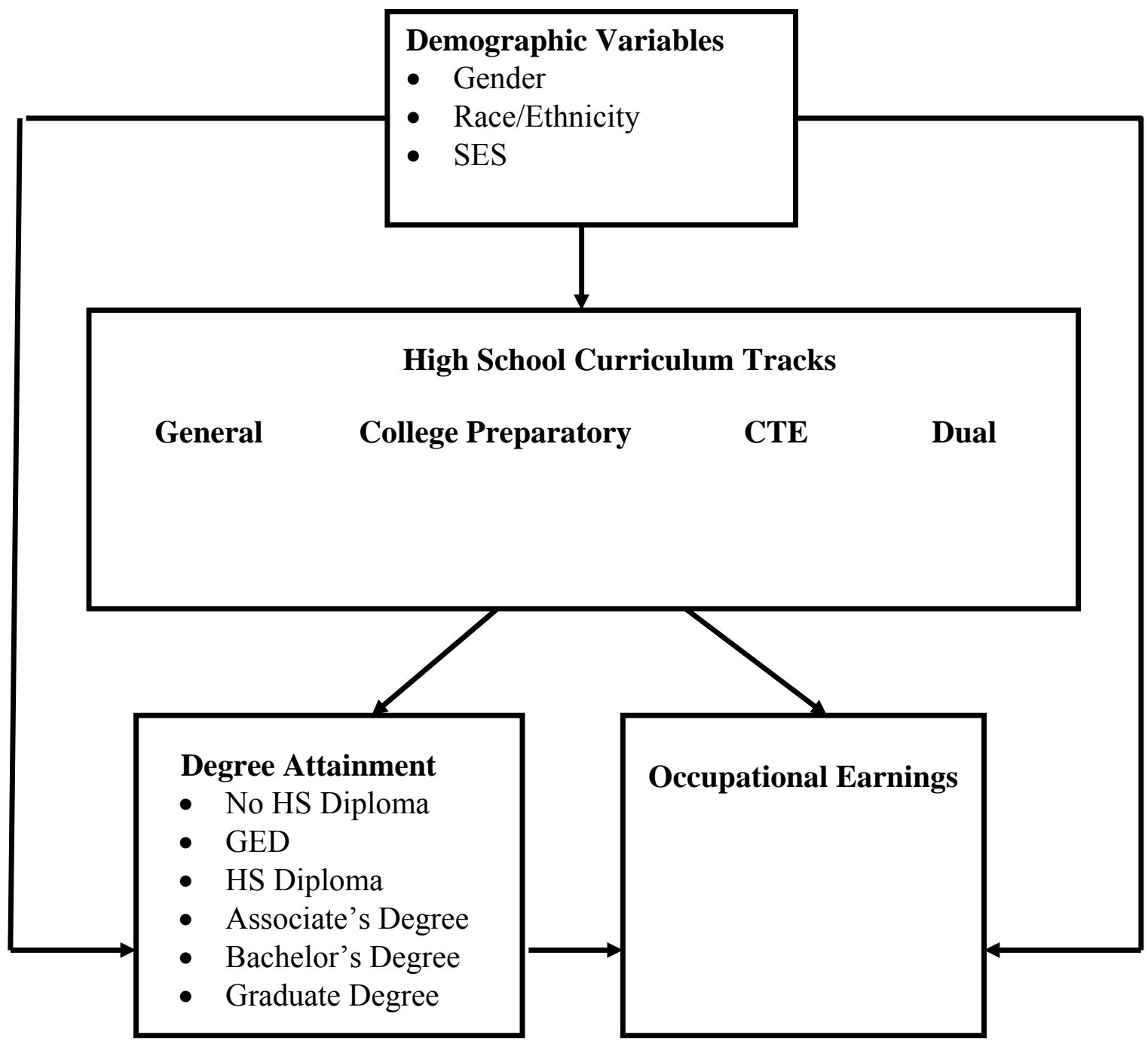

Figure 2.1: Conceptual framework for examining status attainment effects of high school curriculum tracks 


\section{CHAPTER 3}

\section{METHODOLOGY}

This chapter articulates the methods utilized to investigate the research questions stated in chapter one. The first section of the chapter describes the type of research employed for this study. The second section presents the research setting. The third section identifies the sampling procedure administered. The fourth section outlines the operationalization of the variables examined in this research study. Last, the fifth section illustrates the procedures used for data analysis in investigating each of the research questions outlined.

\section{Research Type}

This research study utilized descriptive and inferential statistics. Specifically, multinomial logistic regression analyses were administered to examine the first two research questions and multiple regression analysis was conducted to answer the third research question. The type of research employed for this study may be categorized as ex-post facto (causal-comparative) research. In determining the relationship between high school curriculum tracks and long-term student outcomes, the current researcher examined outcomes based on students engaging in certain types of curricula, which was a 
phenomenon that has already existed. Thus, this research study was in alignment with the primary objective of ex-post facto research (Fraenkel \& Wallen, 2006). Ex-post facto research differs from experimental research in that the researcher, in ex post facto research studies, does not manipulate a difference between treatment groups in order to compare their performances on the dependent variable(s) to examine the effects of the differences. Since the independent variables of this study precede the dependent variables in time, ex-post facto research was most appropriate for evaluating the research questions posed in this study.

Ex-post facto research has several limitations and threats to internal validity. The first and most major concern to internal validity may be characterized as a selection threat. This is a result of the researcher's inability to control the selection of the comparison groups; consequently, the groups may not be initially equivalent on critical variables other than the type of curriculum taken (Fraenkel \& Wallen, 2006). However, this research study employed random selection of participants. Thereby, this type of sampling assists in controlling for the selection threat.

Other limitations may have included mortality (the loss of research participants), location, instrumentation, and the maturation of participants (Fraenkel \& Wallen, 2006). Mortality occurs when the number of research participants at the initiation of the data collection is different than at the end of the data collection; this is particularly an issue when more research participants are missing from one group than the other. The NLSY dataset does have respondents that were unable to be reached subsequent to the initial round of data collection. Location is a threat when the data collected is administered 
under different conditions, or different researchers collect data. The NLSY dataset had multiple researchers collecting data, which indicates that location was a plausible concern. However, all participants responded to the same interview scripts. Maturation is an issue when research is conducted over time and the differences among the groups may be attributed to growth and development of the participants. This threat may be plausible, in that data from this study were collected over nine years, in the time that the respondents were transitioning from adolescence to adulthood.

\section{Research Setting}

The research setting is segmented into three components. The first component outlines criteria for the research setting. The second component identifies the selected sample. The third component articulates the data preparation.

\section{Criteria for Research Setting}

Three criteria were evaluated to determine an appropriate research setting and dataset for this research study. Criteria for this study included reasonably high response rates; random sampling; and an ability to examine the type of curriculum in which a student had participated, their degree attainment, and their earnings over an extended period of time - nine years.

The response rate for the 1997 NLSY dataset during round one was slightly over $93 \%$ and the response rate for round 10 (the last round of data collection - 2006) was slightly over $83 \%$. These response rates were deemed reasonable since the typical response rates of mailed questionnaires are 25 to $40 \%$ (Newton \& Rudestam, 1999). NLSY investigators utilized several methods to ensure high response rates. These 
methods included: (a) attempting to locate the participants by asking the respondents, during the prior round, to provide names and phone numbers of family members and close friends that might be able to locate them if they had moved; (b) sending a letter to the participants in advance, prior to interviewing - a letter that articulated the importance of the interview; (c) attempting to contact the participants on multiple occasions and varying the times and dates of the attempts to maximize the probability of reaching the participants; (d) providing respondents with additional incentives to determine the response rate levels; and (e) matching the same interviewer with the same respondent from prior rounds (Inter-University Consortium for Political and Social Research, 2003). In fulfillment of the second criterion, the 1997 NLSY dataset utilized two independent random samples. The first random sample was comprised of a crosssectional sample. The second random sample was an oversample of Blacks and Hispanics/Latinos. This random sampling procedure was employed to provide a sufficient sample of Black and Hispanic/Latino participants for statistical analyses. The sampling methods are detailed in the next section of this chapter - sampling procedures. Random sampling is the ideal method of selecting respondents and meets the essential assumption of conducting inferential statistics (King \& Minium, 2003). Random sampling was the best method for supporting generalizations from the findings. Random sampling controls for many of the threats to internal validity, particularly selection threat.

The 1997 NLSY dataset met the third criterion of enabling the current researcher to assess the type of high school curriculum track and its relationship with long-term student outcomes, namely: degree attainment and occupational earnings. Among the vast 
array of survey items of the 1997 NLSY, researchers asked respondents questions regarding their schooling experience. In fact, one item from the 1998 questionnaire asked participants to respond to what program or course of study in which they were enrolled in during high school. Participants responded based on the following categories, among others: general program; college preparatory, academic, or specialized academic; vocational technical or business and career; or a combination of academic and vocational curricula.

Another section of the questionnaire enabled participants to respond to their educational status and attainment, specifically the degrees or credentials they have earned. In fact, participants in 2006 indicated the highest degree they had received, among the following categories: none (no high school diploma or GED); GED; high school diploma; associate's degree; bachelor's degree; master's degree; Ph.D.; or professional degree. The current researcher collapsed the master's degree, Ph.D. and professional degree into one indicator - that is, graduate degree.

Lastly, another major factor for selecting the 1997 NLSY dataset was to examine students' long-term earnings. The 1997 NLSY dataset enabled respondents to indicate their total income from wages, salaries, commissions, and tips. Participants responded based on the total dollar amount they earned from all of their jobs prior to tax deductions.

As a result, the 1997 NLSY dataset met the three criteria of having an acceptable response rate, employing random sampling procedures, and having accessible the variables of interest specific to the research questions. Further, the selection of the 1997 NLSY dataset was appropriate in allowing sufficient time for the 1990 Carl D. Perkins 
Vocational and Applied Technology Education Act to be implemented and have an impact on students' long-term outcomes; thereby, enabling the current researcher to assess the influence legislative initiatives had on long-term student outcomes.

\section{Sample and Instrument}

Based on the three criteria articulated previously, the 1997 NLSY dataset was chosen to investigate the research questions for this study. The 1997 NLSY is a dataset that documents the experiences of high school students in their transition from adolescence to adulthood (Inter-University Consortium for Political and Social Research, 2003). This national dataset included 8,984 research participants and was representative of 1997 U.S. residents who were born in the periods between 1980 and 1984. The participants $(7,559)$ were between the ages of 22 and 26 during the last (tenth) round of interviewing in 2006. The dataset included information on postsecondary educational outcomes and labor market experiences. Data from the NLSY included information from interviews (utilizing a computer-assisted personal interviewing system [CAPI]) of a national random selection of households.

\section{Data Preparation}

To focus on specific students enrolled in the four curriculum tracks of interest, the current researcher excluded those respondents that indicated membership in alternative programs. The curricular tracks of interest included the general program, the college preparatory program, the CTE program, and a combination of academic and CTE curricular program (dual). Those respondents that indicated the following tracks were excluded from data analyses: other; special education/learning disabled; alternative; 
GED; college; and not applicable. The total individuals excluded from analyses were 144. In addition, 36 participants indicated that they did not have adequate knowledge to respond, 1,141 validly skipped the question, and 598 were not able to be interviewed. Thus, 4,121 respondents indicated they were in the general program, 2,129 indicated college preparatory, 423 indicated vocational, and 392 indicated participating in a combination of academic and vocational courses. As a result, 7,065 (out of 8,985) respondents were included in the data analyses.

Further, the current researcher excluded cases that had excessive levels of missing data. These excluded cases did not have responses indicating their degree attainment and occupational earnings, which are the dependent variables of interest to this current research study. Despite the exclusion of certain cases, missing data in this research study was not a substantial issue - in that, the missing data in this research study was random due to the probability sampling that occurred to select the participants (Hair et al., 2006).

\section{Sampling Procedures}

As mentioned previously, the 1997 NLSY was comprised of two independent random samples of youth born between the years of 1980 and 1984. One sample was a cross-sectional of 54,179 initial respondent screenings from 100 sampling units in the United States. Subsequent to the initial screening process, 7,327 participants were chosen. Of the 7,327 participants chosen, 6,748 (92.1\%) individuals responded.

The second independent random sample included an oversampling of Black and Hispanic/Latino individuals to ensure appropriate statistical comparisons. These individuals were chosen from 100 sampling units within the United States. A total of 
21,112 individuals born between the years 1980 and 1984 were included in the screening process and 2,479 possible participants were identified. Of the 2,479 possible participants, 2,236 (90.2\%) completed interviews in round one. Thus, a total of 8,984 of participants were interviewed, which comprised the NLSY cohort.

\section{Operationalization of Variables}

This section identifies and describes the variables utilized in this study. The following variables are explained: degree attainment, SES indicators (father's highest grade completed, mother's highest grade completed, and household income), gender, high school curriculum tracks, household income, occupational earnings, and race/ethnicity. SES indicator variables were transformed to include fathers with less than a high school education (the reference group), fathers with a high school education, and fathers with a college education. Similarly, mother's highest grade completed variables were transformed into the same categories. See Appendix A for the actual questionnaire items to which the participants of this research study responded.

\section{Degree Attainment}

Degree attainment was defined as the highest degree or credential that an individual earns. This variable was measured by an item that was created by the NLSY researchers. This item was located in the Ed Status and Attainment section of the 2006 round of the Youth Questionnaire and was denoted as CV_Highest_Degree_Ever_Edt. The following response opportunities were included in this research study: none (not earning a high school diploma), GED, high school diploma, associate's/junior college, bachelor's degree. The participants that indicated earning a master's degree, Ph.D., or 
professional degree were collapsed into one response category and characterized as "graduate degree". Degree attainment is a dependent variable in this research study for the second research question and was an independent variable for the third research question. It was comprised of six levels. However, none - indicating not earning a high school diploma - was the reference category.

\section{Fathers with a College Education}

Fathers with a college education was a variable that was created based on participants' responses to their biological father's highest grade completed. This variable was measured by responses to an item in the Family Background and Demographic Characteristics section of the 1997 round of the Youth Questionnaire, denoted as (CV_HGC_BIO_DAD). Participants chose from a range of none to eighth year or more in college. Fathers with a college education was an independent variable in this research study. The current researcher dummy coded these items. The reference variable included participants that selected first grade to $11^{\text {th }}$ grade. The second variable included participants that selected twelfth grade. The third variable included participants that selected first year to eighth year or more in college. Fathers with a High School Education

Fathers with a high school education was a variable that was created based on participants' responses to their biological father's highest grade completed. This variable was measured by responses to an item in the Family Background and Demographic Characteristics section of the 1997 round of the Youth Questionnaire, denoted as CV_HGC_BIO_DAD. Participants chose from a range of none to eighth year or more in 
college. The fathers with a high school education variable was an independent variable in this study. The current researcher dummy coded these items. The reference variable included participants that selected first grade to $11^{\text {th }}$ grade. The second variable included participants that selected twelfth grade. The third variable included participants that selected first year to eighth year or more in college.

Gender

The gender of the participants were identified as male or female. This variable was measured by responses to an item in the Symbols section of the 1997 round of the Youth Questionnaire, denoted as KEY!SEX. The gender variable was a categorical variable and was an independent variable in this study. Gender was dummy coded with males as the reference group.

High School Curriculum Tracks

High school curriculum tracks are defined as programs or courses of study in which students participated throughout their high school experiences. This variable was measured by responses to an item in the School Experience section of the 1998 round of the Youth Questionnaire, denoted as YSCH-21625. Participants responding as being enrolled in the general program; college preparatory, academic, or specialized academic (college preparatory); vocational technical or business and career (CTE program); or combination of academic and vocational (dual), were included in this research study. The High School Curriculum Track variable was an independent variable in this research study and had four levels. High school curriculum tracks were dummy coded in this research study and the general track was utilized as the reference group. 


\section{Household Income}

The variable household income was the gross dollar amount of income that the participants reported in 1997. This variable was measured by responses to an item in the Income section of the 1997 round of the Youth Questionnaire, denoted as CV_INCOME_GROSS_YR. The household income variable was a continuous variable and functioned as an independent variable in this research study.

\section{Mothers with a College Education}

Mothers with a college education was a variable that was created based on participants' responses to their biological mother's highest grade completed. This variable was measured by responses to an item in the Family Background and Demographic Characteristics section of the 1997 round of the Youth Questionnaire, denoted as CV_HGC_BIO_MOM. Participants chose from a range of none to eighth year or more in college. The mothers with a college education variable was an independent variable in this research study. The current researcher dummy coded these items. The

reference variable included participants that selected first grade to $11^{\text {th }}$ grade. The second variable included participants that selected twelfth grade. The third variable included participants that selected first year to eighth year or more in college. Mothers with a High School Education

Mothers with a high school education was a variable that was created based on participants' responses to their biological mother's highest grade completed. This variable was measured by responses to an item in the Family Background and 
Demographic Characteristics section of the 1997 round of the Youth Questionnaire, denoted as CV_HGC_BIO_MOM. Participants chose from a range of none to eighth year or more in college. The mothers with a high school education variable was an independent variable in this study. The current researcher dummy coded these items. The reference variable included participants that selected first grade to $11^{\text {th }}$ grade. The second variable included participants that selected twelfth grade. The third variable included participants that selected first year to eighth year or more in college.

\section{Occupational Earnings}

Occupational earnings (total income) was defined as an individual's combined annual earnings from wages, salaries, commissions, or tips from all jobs prior to tax deductions, during 2005.. This variable was measured by an item in the Income section on the 2006 Youth Questionnaire and was denoted as YINC-1700. Participants responded with a total dollar figure to indicate their respective total income. Total income was a dependent variable in this research study and was continuous.

\section{Race/Ethnicity}

Race/ethnicity was defined as an individual's cultural background and sub-group that he or she identified; this group typically has shared origins and traditions. This variable was measured by responses to an item in the Symbols section of the 1997 round of the Youth Questionnaire, denoted as KEY!RACE_EHNICITY. Participants responded as: Black; Hispanic; Mixed Race (Non-Hispanic); or Non-Black/Non-Hispanic. Race/ethnicity was an independent variable in this research study and had four levels. 
Race/ethnicity was dummy coded for analytical purposes and Non-Black/Non-Hispanic was utilized as the reference group.

\section{SES Indicators}

This term was used to describe three variables, namely: father's highest grade completed, mother's highest grade completed, and household income. These are similar SES indicators that are commonly used in other studies (Sciarra \& Whitson, 2007).

\section{Data Analysis}

Data from the 1997 NLSY was entered and analyzed utilizing SPSS (Statistical Package for the Social Sciences) 17.0 software. First, descriptive data such as frequencies, means, medians, and modes were identified to describe the students that enrolled in the various curriculum tracks (general, college preparatory, CTE, and dual). In addition, similar descriptive data were reported to characterize respondents' degree attainment and occupational earnings.

Second, the first and second research questions investigating - (a) the relationship between demographic variables and high school curriculum tracks; and (b) demographic variables, high school curriculum tracks, and degree attainment - were analyzed using multinomial logistic regression analysis. The demographic (gender, race/ethnicity, SES indicators) and high school curriculum track variables were entered simultaneously into the multinomial logistic regression analysis. Regression analysis is the most widely utilized and flexible statistical technique used (Hair, Black, Babin, Anderson, \& Tatham, 2006). The main objective of regression analysis is to examine the relationship between an outcome variable and explanatory/predictor variables (Rashid, 2008). Logistic 
regression analyses create odds ratios for the independent variables (Sciarra \& Whitson, 2007). In the case of research question one, four mutually exclusive logits were created. For each high school curriculum track, the log of the ratio of the likelihood of participation in a high school curriculum track is relative to the baseline group (general track). For research question two, the odds ratios were utilized in determining an increase or decrease in the likelihood of an outcome (e.g., degree attainment) based on a one-unit increase in the independent variable. Five mutually exclusive logits were created. In this study, for each degree, the log of the ratio of the likelihood of earning a specific degree was relative to the baseline group (no high school diploma). Thereby, no high school diploma was used as the reference group to which all other degrees were compared. Multinomial logistic regression is a statistical analysis technique designed to deal with categorical dependent variables with more than two levels; thus, this type of analysis is most appropriate for the first two research questions of this study.

Third, the last research question examining the relationship among high school curriculum tracks, degree attainment, and earnings were investigated utilizing multiple regression analysis. The demographic (gender, race/ethnicity, SES), high school curriculum tracks, and degree attainment were entered into the multiple regression equation simultaneously. Multiple regression analysis is appropriate when assessing one metric dependent variable and more than one independent variable; and, multiple regression is by far the most used statistical analysis utilized (Hair et al., 2006). The nonmetric independent variables were transformed into numeric data. The objective of multiple regression for this research study was that of explanation - in that, the current 
researcher desired to investigate the relative importance of each independent variable in predicting the dependent (occupational earnings) variable. As a result of the multiple regression analysis, a proportion of the variance of the dependent variable (occupational earnings) were explained by the linear combination of independent variables (gender, race/ethnicity, SES, and curriculum track - the variate). 


\section{CHAPTER 4}

\section{RESULTS}

This chapter outlines the findings of this study and the results of the research questions. First, descriptive statistics are provided to identify and describe the participants of this research study in terms of demographic variables related to high school curriculum tracks as well as degree attainment and occupational earnings. Second, the results of research question one are explained as well as the assumptions and data interpretation of the multinomial logistic regression analysis utilized. Third, the findings of research question two are detailed including the assumptions and data interpretation of the multinomial logistic regression analysis used. Fourth, the outcomes of research question three are presented as well as the assumptions and data interpretation of the multiple regression analysis employed.

\section{Descriptive Statistics}

Participants in the different high school curriculum tracks included 3,534 (58.3\%) of individuals were in the general track, 1,845 (30.4\%) were in the college preparatory track, $363(6 \%)$ were in the CTE track, and $322(5.3 \%)$ were in the dual track. In terms of gender, the general, CTE, and dual tracks were comprised of primarily males $(52 \%$, 
$56.5 \%$, and $56.5 \%$, respectively) and the college preparatory track consisted mostly of females (56.6\%). The majority of Hispanic students (69.2\%) participated in the general track, non-black/non-Hispanic students (34.3\%) participated in the college preparatory track, and Black students had the highest participation rates in the CTE (9.8\%) and dual tracks (8.3\%). Table 4.1 illustrates participation rates by race/ethnicity based on high school curriculum tracks.

\begin{tabular}{ccccc}
\hline Race & General & College Preparatory & CTE & Dual \\
\hline Black & $859(53.9 \%)$ & $446(28 \%)$ & $156(9.8 \%)$ & $132(8.3 \%)$ \\
Hispanic & $879(69.2 \%)$ & $301(23.7 \%)$ & $48(3.8 \%)$ & $42(3.3 \%)$ \\
White & $1762(56.1 \%)$ & $1078(34.3 \%)$ & $157(5 \%)$ & $146(4.6 \%)$ \\
\hline
\end{tabular}

Table 4.1 Race/Ethnicity Participation Rates based on High School Curriculum Tracks

In terms of degree attainment, the general track had the highest proportion (13\%) of students that did not earn a high school diploma. On the other hand, the college preparatory track graduated the largest proportion of students that earned bachelor's degrees $(36.5 \%)$ and graduate degrees $(1.4 \%)$. The dual track had the highest rate of students earning associate's degrees (8.4\%). Table 4.2 presents descriptive data regarding degree attainment based on high school curriculum tracks. 


\begin{tabular}{lllllll}
\hline High School & No & GED & Diploma & Associate & Bachelor & Graduate \\
Curriculum & Diploma & & & Degree & Degree & Degree \\
Track & & & & & & \\
\hline General & 458 & 388 & 2063 & 182 & 430 & 12 \\
& $(13 \%)$ & $(11 \%)$ & $(58.4 \%)$ & $(5.1 \%)$ & $(12.2 \%)$ & $(.3 \%)$ \\
\hline College & 40 & 76 & 908 & 121 & 674 & 25 \\
Preparatory & $(2.2 \%)$ & $(4.1 \%)$ & $(49.2 \%)$ & $(6.6 \%)$ & $(36.5 \%)$ & $(1.4 \%)$ \\
\hline CTE & 41 & 55 & 229 & 19 & 18 & 1 \\
& $(11.3 \%)$ & $(15.2 \%)$ & $(63.1 \%)$ & $(5.2 \%)$ & $(5 \%)$ & $(.3 \%)$ \\
\hline Dual & 21 & 31 & 214 & 27 & 25 & 3 \\
& $(6.5 \%)$ & $(9.6 \%)$ & $(66.5 \%)$ & $(8.4 \%)$ & $(7.8 \%)$ & $(.9 \%)$ \\
\hline
\end{tabular}

Table 4.2: Degree Attainment in 2006 by High School Curriculum Track based on NLSY Participants from a 1997 Cohort

Related to labor market outcomes, students in the general track earned the lowest total income $(\$ 20,907.29)$ in 2006, while the CTE track earned the highest average income $(\$ 22,731.67)$ in 2006. Table 4.3 demonstrates the average income in 2006 based on high school curriculum tracks. 


\begin{tabular}{lcc}
\hline High School Curriculum Tracks & $M$ & S.D. \\
\hline General & $\$ 20,907.29$ & $14,698.19$ \\
College Preparatory & $\$ 22,183.33$ & $15,270.20$ \\
CTE & $\$ 22,731.67$ & $16,834.55$ \\
Dual & $\$ 22,652.92$ & $14,916.68$ \\
\hline
\end{tabular}

Table 4.3: 2005 Average Earned Income based on High School Curriculum Track

Assessing the Assumptions for Research Question One and Research Question Two

In utilizing multinomial logistic regression, several assumptions should be noted. Multinomial logistic regression was chosen to respond to research question one and two because the dependent variables were polytomous. The independent variables in these analyses were continuous and categorical. Thus, the continuous variable (household income) was entered as a covariate and the categorical variables were dummy coded and entered as factors in both research analyses.

Further, it was assumed that relevant variables were not omitted in the analysis. If relevant variables were omitted, this may have distorted the common variance associated with the included variables, as well as its error. This assumption also is true for irrelevant variables that may be included in the model. In addition, multinomial logistic regression 
assumes that irrelevant alternatives are independent. Thus, adding or removing these variables should not affect the odds ratio.

The explanatory variables in the models also assume that there is a low presence of measurement error and no missing cases. In addition, logistic regression assumes that interactions are not present. Further, by examining the standard errors of the data output, this warrants the conclusion that multicollinearity was not an issue in this analysis.

Large sample sizes for each category in the dependent variables are also assumed in logistic regression. Due to the large sample sizes of this research study, it was determined that an inadequate sample size did not present an issue. In addition, goodnessof-fit measures (i.e., chi-square) assumes that categorical independent variables have at least $20 \%$ of cells that are greater than five. The sampling adequacy was assessed in this study and did not present an issue.

\section{Response to Research Question One}

To what extent do demographic variables predict high school curriculum tracks?

In response to research question one, the current researcher regressed the criterion variable (high school curriculum tracks) on the predictor variables (gender, race/ethnicity, and SES indicators). By examining the model fitting information table, the model that included the predictors, namely: gender, race/ethnicity, mother's highest grade completed, father's highest grade completed, and household income provided adequate predictions $(-2 \log$ likelihood $=6.545 \mathrm{E} 3)$ compared to the intercept only (null model; -2 $\log$ likelihood $=6.830 \mathrm{E} 3)$. In addition, the model was statistically significant $(\mathrm{p}<.001)$. 
By examining the goodness-of-fit table, $\mathrm{p}>.05$, this warranted the conclusion that the model adequately fit the data.

By assessing the pseudo $\mathrm{R}^{2}$ indicators, particularly the Nagelkerke statistic, the proportion of variance explained of high school curriculum tracks by gender, race/ethnicity, mother's highest grade completed, father's highest grade completed, and household income was $86 \%$. However, it is important to note that the Nagelkerke statistic is only a proxy for $\mathrm{R}^{2}$ and may not have been highly accurate.

The likelihood ratio test table indicated that each predictor variable significantly contributed to the model, with the exception of the following variable: individuals with mothers with or without a high school education.

\section{College Preparatory Track}

This section describes the outcome of participating in the college preparatory track in comparison to the general track. The significant predictors of participating in the college preparatory track included the following, namely: gender, those individuals identifying as Hispanic, individuals with mothers with a college education, father's highest grade completed, and household income. Non-significant predictors of participating in the college preparatory track included the following, namely: those individuals identifying as Black and individuals with mothers with a high school education (See Appendix B).

Results of this research study suggested that in comparison to males, females were more likely to participate in the college preparatory track, odds ratio $=1.531, \mathrm{p}<$ .001 . Those individuals that had mothers with a college education were more likely to 
participate in a college preparatory track, odds ratio $=1.377, \mathrm{p}=.014$. Those individuals that had fathers with a high school education were more likely to participate in a college preparatory track, odds ratio $=1.462, \mathrm{p}=.002$. Those individuals that had fathers with a college education were more likely to participate in a college preparatory track, odds ratio $=1.715, \mathrm{p}<.001$. Last, the odds of being in the college preparatory track compared to the college preparatory track are about the same (1:1) regardless of household income, odds ratio $=1.000, \mathrm{p}<.001$

CTE Track

This section describes the outcome of participating in the CTE track in comparison to the general track. The significant predictors of participating in the CTE track included the following, namely: those individuals identifying as Black and Hispanic races, and individuals with fathers with a college education. Non-significant predictors of participating in the CTE track included the following, namely: gender, those individuals with mothers with a high school education and college education, those individuals with fathers with a high school education, and household income.

Results of this research study suggested that those individuals identifying as Black were more likely to participate in a CTE track, odds ratio $=1.675, \mathrm{p}=.004$, in comparison to non-Black/non-Hispanic individuals. In comparison with non-Black/nonHispanic individuals, those individuals indentifying as Hispanic were less likely to participate in a CTE track, odds ratio $=.600, \mathrm{p}=.034$. Last, those individuals with fathers with a college education were less likely to participate in a CTE track, odds ratio $=.583$, $\mathrm{p}=.029$. 


\section{Dual Track}

This section describes the outcome of participating in the dual track in comparison to the general track. The significant predictors of participating in the dual track included gender and those individuals identifying as Black and Hispanic. Nonsignificant predictors of participating in the dual track included the following, namely: mothers and fathers highest grade completed, and household income.

Results of this research study suggested that, in comparison to males, females were less likely to participate in the dual track, odds ratio $=.711, \mathrm{p}=.023$. Those individuals that belong to the Black race, in comparison with their non-Black/nonHispanic counterparts, were more likely to participate in the dual track, odds ratio = $1.661, \mathrm{p}=.003$. Those individuals identifying as Hispanic were less likely to participate in a dual track, odds ratio $=.607, \mathrm{p}=.040$, in comparison to their non-Black/nonHispanic counterparts.

Response to Research Question Two

To what extent do demographic variables and high school curriculum tracks predict degree attainment?

In response to research question two, the current researcher regressed the criterion variable (degree attainment) on the predictor variables of gender, race/ethnicity, SES indicators, and high school curriculum tracks. The model fitting information table demonstrated that the model that included the predictors, namely: gender, race/ethnicity, mother's highest grade completed, father's highest grade completed, household income, and high school curriculum tracks provided adequate predictions $(-2$ log likelihood $=$ 
7.694E3) compared to the intercept only (null model; -2 log likelihood $=8.937 \mathrm{E} 3$ ). In addition, the model was statistically significant $(\mathrm{p}<.001)$. By examining the goodness-offit table, $p>.05$, this warranted the conclusion that the model adequately fit the data.

By assessing the pseudo R-square indicators, particularly the Nagelkerke statistic, the proportion of variance explained of degree attainment by gender, race/ethnicity, mother's highest grade completed, father's highest grade completed, household income, and high school curriculum tracks was approximately $31 \%$. However, it is important to note that the Nagelkerke statistic is only a proxy for $\mathrm{R}^{2}$ and may not have been highly accurate.

The likelihood ratio test table indicated that each predictor variable significantly contributed to the model.

GED

This section describes the outcome of earning a GED in comparison to not earning a high school diploma. The statistically significant predictors of GED included mother's highest grade completed and household income. Non-significant predictors of GED included gender, participants identifying as Black, participants identifying as Hispanic, father's highest grade completed, and those individuals that participated in the college preparatory, CTE, and dual tracks (See Appendix C).

Results of this research study suggested that for those individuals whose mothers did have a high school education were more likely to earn a GED, odds ratio $=1.745, \mathrm{p}=$ .010 , in comparison to those individuals whose mothers did not earn a high school education. Similarly, those individuals whose mothers did have a college education were 
more likely to earn a GED, odds ratio $=2.326, \mathrm{p}=.001$, in comparison to those individuals whose mothers did not earn a college education.

\section{High School Diploma}

This section describes the outcome of earning a high school diploma in comparison to not earning a high school diploma. Statistically significant predictors for high school diploma included gender, mothers' and fathers' highest grades completed, those individuals of the Hispanic race, and those individuals that participated in college preparatory and dual tracks. Non-statistically significant predictors for high school diploma included those individuals identifying as Black and those individuals that participated in the CTE track.

In comparison to males, females were more likely to earn a high school diploma, odds ratio $=1.441, \mathrm{p}=.008$. In comparison to those individuals whose mothers did not have a high school education, those individuals that had mothers with a high school education were more likely to have earned a high school diploma, odds ratio $=2.083, \mathrm{p}<$ .001 . In comparison to those individuals whose mothers did not have a college education, those individuals that had mothers with a college education were more likely to earn a high school diploma, odds ratio $=2.976, \mathrm{p}<.001$. In comparison to those individuals whose fathers did not have a high school education, those individuals that had fathers with a high school education were more likely to have earned a high school diploma, odds ratio $=2.342, p<.001$. In comparison to those individuals whose fathers did not have a college education, those individuals that had fathers with a college education were more likely to earn a high school diploma, odds ratio $=2.538, \mathrm{p}<.001$. In comparison to 
those individuals of the Hispanic race, those individuals of the non-Black/non-Hispanic race were more likely to earn a high school diploma, odds ratio $=1.650, \mathrm{p}=.007$. In comparison to those individuals participating in the general track, those individuals in the college preparatory track were more likely to earn a high school diploma, odds ratio $=$ $3.425, \mathrm{p}<.001$. Last, in comparison to those individuals participating in the general track, those individuals in the dual track were more likely to earn a high school diploma, odds ratio $=2.667, \mathrm{p}=.004$.

\section{Associate's Degree}

This section describes the outcome of earning an associate's degree in comparison to not earning a high school diploma. Statistically significant predictors for associate's degree included gender, those individuals identifying as Black, mothers' and fathers' highest grades completed, those individuals in the college preparatory and dual tracks, and household income. Non-statistically significant predictors for associate's degree included those individuals identifying as Hispanic and those individuals that participated in the CTE track.

In comparison to males, females were more likely to earn an associate's degree, odds ratio $=1.852, \mathrm{p}=.001$. In comparison to non-Blacks/non-Hispanics, Blacks were less likely to earn an associate's degree, odds ratio $=.517, \mathrm{p}=.008$. In comparison to those individuals that had mothers without a high school education, those individuals with mothers with a high school education were more likely to earn associate's degrees, odds ratio $=1.984, p=.008$. In comparison to those individuals that had mothers without a college education, those individuals that had mothers with a college education were 
more likely to earn associate's degrees, odds ratio $=2.525, \mathrm{p}=.002$. In comparison to those individuals that had fathers without a high school education, those individuals that had fathers with a high school education were more likely to earn associate's degrees, odds ratio $=2.597, \mathrm{p}<.001$. In comparison to those individuals that had fathers without a high school education, those individuals that had fathers with a college education were more likely to earn associate's degrees, odds ratio $=3.367, \mathrm{p}<.001$. In comparison to those individuals that participated in the general track, those individuals in the college preparatory track were more likely to earn associate's degrees, odds ratio $=5.076, \mathrm{p}<$ .001. Last, in comparison to those individuals that participated in the general track, those individuals in the dual track were more likely to earn associate's degrees, odds ratio = $5.208, \mathrm{p}<.001$

Bachelor's Degree

This section describes the outcome of earning a bachelor's degree in comparison with not earning a high school diploma. Statistically significant predictors for bachelor's degree included gender, those individuals that belonged to the Black race, mothers' and fathers' highest grades completed, and those individuals belonging to the college preparatory track. Non-statistically significant predictors for bachelor's degree included those individuals that belonged to the Hispanic race and those individuals that participated in the CTE and dual tracks.

In comparison to males, females were more likely to earn a bachelor's degree, odds ratio $=2.618, \mathrm{p}<.001$. In comparison to non-Blacks/non-Hispanics, Blacks were less likely to earn a bachelor's degree, odds ratio $=.525, \mathrm{p}=.002$. In comparison to those 
individuals with mothers that did not have a high school education, those individuals that had mothers with a high school education were more likely to earn a bachelor's degree, odds ratio $=2.577, \mathrm{p}<.001$. In comparison to those individuals with mothers that did not have a college education, those individuals that had mothers with a college education were more likely to earn a bachelor's degree, odds ratio $=5.814, \mathrm{p}<.001$. In comparison to those individuals with fathers that did not have a high school education, those individuals that had fathers with a high school education were more likely to earn a bachelor's degree, odds ratio $=4.405, \mathrm{p}<.001$. In comparison to those individuals with fathers that did not have a college education, those individuals that had fathers with a college education were more likely to earn a bachelor's degree, odds ratio $=9.804, \mathrm{p}<$ .001. In comparison to those individuals that participated in the general track, those individuals that participated in the college preparatory track were more likely to earn a bachelor's degree, odds ratio $=9.901, \mathrm{p}<.001$. Last, the odds of earning a bachelor's degree in comparison to not earning a high school diploma are about the same (1:1) regardless of household income, odds ratio $=1.000, \mathrm{p}<.001$.

\section{Graduate Degree}

This section describes the outcome of earning a graduate degree in comparison to not earning a high school diploma. Statistically significant predictors for graduate degree included gender, those individuals with mothers with a college education, those individuals that participated in college preparatory and dual tracks, and household income. Non-statistically significant predictors of graduate degree included 
race/ethnicity, those individuals that had mothers with a high school education, father's highest grade completed, and those individuals that participated in the CTE track.

In comparison to males, females were more likely to earn a graduate degree, odds ratio $=4.808, \mathrm{p}=.001$. In comparison to those individuals that had mothers without a college education, those individuals that had mothers with a college education were more

likely to earn a graduate degree, odds ratio $=6.803, p=.025$. In comparison to those that participated in the general track, those individuals that participated in the college preparatory track were more likely to earn a graduate degree, odds ratio $=11.765, \mathrm{p}<$ .001. In comparison to those that participated in the general track, those individuals that participated in the dual track were more likely to earn a graduate degree, odds ratio $=$ $10.753, \mathrm{p}=.002$. Lastly, the odds of earning a graduate degree compared to not earning a high school diploma are about the same (1:1) regardless of household income, odds ratio $=1.000, \mathrm{p}<.001$.

Assumptions of Research Question Three

One assumption of multiple regression is that the residuals are independent. By utilizing the Durbin-Watson test, the Durbin-Watson value equaled approximately 1.99 for this model. Since the Durbin-Watson statistic was near 2.00, this indicated that the assumption of independence was not violated.

A second assumption of multiple regression is that the residuals have a mean of zero. For this model, the mean of the residuals equals (7.200E11). Thus, this suggested that this assumption was not violated. 
A third assumption of multiple regression is that the residuals are normally distributed. The histogram of residuals and normal probability plot demonstrated a normal bell-shaped curve (See Appendix D). As a result, this assumption was not violated.

A fourth assumption of multiple regression is that the residuals have constant variance. The plot of residuals and predicted $\mathrm{Y}$ indicated that this assumption was not violated (See Appendix E).

\section{Assessing Multicollinearity Issues}

The correlation matrix was consulted to assess any potential issues with multicollinearity. In examining the correlations between the 15 independent variables, only a few coefficients exceeded .60 , with the exception of mixed race. As a result, the current researcher removed mixed race from the analysis. With the exception of mixed race, the inspection of the correlation matrix did not suggest that multicollinearity presented a problem.

Examining tolerance is a direct metric of multicollinearity (Hair et al., 2006). Tolerance is the amount of variability by an independent variable that is not explained by the other independent variables in the model. The tolerance values in this research study were lower than 1.0 (the highest was .96), indicating that multicollinearity was not a problem.

Further, the variance inflation factor (VIF) is another indicator of multicollinearity (Hair et al., 2006). Low values for VIF indicate that an independent variable is not a linear combination of all other variables in the model. VIF values that 
are larger than 10 indicates a problem with multicollinearity. In assessing the VIF values in this research study, all values were less than 10. In fact, the highest value for VIF in this research study was approximately 4.9. Thus, this further indicated that multicollinearity was not a concern.

Response to Research Question Three

To what extent do demographic variables, degree attainment, and high school curriculum tracks predict occupational earnings?

In response to research question three, the current researcher regressed the criterion variable (occupational earnings) on the predictor variables of gender, race/ethnicity, SES indicators, degree attainment, and high school curriculum tracks (See Appendix F). A weak relationship of approximately .29 $(\mathrm{R}=.29)$ existed between occupational earnings and gender, race/ethnicity, mother's highest grade completed, father's highest grade completed, household income, degree attainment, and high school curriculum tracks.

The proportion of variance in occupational earnings explained by the linear regression of gender, race/ethnicity, mother's highest grade completed, father's highest grade completed, household income, degree attainment, and high school curriculum tracks is .08. This indicated the goodness-of-fit of the linear regression model. Thus, the simultaneous multiple regression model produced a significant model $\left(\mathrm{R}^{2}=.082 ; \mathrm{F}_{(13,2646)}\right.$ $=17.10, \mathrm{p}<.001)$ of occupational earnings from the predictor variables, at an alpha level of .05 . For the decision rule, if the probability associated with the calculated test statistic is equal to or less than alpha, reject the null hypothesis. The null hypothesis is that 
occupational earnings is not affected by gender, race/ethnicity, SES, and degree attainment. Therefore, the decision in this case was to reject the null hypothesis, the full model was statistically significant.

Among the predictor variables, gender, participants identifying as Black, household income, those participants that were members of the college preparatory, CTE, and dual tracks, and degree attainment (with the exception of high school diploma and GED) had a statistically significant relationship to occupational earnings. Of the statistically significant predictor variables, being female was negatively related to occupational earnings and had the largest relative importance $(\beta=-.200, \mathrm{p}<.01)$ in comparison with all other predictor variables in the model. In addition, the bachelor's degree variable was positively related to occupational earnings and had the second largest relative importance $(\beta=.159, \mathrm{p}<.01)$ in comparison with all other predictor variables in the model.

The non-statistically significant predictor variables in the model included participants identifying as Hispanic, mothers' and fathers' highest degrees completed, and participants with a GED as well as a high school diploma.

By examining the partial regression coefficients for the significant predictor variables, females were expected to have lower earnings by $\$ 6,029$ than their male counterparts, when all other independent variables were held constant. Those individuals identifying as Black were expected to have lower earnings by $\$ 2,862$ than their nonBlack/non-Hispanic counterparts, when all other independent variables are held constant. In addition, for a one-unit increase in household income, there was an expected increase 
in occupational earnings of 25 cents, when all other independent variables are held constant.

Further, those individuals that participated in the college preparatory track were expected to have higher earnings by $\$ 1,386$ (relative to the general track), when all other independent variables were held constant. Those in the CTE track were expected to have higher earnings by $\$ 3,279$ than their general track counterparts, when all other independent variables are held constant. Last, those in the dual track are expected to have higher earnings by $\$ 2,754$ (relative to the general track), when all other independent variables are held constant.

In terms of degree attainment, for those individuals that earned an associate's degree, they were expected to have higher earnings by $\$ 6,857$ in comparison to those individuals who did not earn a high school diploma, when all other independent variables are held constant. For those individuals that earned a bachelor's degree, they are expected to have higher earnings by $\$ 5,659$ than those individuals that did not earn a high school diploma, when all other independent variables are held constant. Last, for those individuals that earned a graduate degree, they are expected to have higher earnings by $\$ 12,904$ in comparison to those that did not earn a high school diploma.

In terms of the residual variance, the proportion of variance in occupational earnings not explained by the linear combination of gender, race/ethnicity, mother's highest grade completed, father's highest grade completed, household income, degree attainment, and high school curriculum tracks was .92. 


\section{CHAPTER 5}

\section{SUMMARY, DISCUSSION, AND IMPLICATIONS}

This chapter is comprised of four sections. The first section summarizes the

results of this research study. The second section presents an interpretative discussion of the findings of this research study. The third section sets forth the implications of this study for future research and for practice. The fourth section includes an explanation of the importance of this study.

A Summary of Results from this Research Study

The main objectives of this study were three-fold. The first objective of this research study was to examine the type of students that enroll in the various high school curriculum tracks in terms of demographic indicators. The second and third objectives were to examine the impact of high school curriculum tracking on long-term student outcomes - degree attainment and occupational earnings. The underlying research problem dealt with the historical nature of the varied federal legislation that guided the objectives of CTE. Specifically, the Carl D. Perkins Vocational and Applied Technology Education Act of 1990 was a transformational legislative initiative that expanded the goals of CTE to prepare students for not only the workforce, but for postsecondary 
education as well. Thus, this research was carried out to investigate whether CTE and dual tracked students do indeed attain higher levels of occupational earnings, as well as attain postsecondary degrees.

\section{Summary of Results for Research Question One}

To what extent do demographic variables predict high school curriculum tracks?

Based on a random sample of former high school students, females were 1.5 times more likely to participate in the college preparatory track. In terms of SES indicators, those individuals that had higher household incomes and had mothers and fathers with college educations were more likely to participate in the college preparatory track.

In the case of the CTE track, Blacks were 1.7 times more likely to participate than non-Black/non-Hispanic individuals; while, non-Black/non-Hispanics were 1.7 times more likely to participate than Hispanics.

In terms of the dual track, males were 1.4 times more likely to participate. Blacks were 1.7 times more likely to participate in the dual track. Non-Blacks/non-Hispanics were 1.6 times more likely to participate in the dual track in comparison to Hispanics. Summary of Results for Research Question Two To what extent do demographic variables and high school curriculum tracks predict degree attainment?

Based on a random sample of former high school students, females are 1.4 times as likely to earn a high school diploma than males. In terms of high school curriculum tracks, individuals participating in the college preparatory track are 3.4 times as likely to earn a high school diploma than those in the general track. Further, those in the dual track 
are 2.7 times more likely to earn a high school diploma, in comparison to the general track.

In terms of bachelor's degrees, females are 2.6 times as likely to earn a bachelor's degree than males. Non-Blacks/non-Hispanics are 1.9 times as likely to earn a bachelor's degree than Blacks. Those in the college preparatory track are 9.8 times as likely to earn a bachelor's degree than their general track counterparts.

In terms of graduate degrees, females are 4.8 times more likely to earn a graduate degree. Those in the college preparatory track are 11.8 times as likely to earn a graduate degree than those in the general track. Those in the dual track are 10.8 times as likely to earn a graduate degree than those in the general track.

\section{Summary of Results for Research Question Three}

To what extent do demographic variables, degree attainment, and high school curriculum tracks predict occupational earnings?

Based on a random sample of former high school students, eight percent of the variance in their occupational earnings was explained by their gender, race/ethnicity, SES indicators, degree attainment, and high school curriculum tracks. Generally, as their occupational earnings increase, so do their SES levels and degree attainment. In terms of gender, male high school students have significantly higher occupational earnings than their female counterparts by $\$ 6,029$. In fact, gender was the most important variable in comparison to all other variables in the model. In terms of race/ethnicity, Black high school students have lower earnings than their non-Black/non-Hispanic counterparts by $\$ 2,862$. 
In terms of high school curriculum tracking, college preparatory, CTE, and dual, tracked students all have higher earnings compared to general tracked students.

Compared to the general track, students from the CTE track are expected to have a higher increase $(\$ 3,279)$ in earnings than college preparatory and dual tracked students $(\$ 1,386$ and $\$ 2,754$, respectively).

In terms of degree attainment, associate's degrees, bachelor's degrees, and graduate degrees all assist in the facilitation of higher occupational earnings relative to high school dropouts. Those individuals with graduate degrees benefit from the largest increase in occupational earnings in comparison to students without high school diplomas. Obtaining a bachelor's degree was the second most important variable in comparison to all other variables in the model.

\footnotetext{
A Discussion of the Results of this Study Participation in High School Curriculum Tracks

Findings from this research study substantiate prior research regarding participation rates in CTE tracks. As found in previous studies (e.g., Stone \& Aliaga, 2005), this study demonstrated that all of the race/ethnicity variables and those individuals with fathers with a college education (one indicator of SES) are indeed predictors of CTE participation. Despite the finding that Hispanics participated in CTE at lower rates than their non-Black/non-Hispanic counterparts, Blacks were found to participate in CTE at much higher rates than their non-Black/non-Hispanic counterparts. However, gender and other measures of SES were not found to be significantly related to CTE participation.
} 
When examining the literature on tracking, race/ethnicity (Akos et al., 2007; Alvarez \& Mehan, 2007; Burris, \& Welner, 2005; Hallinan, 1991; Kelly, 2007; Lee \& Byrk, 1988; Lewis, 2007; Lewis \& Cheng, 2006; Oakes \& Guiton, 1995; Rubin, 2006; Welner \& Oakes, 1996; Yonezawa et al., 2002) and SES (Akos et al., 2007; Alvarez \& Mehan, 2007; Gamoran, 1989; Kelly, 2007; Kilgore, 1991; Lee \& Byrk, 1988; Lewis, 2007; Lewis \& Cheng, 2006; Oakes \& Guiton; Rojewski, 1997; Rubin, 2006; Vanfossen et al., 1987; Yonezawa et al., 2002) have been indicators utilized to track students, as well as limit individuals' long-term opportunities. Thus, if minorities such as Blacks are overrepresented in CTE tracks, this suggests an area of concern. Prior research has suggested that tracking minorities in the CTE track contributes to the exacerbation of long-held social inequalities and decreased opportunities for these individuals to gain access to "high-status knowledge" - the college preparatory curriculum (Lewis, 2007, p. 330). Further, findings from this research study indicated that those individuals participating in the CTE tracks had lower probabilities of degree attainment, particularly compared to college preparatory and dual tracked students.

Similarly, Blacks were found to have high probabilities of participating in the dual track, while Hispanics were less likely to participate. For Blacks, this finding seems much more promising, in terms of degree attainment, in that the dual track was also associated with a higher likelihood of an individual earning a graduate degree, in comparison with their general track counterparts. 


\section{Degree Attainment}

In terms of meeting the objectives of the Carl D. Perkins Vocational and Applied Technology Education Act of 1990 in regards to degree attainment, this study, as expected, found that those in the college preparatory tracks had the most positive postsecondary outcomes, but not the CTE track. This is consistent with prior studies on the long-term effects of tracking students in high school (Kulik, 1998; Vanfossen et al., 1987).

Participants that were in the college preparatory track were more likely than their general track counterparts to earn associate's, bachelor's, and graduate degrees. Those in the dual track were more likely to earn associate's and graduate degrees. Thus, the promising postsecondary outcomes of the dual track suggests this track is a more positive alternative for those students which may not be suited for the college preparatory track, but have goals and aspirations of earning postsecondary degrees. In fact, the literature and prior research on the dual track indicate that the dual track may result in positive long-term student outcomes (Lewis, 1998; Lewis \& Cheng, 2006; Novel, 2009; Silverberg et al., 2004). What is not clear from this study is the impact Tech Prep programs had on students from the dual track. The emergence of Tech Prep programs certainly is a plausible rationale for the increase in the likelihood of dual tracked students earning associate's degrees.

It is important to note that very few participants $(n=27)$ actually earned a graduate degree. Thus, future research examining later rounds of data from the NLSY 
dataset may permit more accurate findings in terms of graduate degree attainment by the various high school curriculum tracks.

\section{Occupational Earnings}

Prior research on labor market outcomes (e.g., occupational earnings) of the CTE track has resulted in inconclusive findings (Bishop \& Mane, 2004; Mane, 1999; Meer, 2007). In terms of meeting objectives of the Carl D. Perkins Vocational and Applied Technology Education Act of 1990 in regards to economic outcomes, this study found that high school curriculum tracking was significantly related to occupational earnings. In fact, students from the CTE track were expected to have higher earnings than their general track counterparts by $\$ 3,279$. Further, those in the dual track were expected to have higher earnings by $\$ 2,754$, in comparison to those in the general track. However, in relation to the general track, those in the college preparatory track were only expected to have higher earnings by $\$ 1,386$. This finding is certainly promising for college preparatory, CTE, and dual tracks. In addition this finding is consistent with several research studies regarding labor market outcomes of CTE track students (Meer, 2007).

Despite the promising labor market outcomes of the various tracks investigated, it is quite plausible that since these participants in this research study were only around the ages of 22 and 26, these individuals' earnings might not be reflective of their future potential earnings. It could certainly be argued that many of the participants in this study were attending, or at the time of the study were currently enrolled in higher education; thereby, one would expect their earnings to be quite lower than those individuals who were not in school and who were employed full-time. College attendance would probably 
have the most affect on those in the college preparatory track, since these individuals had much higher rates and probabilities of earning associate's, bachelor's, and graduate degrees.

Another finding of this study was that as individuals increase their degree attainment, the higher their earnings tended to be. This finding is consistent with the overwhelming majority of studies regarding degree attainment (Bailey et al., 2004b; Liming \& Wolf, 2008). Further, this study found that earning a bachelor's degree was the most important variable in the model related to occupational earnings. Last, it was found that females earn less than males in terms of occupational earnings. This finding was expected; in that, females have historically earned substantially less than their male counterparts.

\section{Implications for Further Research}

\section{Participation in High School Curriculum Tracks}

Several other variables are likely to have the capacity to predict high school curriculum tracks, besides the demographic variables investigated in this research study such as variables that are not fixed. First, geographical variables such as whether the participants resided in a rural, suburban, or urban environment is likely to assist in the prediction of choosing a high school curriculum track. Second, college and career aspirations may also influence a student's likelihood of participating in a high school curriculum track. Third, parental expectations and influence may be predictors of high school curriculum tracks. Fourth, academic measures such as G.P.A., high school grades, and standardized achievement assessment scores (i.e., ACT and SAT) are likely to 
influence participation rates as well. Future studies might introduce additional variables, as discussed previously, into the model when attempting to predict participation in the various high school curriculum tracks.

Qualitative studies on the perceptions of Black students in CTE tracks regarding the reasons why they were placed in the CTE track seems warranted. Prior research on tracking has suggested that Blacks are often funneled into the CTE track, resulting in further widening of the achievement gap and exacerbating long-term social inequalities. Hence, exploring the lived experiences of Blacks in CTE tracks as well as the reasons why they participated may be quite telling. In addition, it was found that Hispanic students had high participation rates in the general track (69.2\%). Thus, qualitative analyses examining the reasons for their participation in the general track would also be warranted.

\section{Degree Attainment}

All of the above mentioned variables in the Participation in High School Curriculum Tracks section may also predict an individual's degree attainment. Other variables that may be relevant to degree attainment might include parents' influence as well as students' connectedness to their schools, parents, and teachers. Self-efficacy in school related tasks could also significantly influence their degree attainment (Lent et al., 1994). Moreover, institutional factors related to the institutions of higher education such as academic and social integration within the fabric of college life may also have a considerable influence on students' persistence (Tinto, 1993). Factors related to 
persistence while the participants were attending college were not explored in this study, but might be more aligned to student degree attainment.

\section{Occupational Earnings}

Only eight percent of the variance was explained in occupational earnings by gender, race/ethnicity, SES indicators, degree attainment, and high school curriculum tracks. Thereby, $92 \%$ of the variance was unexplained. Future research may investigate confounding variables that were not included in this research study. Variables that may be of interest include career aspirations, experience in the workforce, employment history, major in college, and participation in CTE school reform initiatives such as Tech Prep, school-to-work, and work-based learning.

\section{Longitudinal Studies}

One limitation of this study was the relatively short duration between participants' high school graduation and the various outcomes assessed in this study (degree attainment and occupational earning), which was nine years for some. Future analyses of subsequent rounds of data may produce more substantial findings in terms of degree attainment and occupational earnings. Further, studies that examine student outcomes over time (longitudinal studies) may be more explanatory in terms of assessing trends in degree attainment and occupational earnings. An interesting research endeavor might evaluate the point at which students' earnings increase most drastically, as well as capture a more holistic picture of students who enter into postsecondary education at later stages of their lives. 


\section{Future Research on CTE High School Reform Initiatives}

Future studies are also warranted in evaluating CTE high school reform initiatives such as High Schools That Work (HSTW), Tech Prep, and career academies in terms of long-term student outcomes. These reform initiatives all have an emphasis on integrating core academic and CTE content, as well as objectives to increase CTE students' opportunities to gain access and earn degrees in institutions of higher education, and provide students with promising, long-term labor market outcomes.

\section{Implications for Practice}

\section{Educational Policymakers}

Educational policymakers may also consider ensuring fair and equitable representation of all groups of individuals in the various high school curriculum tracks. Schools could include written documentation on how they are ensuring diverse classes with equitable representation of minorities, females, and those individuals with disabilities in college preparatory, CTE, and dual tracks. In addition, funding for professional development opportunities may be considered for teachers and guidance counselors to gain a better understanding of the effects of tracking students and how their dispositions may affect participation rates in the various high school curriculum tracks.

Results of this study illustrated that the general track contributes the least, in comparison to the other tracks, in regards to positive student outcomes such as degree attainment and occupational earnings. This indicates that students may be better suited to participate in the college preparatory, CTE, or dual tracks. Educational legislation such as the NCLB legislation may be more effective by including provisions that mandate all 
students to take courses that are consistent with four-year institutions' requirements, earn career-oriented credits in CTE, or enroll in a combination of both types of courses. The phenomenon of abandoning the general track has already occurred in some school districts and school reform models. Thus, the findings of this study might explain the emergence of schools abandoning the general track.

The Carl D. Perkins Vocational and Applied Technology Education Act of 1990 was implemented to provide students with advanced opportunities, particularly in the realm of core academic skills needed to prepare students for postsecondary education. This research study indicated that CTE students do have higher earnings than their general track counterparts; however, in terms of degree attainment, the CTE track was less likely to earn degrees than their general track counterparts. Thus, findings suggest that the Carl D. Perkins Vocational and Applied Technology Education Act of 1990 may not be meeting its goal of CTE students earning postsecondary degrees.

However, dual track students do have higher probabilities of earning associate's and graduate degrees, in comparison to their general track counterparts. Thus, this finding suggests that the dual track may be a much better option for students with an interest in a certain occupational area. It is also important to note that not all students have the desire to enter into postsecondary education. If this is the case, students may be better suited for the CTE track, particularly in relation to the general track. This study indicated that students in the CTE track do earn more than general track students, thus providing a benefit for those that are not compelled to earn postsecondary degrees. 
Research that investigates long-term student outcomes such as degree attainment and occupational earnings is warranted within school districts to evaluate whether school districts are making progress in alignment with legislative goals. A possible tactic to ensure that schools are providing rigor and effectively integrating core academic and CTE content in support of the mission of the legislation may be to establish accrediting bodies. This may regulate whether CTE programs are indeed successfully implementing the legislative provisions.

Implications for Administrators, Guidance Counselors, Parents, Teacher Education, Teachers, and Students

The findings of this research study are also pertinent to guidance counselors, parents, teacher education, teachers, and students. Guidance counselors, particularly, should be informed of the overrepresentation of Blacks in CTE and dual tracks and Hispanics in general tracks. Efforts should be extended to help Black and Hispanic students learn of the long-term benefits of participating in the college preparatory track. Guidance counselors should be more aware of possible biases or dispositions that may predispose them to advise higher percentages of Black students in the CTE track and Hispanics in the general track.

Students and parents should be informed of the likely long-term outcomes that are predicted for students' futures in regards to degree attainment and occupational earnings. Teachers should also be aware of the findings of this study. CTE teachers especially should be informed of the need to integrate core academic and CTE content, as well as the relationship between degree attainment and occupational earnings. In fact, CTE 
teacher preparation programs should teach their teacher candidates about integration, particularly in curriculum and instruction courses. Schools might consider providing CTE practicing teachers with professional development opportunities aimed at teaching them how to integrate core academic content into their subjects. In addition, core academic teachers could benefit from professional development aimed at understanding the benefits of collaborating with CTE teachers to enhance their curricula. School administrators might consider attempting to better establish collaborative relationships with core academic and CTE teachers to develop interdisciplinary lessons and integrative planning time. Further, students, parents, and teachers should all be cognizant of the contemporary demands of employees in the workforce and the current expectations for students in terms of degree attainment and skills acquisition.

This study also demonstrated that parents' educational levels are positively related to their children's degree attainment. Thus, parents with children at the $\mathrm{P}-12$ levels that did not have a college education might consider educating themselves about the college admissions process and encourage their children to be proactive in learning about the expectations of institutions of higher education.

\section{Importance of the Study}

This study sheds light on whether the CTE community is meeting its legislative goals and whether the efforts of legislation-directed school reform initiatives are indeed impacting long-term student outcomes of students' obtaining postsecondary degrees and increasing students' earning potential. It is important to note that this study was one of the few assessments that have examined the impact of the Carl D. Perkins Vocational and 
Applied Technology Education Act of 1990, as well as one of the few inquiries that have investigated the impact of the fairly recent dual track (Novel, 2009). Even with the limited number of research on the dual track, this study and other research has found that, compared to the general track, the dual track is a promising track for students in terms of long-term outcomes (Hudson \& Hurst, 1999; Novel, 2009).

It is hoped that this research study will assist in setting precedence for the CTE community to evaluate long-term student outcomes. Future studies should consider examining degree attainment and labor market outcomes (occupational earnings) of CTE students with a longer duration subsequent to high school graduation, such as 20 years. Further studies might consider assessing students' long-term outcomes with students graduating later than 1997. The 1990 legislation may have taken longer than seven years to achieve full adoption throughout all schools in the nation that receive its funding. 


\section{REFERENCES}

Alvarez, D., \& Mehan, H. (2007). Whole school de-tracking: A strategy for equity and excellence. Theory Into Practice, 45(1), 82-89.

Akos, P., Lambie, G., Milsom, A., \& Gilbert, K. (2007). Early adolescents' aspirations and academic tracking: An exploratory investigation. Professional School Counseling, 11(1), 57-64.

Alexander, K., \& McDill, E. (1976). Selection and allocation within schools: Some causes and consequences of curriculum placement. American Sociological Review, 41(6), 963-980.

Alfeld, C., Hansen, D., Aragon, S., \& Stone, J. (2006). Inside the black box: Exploring the value added by career and technical student organizations to students' high school experience. Career and Technical Education Research, 31(3), 121-155.

Arum, R., \& Shavit, Y. (1995). Secondary vocational education and the transition from school to work. Sociology of Education, 68(3), 187-204.

Association for Career and Technical Education. (2006). What is career and technical education fact sheet. Retrieved July 1, 2006, from

http://www.acteonline.org/career_tech/upload/CTUFactSheet.doc.

Ayalon, H., \& Gamoran, A. (2000). Stratification in academic secondary programs and educational inequality in Israel and the United States. Comparative Education Review, 44(1), 54-80.

Bailey, T., Alfonso, M., Scott, M., \& Leinbach, T. (2004a). Educational outcomes of occupational postsecondary students. Washington, DC: U.S. Department of Education.

Bailey, T., Kienzl, G., \& Marcotte, D. (2004b). The return to a sub-baccalaureate education: The effects of schooling, credentials, and program of study on economic outcomes. Washington, DC: U.S. Department of Education. 
Biafora, F., \& Ansalone, G. (2008). Perceptions and attitudes of school principals towards school tracking: Structural considerations of personal beliefs. Education, 128(4), 588-602.

Bishop, J., \& Mane, F. (2004). The impacts of career-technical education on high school labor market success. Economics of Education Review, 23(4), 381-402.

Blanchett, W., Mumford, W., \& Beachum, F. (2005). Urban school failure and disproportionality in a post-Brown era: Benign neglect of the constitutional rights of students of color. Remedial and Special Education, 26(2), 70-81.

Bragg, D. (1999). Reclaiming a lost legacy: Integration of academic and vocational education. In A. J. Pautler (Ed.), Workforce education: Issues for the new century (pp. 181-196). Ann Arbor, MI: Prakken.

Burris, C., \& Welner, K. (2005). Closing the achievement gap by de-tracking. Phi Delta Kappan, 86(8), 594-598.

Carl D. Perkins Career \& Technical Education Act, 20 U.S.C. § 2301 (2006).

Castellano, M., Stringfield, S., \& Stone, J. (2003). Secondary career and technical education and comprehensive school reform: Implications for research and practice. Journal of Vocational Education Research, 73(2), 231-272.

Cohen, E., \& Lotan, R. (1995). Producing equal-status interaction in the heterogeneous classroom. American Educational Research Journal, 32(1), 99-120.

Corazzini, A., Dugan, D., \& Grabowski, H. (1972). Determinants and distributional aspects of enrollment in U.S. higher education. Journal of Human Resources, $7(1), 26-38$.

Courtade, G., \& Ludlow, B. (2008). Ethical issues and severe disabilities: Programming for students and preparation for teachers. Rural Special Education Quarterly, $27(1 / 2), 36-42$.

Dare, D. (2006). The role of career and technical education in facilitating student transitions to postsecondary education. New Directions for Community Colleges, $135,73-80$.

DeLuca, S., Plank, S., \& Estacion, A. (2006, February). Does career and technical education affect college enrollment? Columbus, $\mathrm{OH}$ : National Dissemination Center for Career and Technical Education. Retrieved on July 18, 2008, http://www.nccte.org/publications/infosynthesis/r\&dreport/DoesCTEAffect CollegeEnrollment/DoesCTEAffectCollegeEnrollment.html 
Elliott, J. (2006). The 2006 ACTER presidential address: The premier educational delivery system. Career and Technical Education Research, 32(1), 3-7.

Esters, L. (2007). Factors influencing postsecondary education enrollment behaviors of urban agricultural education students. Career and Technical Education Research, 32(2), 79-98.

Fike, D., \& Fike, R. (2008). Predictors of first-year student retention in community college. Community College Review, 36(2), 68-88.

Fletcher, E. (2006). No curriculum left behind: The effects of the No Child Left Behind Legislation on career and technical education. Career and Technical Education Research, 31(3), 157-174.

Fletcher, E., \& Zirkle, C. (2009). Career and technical education in light of the No Child Left Behind legislation. In V. Wang (Ed.), The Handbook of Research on E-Learning Applications for Career and Technical Education: Technologies for Vocational Training. IGI Global.

Franklin, J., \& Wallen, N. (2006). How to design and evaluate research in education. $\left(6^{\text {th }}\right.$ ed.). New York, NY: McGraw Hill.

Fuller, W., Manski, C., \& Wise, D. (1982). New evidence on the economic determinants of postsecondary schooling choices. The Journal of Human Resources, 17(4), 477-498.

Gamoran, A. (1987). The stratification of high school learning opportunities. Sociology of Education, 60(3), 135-155.

Gamoran, A. (1989). Measuring curriculum differentiation. American Journal of Education, 97(2), 129-143.

Gamoran, A., \& Mare, R. (1989). Secondary school tracking and educational inequality: Compensation, reinforcement, or neutrality. American Journal of Sociology, 94(5), 1146-1183.

Gamoran, A., Kulik, J., Lynch, R., Rasinski, K., \& Pedlow, S. (1998). The quality of vocational education: Background papers from the 1994 national assessment of vocational education. Retrieved on January 22, 2009, from http://www.ed.gov/pubs/VoEd/index.html 
Gamoran, A., \& Nystrand, M. (1991). Background and instructional effects on achievement in eight-grade English and social studies. Journal of Research on Adolescence, 1(3), 277-300.

Gamoran, A., Nystrand, M., Berends, M., \& LePore, P. (1995). An organizational analysis of the effects of ability grouping. American Educational Research Journal, 32(4), 687-715.

Gamoran, A., \& Weinstein, M. (1998). Differentiation and opportunity in restructured schools. American Journal of Education, 106(3), 385-415.

Gordon, H. (2008). The history and growth of career and technical education in America. $\left(3^{\text {rd }}\right.$ ed.) Long Grove, IL: Waveland Press.

Gray, K. (1999). High school vocational education: Facing and uncertain future. In A. J. Pautler (Ed.), Workforce education: Issues for the new century (pp. 159-169). Ann Arbor, MI: Prakken.

Gray, K. C., \& Herr, E. L. (1998). Workforce education: The basics. Needham Heights, MA: Viacom.

Hair, J., Black, W., Babin, B., Anderson, R., \& Tatham, R. (2006). Multivariate data analysis. $\left(6^{\text {th }}\right.$ ed.). Upper Saddle River, NJ: Pearson.

Hallinan, M. (1991). School differences in tracking structures and track assignments. Journal of Research and Adolescence, 1(3), 251-275.

Hallinan, M. (1994). School differences in tracking effects on achievement. Social Forces, 72(3), 799-821.

Hardman, M., \& Dawson, S. (2008). The impact of federal public policy on curriculum and instruction for students with disabilities in the general classroom. Preventing School Failure, 52(2), 5-11.

Harnish, D., \& Lynch, R. (2005). Secondary to postsecondary technical education transitions: An exploratory study of dual enrollment in Georgia. Career and Technical Education Research, 30(3), 169-188.

Harris, D., \& Herrington, C. (2006). Accountability, standards, and the growing achievement gap: Lessons from the past half-century. American Journal of Education, 112, 209-238. 
Hause, J. (1982). Ability and schooling as determinants of lifetime earnings or if you're so smart, why aren't you rich? American Economic Review, 61(2), 289-298.

Hearn, J. (1984). The relative roles of academic, ascribed, and socioeconomic characteristics in college destinations. Sociology of Education, 57(1), 22-30.

Hossler, D., \& Stage, F. (1992). Family and high school experience influences on the postsecondary educational plans of ninth-grade students. American Educational Research Journal, 29(2), 425-451.

Hudson, L., \& Hurst, D. (1999). Students who prepare for college and a vocation (National Center for Education Statistics Rep. No. 1999-072). Washington, D.C.

Inter-University Consortium for Political and Social Research. (2003). National longitudinal survey of youth, 1997. (Center for Human Resource Research: Ohio State University). Ann Arbor, MI: US Bureau of Labor Statistics.

Jacobs, J., \& Grubb, W. (2003). The federal role in vocational-technical education. Community College Research Center Brief, 18, 1-4.

Jackson, G. (1978). Financial aid and student enrollment. The Journal of Higher Education, 49(6), 548-574.

Kao, G., \& Tienda, M. (1998). Educational aspirations of minority youth. American Journal of Education, 106(3), 349-384.

Kelly, S. (2007). The contours of tracking in North Carolina. The High School Journal, 90(4), 15-31.

Kerckhoff, A. (1976). The status attainment process: Socialization or allocation? Social Forces, 55(2), 368-381.

Kilgore, S. (1991). The organizational context of tracking in schools. American Sociological Review, 56(2), 189-203.

King, B., \& Minium, E. (2003). Statistical reasoning in psychology and education. (4 $4^{\text {th }}$ ed.). Hoboken, NJ: John Wiley \& Sons.

King, C., Schexnayder, D., \& Gourgey, H. (2005). Beyond the numbers: Improving postsecondary success through a central Texas high school data center. University of Texas at Austin: The LBJ School of Public Affairs. 
Konstantopoulos, S. (2006). Trends of school effects on student achievement: Evidence from the NLS:72, HSB:82, and NELS:92. Teachers College Record, 108(12), 2550-2581.

Kulik, J. (1998). Curricular tracks and high school vocational education. In A. Gamoran, \& H. Himmelfarb (Eds.). The quality of vocational education: Background paper from the 1994 national assessment of vocational education. Washington, DC: U.S. Department of Education. Retrieved on November 11, 2008, from http://www.ed.gov/pubs/VoEd/Chapter3/Part2.html

Lee, V., \& Byrk, S. (1988). Curriculum tracking as mediating the social distribution of high school achievement. Sociology of Education, 61(3), 78-94.

Legutko, R. (2005). A decade's difference: Research revisited on family influence of rural high school students' postsecondary decisions. The Rural Educator, 29(2), 4-7.

Lent, R., Brown, S., \& Hackett, G. (1994). Toward a unifying social cognitive theory of career and academic interest, choice, and performance. Journal of Vocational Behavior, 45, 79-122.

LeTendre, G., Hofer, B, \& Shimizu, H. (2003). What is tracking? Cultural expectations in the United States, Germany, and Japan. American Educational Research Journal, 40(1), 43-89.

Lewis, T., \& Cheng, S. (2006). Tracking, expectations, and the transformation of vocational education. American Journal of Education, 113(1), 67-99.

Lewis, T. (2007). Social inequality in education: A constraint on an American high-skills future. Curriculum Inquiry, 37(4), 329-349.

Lewis, T. (1998). Vocational education as general education. Curriculum Inquiry, 28(3), 283-309.

Liming, D., \& Wolf, M. (2008). Job outlook by education, 2006-16. Occupational Outlook Quarterly, 3(52), 2-29.

Lucas, S., \& Berends, M. (2002). Sociodemographic diversity, correlated achievement, and de facto tracking. Sociology of Education, 75(4), 306-327.

Lynch, R. (2000). High school career and technical education for the first decade of the $21^{\text {st }}$ Century. Journal of Vocational Education Research, 25(2), 155-198. 
Mane, F. (1999). Trends in the payoff to academic and occupation-specific skills: The short and medium run returns to academic and vocational high school courses for non-college-bound students. Economics of Education Review, 18(4), 417-437.

Mantel, B. (2005, May 27). No Child Left Behind: Is the law improving student performance? The CQ Researcher, 15(20), 469-492.

Mayer, A. (2008). Understanding how U.S. schools sort students for instructional purposes: Are all students being served equally? American Secondary Education, 36(2), 7-25.

McDonnell, L. (2005). No Child Left Behind and the federal role in education: Evolution or revolution? Peabody Journal of Education, 80(2), 19-38.

McPartland, J., \& Schneider, B. (1996). Opportunities to learn and student diversity" Prospects and pitfalls of a common core curriculum. Sociology of Education, extra issue, 69(2), 66-81.

Meer, J. (2007). Evidence on the returns to secondary vocational education. Economics of Education Review, 26(5), 559-573.

Metz, G. (2005). Challenge and changes to Tinto's persistence theory: A historical review. Journal of College Student Retention, 6(2), 191-207.

Moncarz, R., \& Crosby, O. (2004). Job outlook for people who don't have a bachelor's degree. Occupational Outlook Quarterly, 48(4), 3-13.

National Commission on Excellence in Education. (1983). A Nation at Risk: The imperative for educational reform. Retrieved July 18, 2008, from http://www.ed.gov/pubs/NatAtRisk/index.html

Newton, R., \& Rudestam, K. (1999). Your statistical consultant: Answers to your data analysis questions. Thousand Oaks, CA: Sage.

No Child Left Behind Act, 115 U.S.C. § 1425 (2001)

Novel, J. (2009) Implementation of the Carl D. Perkins Career and Technical Education reforms of the 1990s: Postsecondary education outcomes of students taking an enhanced vocational curriculum. (Unpublished Dissertation)

Oakes, J., \& Guiton, G. (1995). Matchmaking: The dynamics of high school tracking decisions. American Educational Research Journal, 32(1), 3-33. 
Oakes, J., Wells, A., Jones, M., \& Datnow, A. (1997). De-tracking: The social construction of ability, cultural politics and resistance to reform. Teachers College Record, 98, 482-510.

Page, R. (1990). Games of chance: The lower-track curriculum in a college-preparatory high school. Curriculum Inquiry, 20(3), 249-281.

Park, T., \& Osborne, E. (2007). Reading strategy instruction in secondary agricultural science courses: An initial perspective. Career and Technical Education Research, 32(1), 45-75.

Plank, S. (2001). A question of balance: CTE, academic courses, high school perspective, and student achievement. Journal of Vocational Education Research, 26(3), 279327.

Rashid, M. (2008). Inference on logistic regression models. Unpublished doctoral dissertation, Bowling Green State University.

Rasinski, K., \& Pedlow, S. (1998) The effect of high school vocational education on academic achievement gain and high school persistence: Evidence from NELS:88. In A. Gamoran, \& H. Himmelfarb (Eds.), The quality of vocational education: Background paper from the 1994 national assessment of vocational education. Washington, D.C.: U.S. Department of Education. Retrieved on November 11, 2008, from http://www.ed.gov/pubs/VoEd/Chapter5/index.html.

Rosenbaum, J., Kariya, T., Settersen, R., \& Maier, T. (1990). Market and network theories of the transition from high school to work: Their application to industrialized societies. Annual Review of Sociology, 16, 263-299.

Rojewski, J. (1997). Effects of economic disadvantaged status and secondary vocational education on adolescent work experience and postsecondary aspirations. Journal of Vocational and Technical Education, 14(1), Retrieved October 22, 2008. from http://scholar.lib.vt.edu/ejournals/JVTE/v14n1/JVTE-4.html.

Rojewski, J. (2002). Preparing the workforce of tomorrow: A conceptual framework for career and technical education. Journal of Vocational Education Research, 27(1), 7-35.

Rojewski, J., \& Kim, H. (2003). Career choice patterns and behavior of work-bound youth during early adolescence. Journal of Career Development, 30(2), 89-108. 
Rubin, B. (2003). Unpacking de-tracking: When progressive pedagogy meets students' social worlds. American Educational Research Journal, 40(2), 539-573.

Rubin, B. (2006). Tracking and de-tracking: debates, evidence, and best practices for a heterogeneous world. Theory into Practice, 45(1), 4-14.

Rumberger, R. (1983). The influence of family background on education, earnings, and wealth. Social Forces, 61(3), 755-773.

Ryken, A. (2006). “Goin' somewhere”: How career technical education programs support and constrain urban youths' career decision-making. Career and Technical Education Research, 31(1), 49-71.

Schultz, T. (1961). Investment in human capital. The American Economic Review, 11(1), $1-17$.

Sciarra, D., \& Whitson, M. (2007). Predictive factors in postsecondary educational attainment among Latinos. Professional School Counseling, 10(3), 307-316.

Scott, J., \& Sarkees-Wircenski, M. (2008). Overview of career and technical education. ( $4^{\text {th }}$ ed.). Homewood, IL: American Technical Publishers.

Sewell, W., Haller, A., \& Portes, A. (1969). The educational and early occupational attainment process. American Sociological Review, 34(1), 82-92.

Sewell, W., \& Shah, V. (1968). Social class, parental encouragement, and educational aspirations. The American Journal of Sociology, 73(5), 559-572.

Silverberg, M., Warner, E., Fong, M., \& Goodwin, D. (2004). National assessment of vocational education: Final report to Congress. Washington, DC: U.S. Department of Education.

Spady, W. (1970). Lament for the letterman: Effects of peer status and extracurricular activities on goals and achievement. The American Journal of Sociology, 75(4), 680-702.

Stage, F., \& Hossler, D. (1989). Differences in family influences on college attendance plans for male and female ninth graders. Research in Higher Education, 30(3), 301-315.

Stasz, C., \& Bodilly, S. (2004). Efforts to improve the quality of vocational education in secondary schools: Impact of federal and state policies. Washington, DC: U.S. Department of Education. 
Stone, J., \& Aliaga, O. (2005). Career and technical education and school-to-work at the end of the $20^{\text {th }}$ century: Participation and outcomes. Career and Technical Education Research, 30(2), 125-144.

Swail, W., Perna, L., \& Redd, K. (2003). Retaining minority students in higher education: A framework for success. ASHE-ERIC Higher Education Reports, 30(2), 1-172.

Tinto, V. (1987). Leaving college: Rethinking the causes and cures of student attrition ( $1^{\text {st }}$ ed.). Chicago, IL: The University of Chicago Press.

Tinto, V. (1993). Leaving college: Rethinking the causes and cures of student attrition ( $2^{\text {nd }}$ ed.). Chicago, IL: The University of Chicago Press.

Tinto, V. (2006). Research and practice of student retention: What next? Journal of College Student Retention, 8(1), 1-19.

Umpstead, R. (2008). The No Child Left Behind Act: Is it an unfunded mandate or a promotion of federal educational ideas? Journal of Law \& Education, 37(2), 193229.

Vanfossen, B., Jones, J., \& Spade, J. (1987). Curriculum tracking and status maintenance. Sociology of Education, 60(2). 104-122.

Venezia, A., \& Kirst, M. (2005). Inequitable opportunities: How current education systems and policies undermine the chances for student persistence and success in college. Educational Policy, 19(2), 283-307.

Walters, D. (2004). The relationship between postsecondary education and skill: Comparing credentialism with human capital theory. The Canadian Journal of Higher Education, 34(2), 97-124.

Watanabe, M. (2007). "Some people think this school is tracked and some people don't:" Using inquiry groups to unpack teachers' perspectives on de-tracking. Theory Into Practice, 45(1), 24-31.

Wells, R. (2008). The effects of social and cultural capital on student persistence: Are community colleges more meritocratic? Community College Review, 36(1), 2546.

Welner, K., \& Oakes, J. (1996). Li(ability grouping): The new susceptibility of school tracking systems to legal challenges. Harvard Educational Review, 66(3), 451470 . 
Yates, J. (2005). The transition from school to work. Monthly Labor Review, 128(2), 21 32.

Yonezawa, S., \& Jones, M. (2006). Students' perspectives on tracking and de-tracking. Theory Into Practice, 45(1), 15-23.

Yonezawa, S., Wells, A., \& Serna, I. (2002). Choosing tracks: "Freedom of choice" in de-tracking schools. American Educational Research Journal, 39(1), 37-67. 
APPENDIX A

1997 NLSY Questionnaire Items 


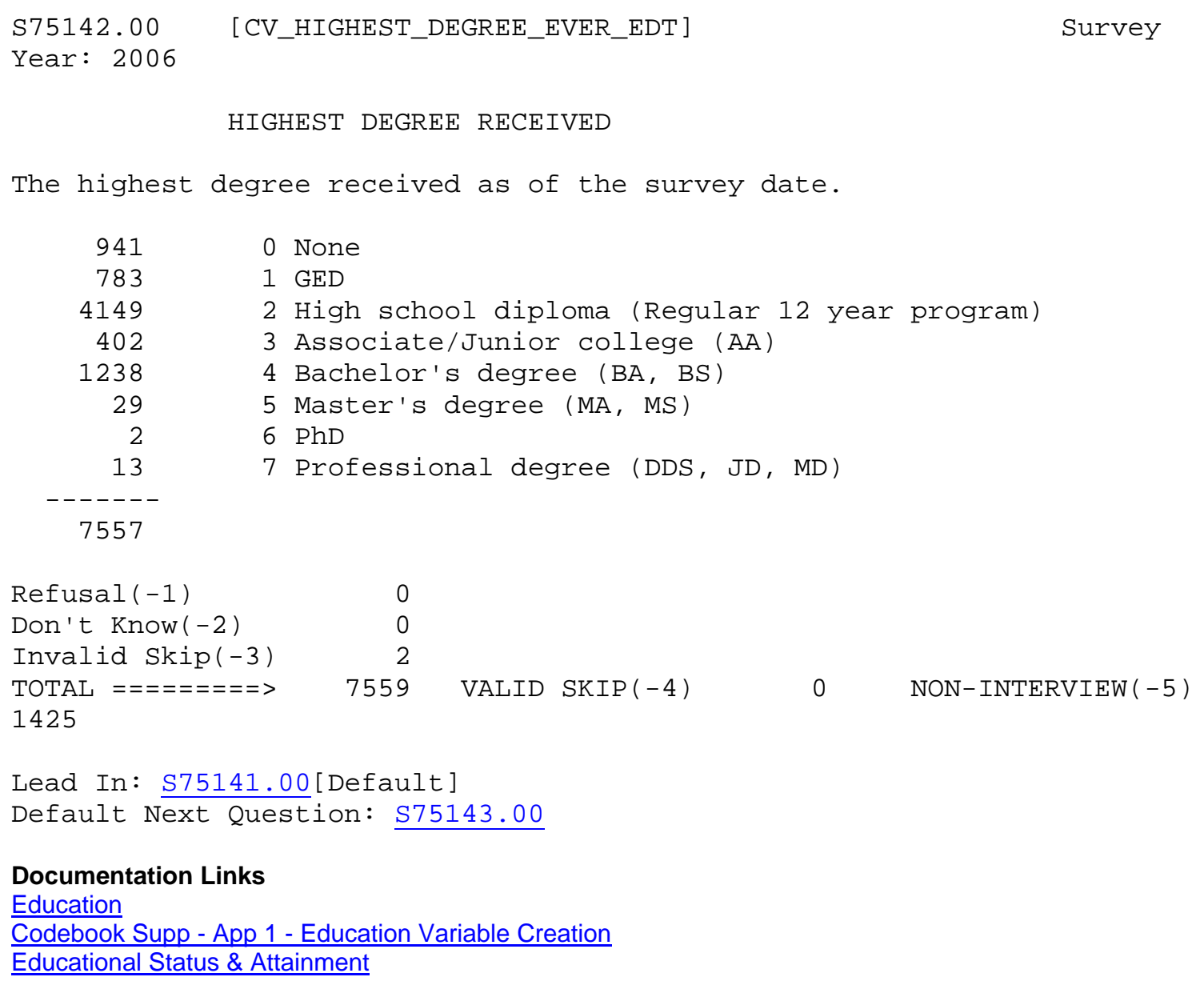




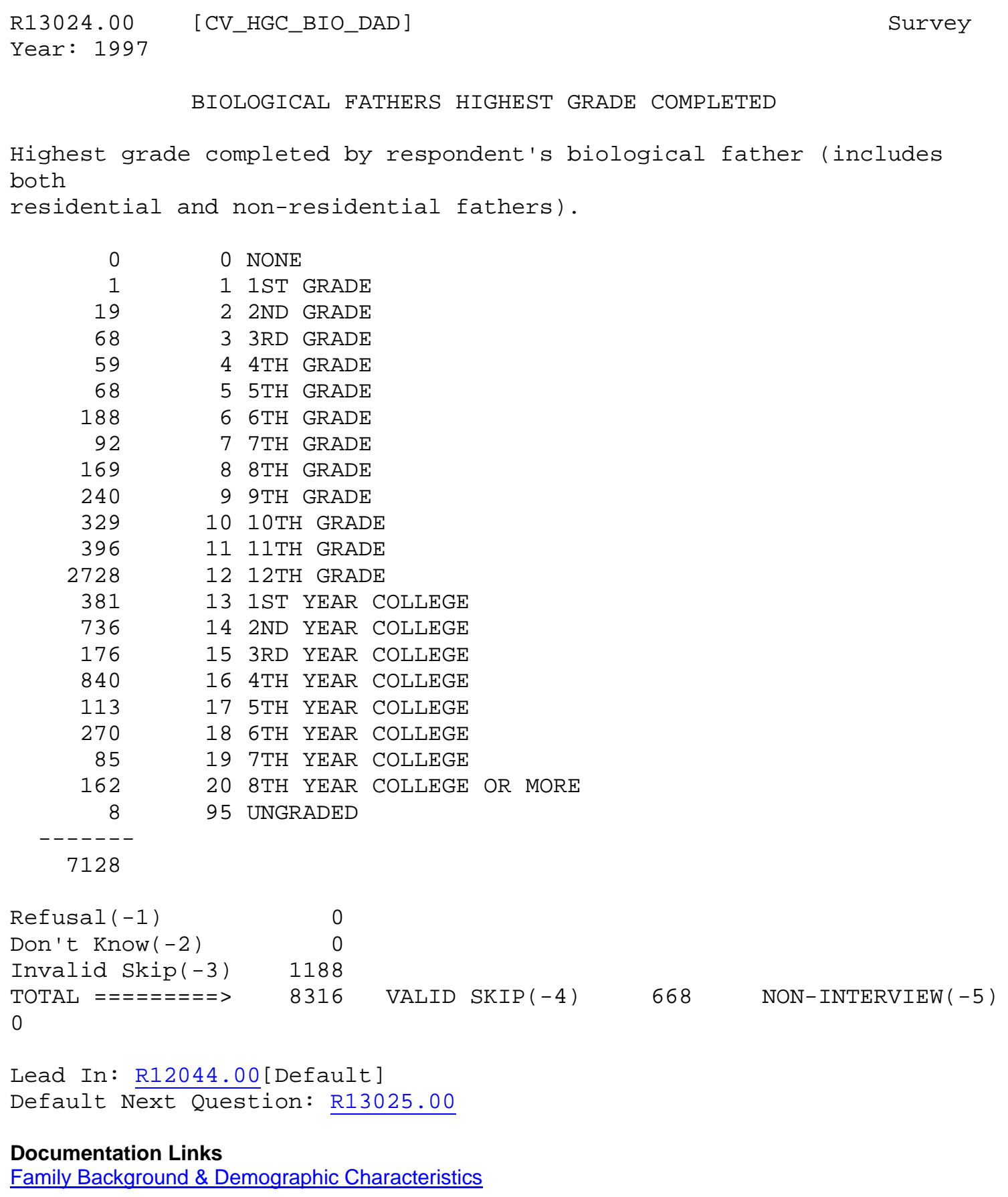




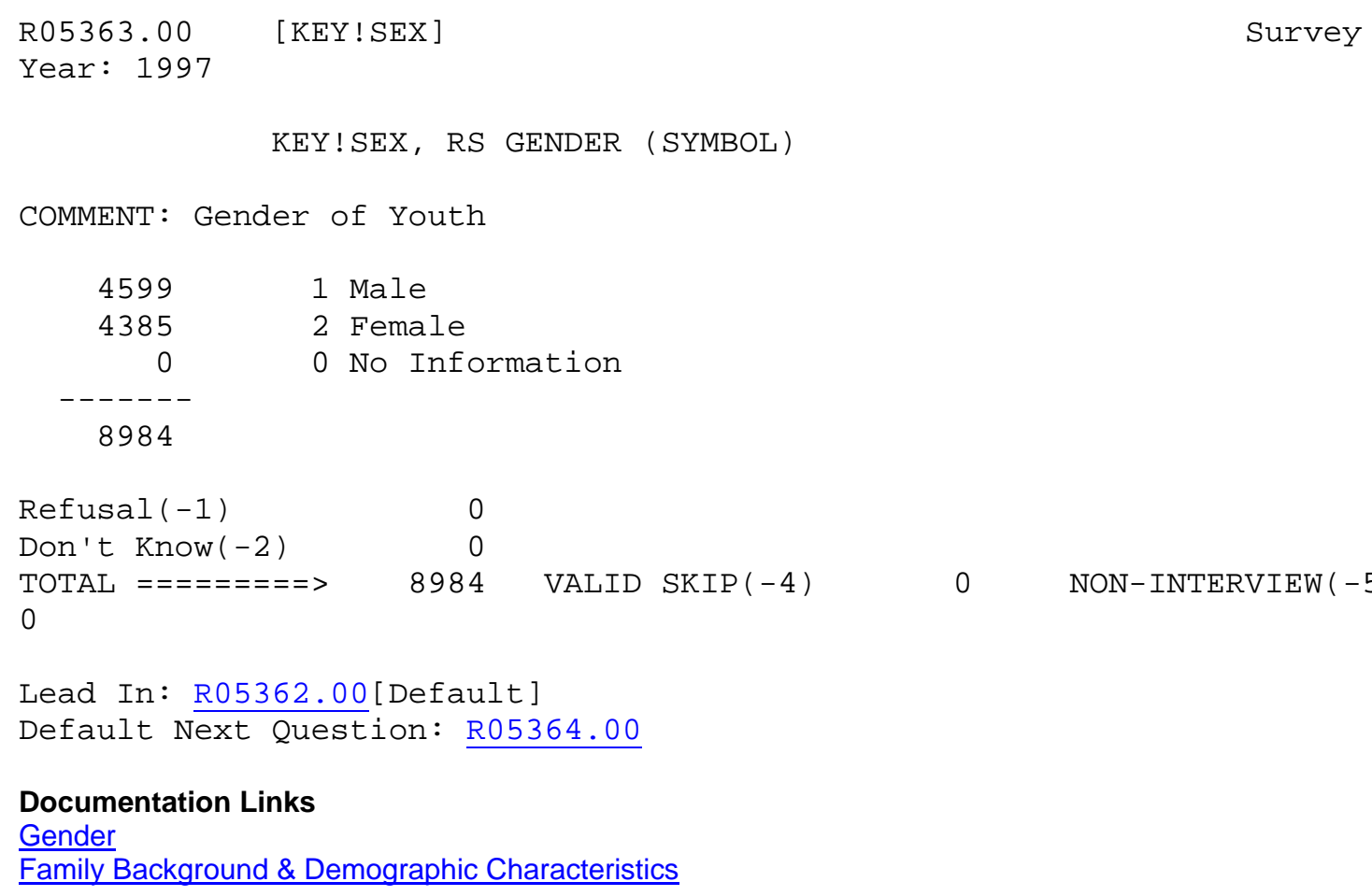

- SYMBOLS 


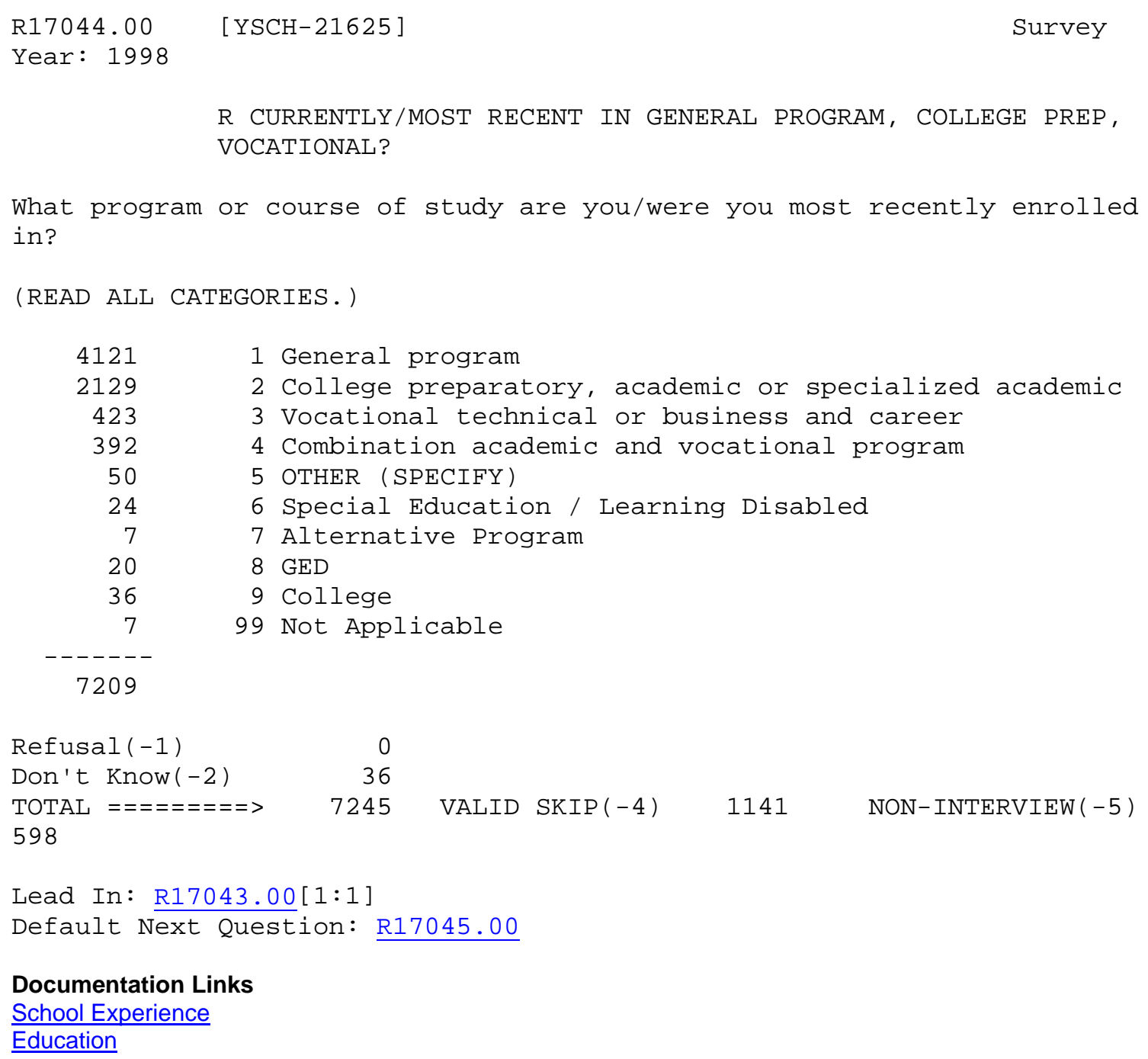


R12045.00

Year: 1997

\section{GROSS HH INCOME IN PAST YEAR}

Gross household income in the previous year.

$/{ }^{*}$ Topcoded at the $2 \backslash \%$ level. Truncated values are applied to the top 2 percent

of respondents with valid non-missing responses. The average value of the top 2

percent of cases is used as the value. Negative values of $-1,-2,-3$, -4 , or -5

do not reflect negative monetary amounts; these numbers represent standard

NLSY97 codes. * /

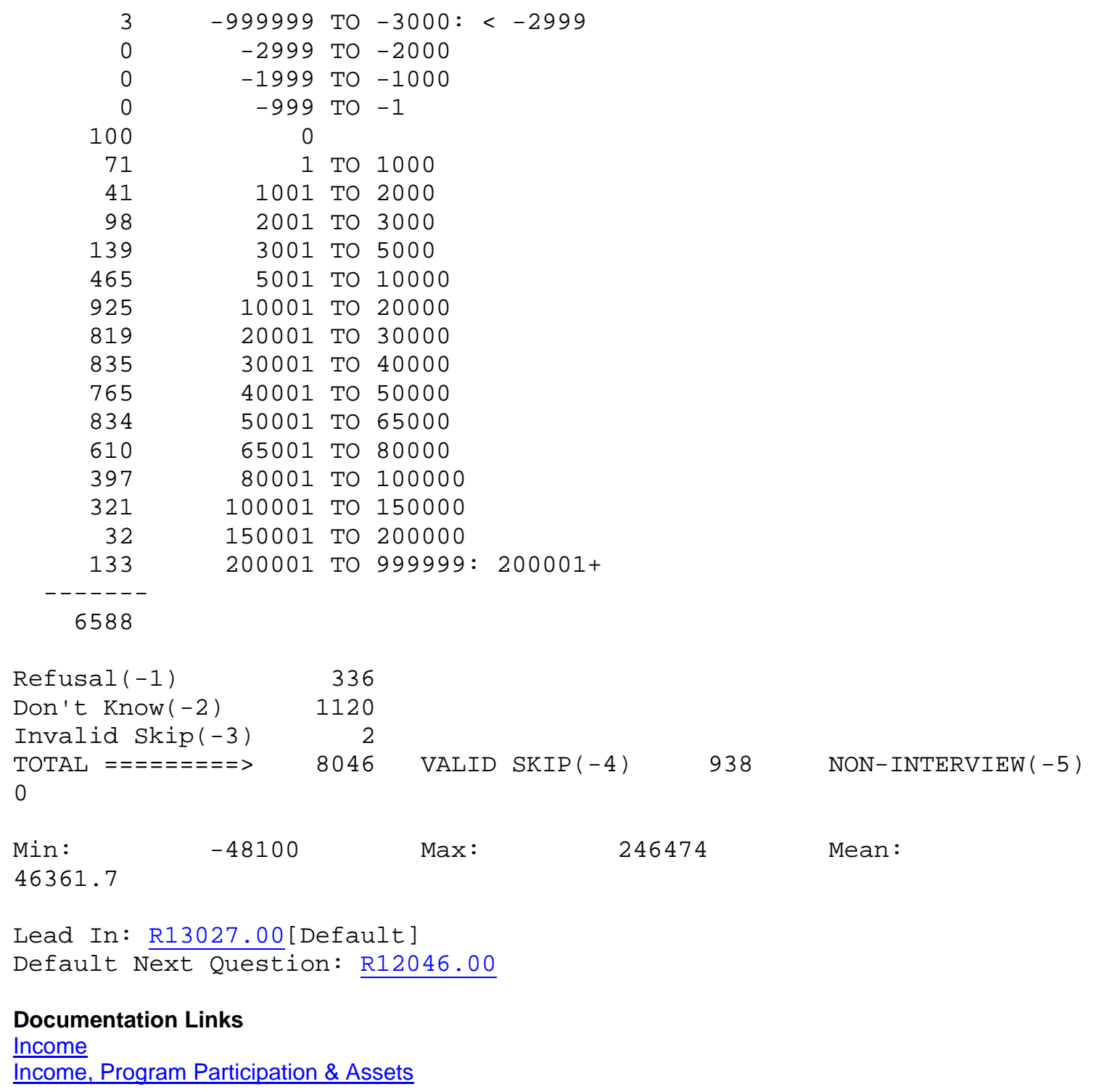


Areas of Interest

- $\quad$ CREATED VARIABLES

- INCOME

$\begin{array}{lll}\text { R13025. } 00 & \text { [CV_HGC_BIO_MOM] } & \text { Survey } \\ \text { Year: } 1997 & \end{array}$

BIOLOGICAL MOTHERS HIGHEST GRADE COMPLETED

Highest grade completed by respondent's biological mother (includes both

residential and non-residential mothers).

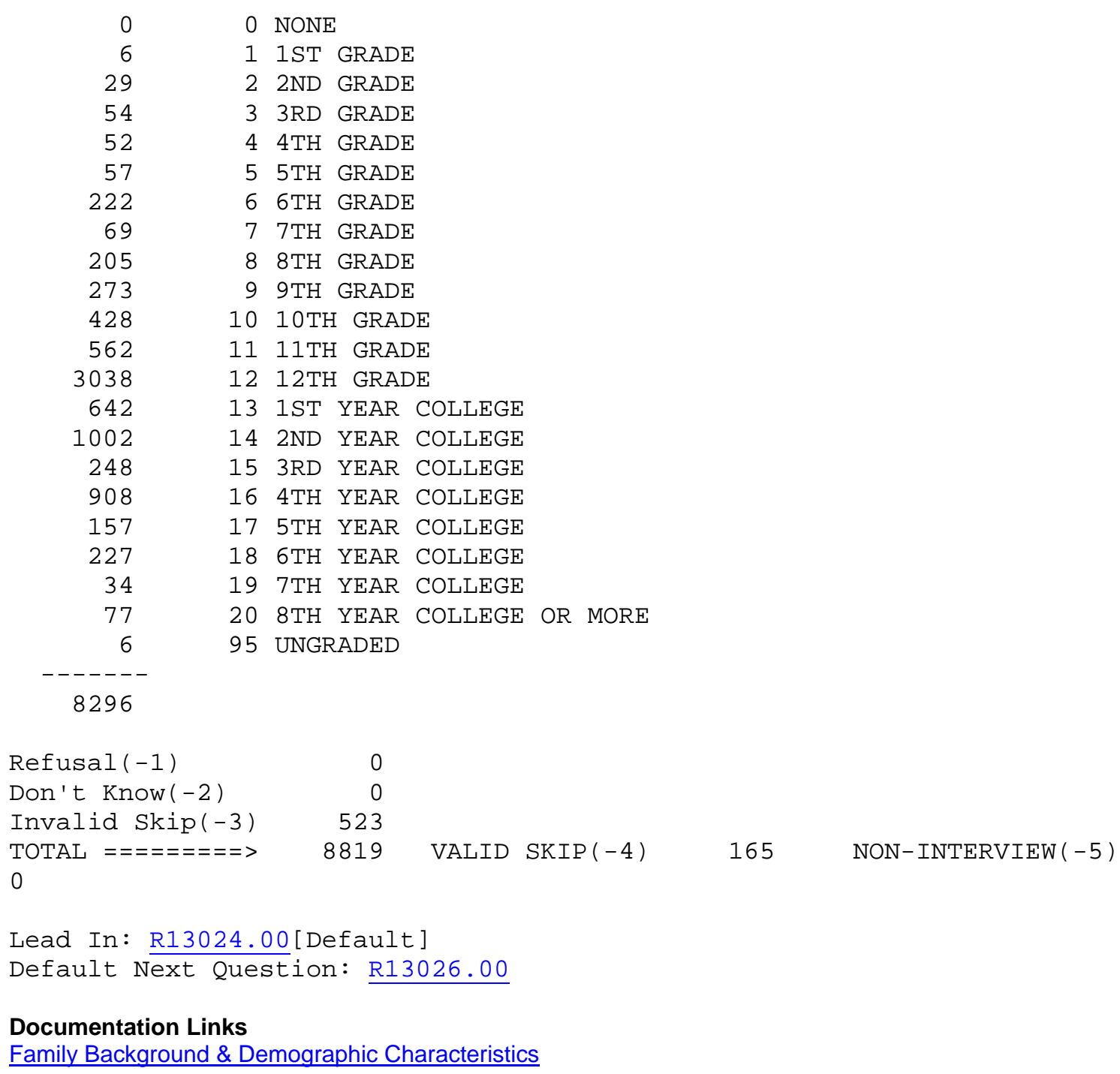

Documentation Links

Family Background \& Demographic Characteristics

\section{Areas of Interest}


- $\quad$ CREATED VARIABLES

- DEMOGRAPHIC INDICATORS

S84965.00 [YINC-1700]

Survey

Year: 2006

TOTAL INCOME FROM WAGES AND SALARY IN PAST YEAR

During 2005, how much income did you receive from wages, salary, commissions, or

tips from all jobs, before deductions for taxes or for anything else?

Truncated values are applied to the top 2 percent of respondents with valid

non-missing responses. The lowest value for the top 2 percent of cases is used

as the truncation level (\$80,471 for this variable). Values for all cases at

or over that level are averaged. That average is then assigned to each of the

top 2 percent of the cases.

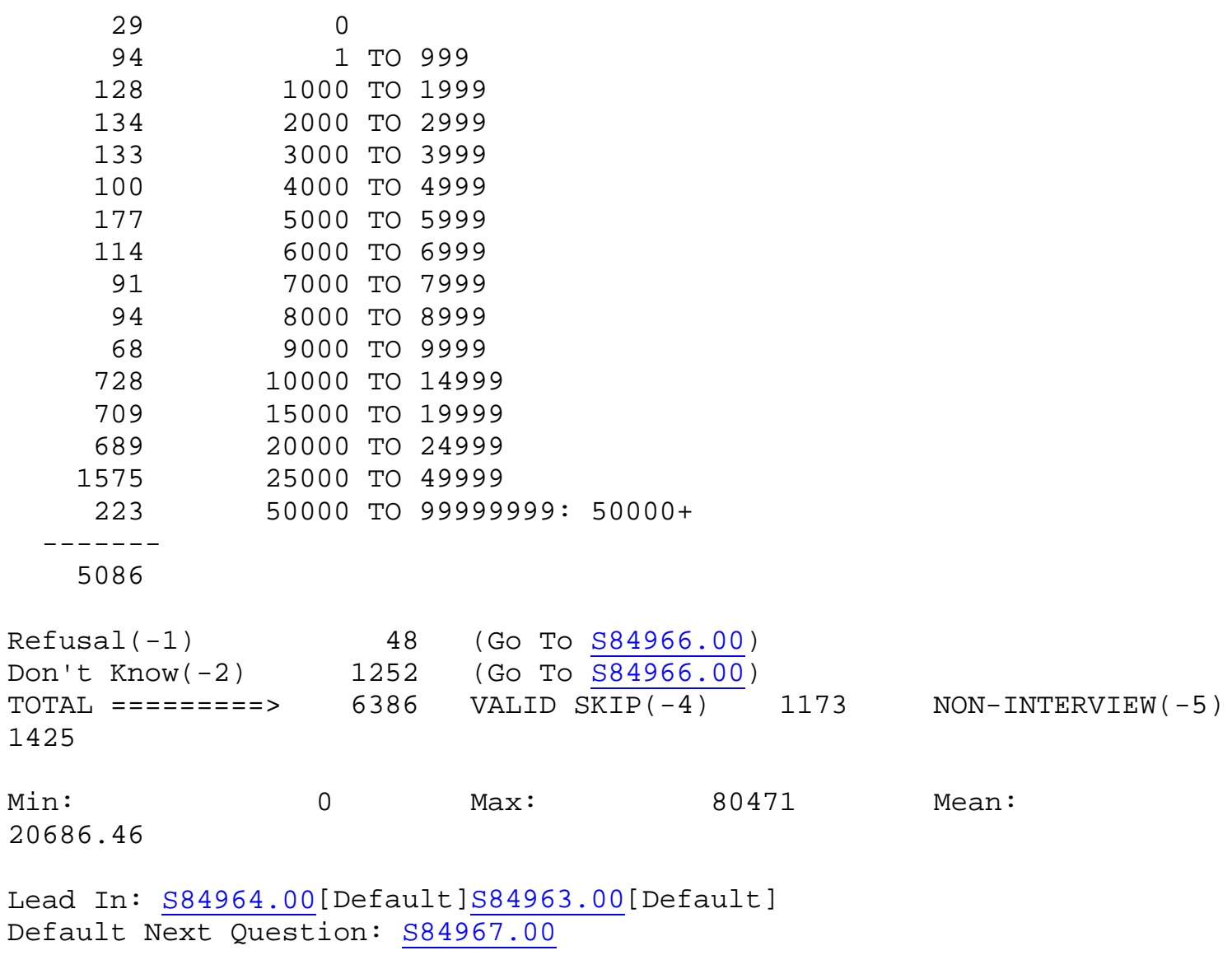


Documentation Links

Income, Program Participation \& Assets

Income

\section{Areas of Interest}

- INCOME

- WAGES \& COMPENSATION

R14826. 00

[KEY!RACE_ETHNICITY]

Year: 1997

KEY!RACE_ETHNICITY, COMBINED RACE AND ETHNICITY (SYMBOL)

COMMENT: Combined race - ethnicity variable

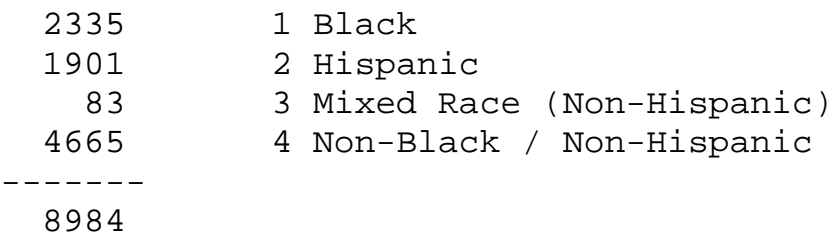

1 Black

2 Hispanic

3 Mixed Race (Non-Hispanic)

83

4 Non-Black / Non-Hispanic

$-\cdot-\cdots$

8984

Refusal (-1)

Don't $\operatorname{Know}(-2)$

$\odot$

TOTAL =ニニ=ニニ=ニ=> 8984 $\odot$

Lead In: R05387.00[Default]

Default Next Question: R05388.00

Documentation Links

Race \& Ethnicity

Family Background \& Demographic Characteristics

Area of Interest

- SYMBOLS 
APPENDIX B

Participation based on High School Curriculum Tracks 


\begin{tabular}{|c|c|c|c|c|c|c|}
\hline $\begin{array}{l}\text { College } \\
\text { Preparatory }\end{array}$ & B & Std. Error & Wald & $\mathrm{df}$ & Sig. & $\operatorname{Exp}(B)$ \\
\hline $\begin{array}{l}\text { Household } \\
\text { Income }\end{array}$ & .000 & .000 & 33.799 & 1 & .000 & 1.000 \\
\hline Female & -.426 & .075 & 32.140 & 1 & .000 & 1.531 \\
\hline $\begin{array}{l}\text { Mothers } \\
\text { with a High } \\
\text { School } \\
\text { Education }\end{array}$ & -.082 & .127 & .419 & 1 & .517 & 1.086 \\
\hline $\begin{array}{l}\text { Mothers } \\
\text { with a } \\
\text { College } \\
\text { Education }\end{array}$ & -.321 & .130 & 6.073 & 1 & .014 & 1.377 \\
\hline $\begin{array}{l}\text { Fathers } \\
\text { with a High } \\
\text { School } \\
\text { Education }\end{array}$ & -.380 & .121 & 9.911 & 1 & .002 & 1.462 \\
\hline $\begin{array}{l}\text { Fathers } \\
\text { with a } \\
\text { College } \\
\text { Education }\end{array}$ & -.540 & .128 & 17.804 & 1 & .000 & 1.715 \\
\hline Black & -.139 & .100 & 1.936 & 1 & .164 & .870 \\
\hline Hispanic & .089 & .111 & .647 & 1 & .421 & .915 \\
\hline
\end{tabular}




\begin{tabular}{|c|c|c|c|c|c|c|}
\hline CTE & B & Std. Error & Wald & df & Sig. & $\operatorname{Exp}(B)$ \\
\hline $\begin{array}{l}\text { Household } \\
\text { Income }\end{array}$ & .000 & .000 & 1.624 & 1 & .203 & 1.000 \\
\hline Female & .107 & .153 & .496 & 1 & .481 & 1.113 \\
\hline $\begin{array}{l}\text { Mothers } \\
\text { with a High } \\
\text { School } \\
\text { Education }\end{array}$ & .022 & .206 & .011 & 1 & .915 & 1.022 \\
\hline $\begin{array}{l}\text { Mothers } \\
\text { with a } \\
\text { College } \\
\text { Education }\end{array}$ & .322 & .240 & 1.807 & 1 & .179 & 1.380 \\
\hline $\begin{array}{l}\text { Fathers } \\
\text { with a High } \\
\text { School } \\
\text { Education }\end{array}$ & .060 & .194 & .095 & 1 & .758 & 1.062 \\
\hline $\begin{array}{l}\text { Fathers } \\
\text { with a } \\
\text { College } \\
\text { Education }\end{array}$ & .540 & .247 & 4.772 & 1 & .029 & .583 \\
\hline Black & -.516 & .179 & 8.320 & 1 & .004 & 1.675 \\
\hline Hispanic & .510 & .241 & 4.474 & 1 & .034 & .600 \\
\hline
\end{tabular}




\begin{tabular}{lllllll}
\hline Dual & B & Std. Error & Wald & df & Sig. & Exp(B) \\
\hline $\begin{array}{l}\text { Household } \\
\text { Income }\end{array}$ & .000 & .000 & 1.294 & 1 & .255 & 1.000 \\
Female & .341 & .150 & 5.187 & 1 & .023 & .711 \\
$\begin{array}{l}\text { Mothers } \\
\text { with a High }\end{array}$ & -.130 & .218 & .357 & 1 & .550 & .878 \\
$\begin{array}{l}\text { School } \\
\text { Education }\end{array}$ & & & & & & \\
$\begin{array}{l}\text { Mothers } \\
\text { with a }\end{array}$ & .097 & .242 & .160 & 1 & .690 & 1.102 \\
$\begin{array}{l}\text { College } \\
\text { Education }\end{array}$ & & & & & & \\
$\begin{array}{l}\text { Fathers } \\
\text { with a High }\end{array}$ & -.176 & .208 & .720 & 1 & .396 & .838 \\
$\begin{array}{l}\text { School } \\
\text { Education }\end{array}$ & & & & & & \\
$\begin{array}{l}\text { Fathers } \\
\text { with a }\end{array}$ & -.102 & .237 & .186 & 1 & .666 & .903 \\
$\begin{array}{l}\text { College } \\
\text { Education }\end{array}$ & & & & & & \\
$\begin{array}{l}\text { Black } \\
\text { Hispanic }\end{array}$ & -.507 & .174 & 8.549 & 1 & .003 & .607 \\
\hline
\end{tabular}


APPENDIX C

Degree Attainment based on High School Curriculum Tracks 


\begin{tabular}{|c|c|c|c|c|c|c|}
\hline GED & B & Std. Error & Wald & $\mathrm{df}$ & Sig. & $\operatorname{Exp}(B)$ \\
\hline $\begin{array}{l}\text { Household } \\
\text { Income }\end{array}$ & .000 & .000 & 6.209 & 1 & .013 & 1.000 \\
\hline Female & -.136 & .174 & .617 & 1 & .432 & .873 \\
\hline $\begin{array}{l}\text { Mothers } \\
\text { with a High } \\
\text { School } \\
\text { Education }\end{array}$ & -.557 & .215 & 6.725 & 1 & .010 & 1.745 \\
\hline $\begin{array}{l}\text { Mothers } \\
\text { with a } \\
\text { College } \\
\text { Education }\end{array}$ & -.844 & .262 & 10.382 & 1 & .001 & 2.326 \\
\hline $\begin{array}{l}\text { Fathers } \\
\text { with a High } \\
\text { School } \\
\text { Education }\end{array}$ & -.264 & .210 & 1.578 & 1 & .209 & .768 \\
\hline $\begin{array}{l}\text { Fathers } \\
\text { with a } \\
\text { College } \\
\text { Education }\end{array}$ & -.267 & .269 & .991 & 1 & .320 & .765 \\
\hline Black & -.143 & .212 & .453 & 1 & .501 & .867 \\
\hline Hispanic & -.081 & .239 & .115 & 1 & .734 & .922 \\
\hline $\begin{array}{l}\text { College } \\
\text { Preparatory }\end{array}$ & -.423 & .279 & 2.289 & 1 & .130 & .655 \\
\hline CTE & -.338 & .338 & .996 & 1 & .318 & .713 \\
\hline Dual & -.542 & .414 & 1.717 & 1 & .190 & .582 \\
\hline
\end{tabular}




\begin{tabular}{|c|c|c|c|c|c|c|}
\hline $\begin{array}{l}\text { High } \\
\text { School } \\
\text { Diploma }\end{array}$ & B & Std. Error & Wald & df & Sig. & $\operatorname{Exp}(B)$ \\
\hline $\begin{array}{l}\text { Household } \\
\text { Income }\end{array}$ & .000 & .000 & 31.401 & 1 & .000 & 1.000 \\
\hline Female & -.365 & .138 & 6.950 & 1 & .008 & 1.441 \\
\hline $\begin{array}{l}\text { Mothers } \\
\text { with a High } \\
\text { School } \\
\text { Education }\end{array}$ & -.733 & .166 & 19.408 & 1 & .000 & 2.083 \\
\hline $\begin{array}{l}\text { Mothers } \\
\text { with a } \\
\text { College } \\
\text { Education }\end{array}$ & -1.091 & .209 & 27.317 & 1 & .000 & 2.976 \\
\hline $\begin{array}{l}\text { Fathers } \\
\text { with a High } \\
\text { School } \\
\text { Education }\end{array}$ & -.852 & .167 & 26.082 & 1 & .000 & 2.342 \\
\hline $\begin{array}{l}\text { Fathers } \\
\text { with a } \\
\text { College } \\
\text { Education }\end{array}$ & -.931 & .215 & 18.668 & 1 & .000 & 2.538 \\
\hline Black & .096 & .173 & .308 & 1 & .579 & 1.101 \\
\hline Hispanic & -.500 & .186 & 7.253 & 1 & .007 & .606 \\
\hline $\begin{array}{l}\text { College } \\
\text { Preparatory }\end{array}$ & -1.230 & .227 & 29.389 & 1 & .000 & 3.425 \\
\hline CTE & -.510 & .277 & 3.403 & 1 & .065 & .600 \\
\hline Dual & -.981 & .344 & 8.121 & 1 & .004 & 2.667 \\
\hline
\end{tabular}




\begin{tabular}{|c|c|c|c|c|c|c|}
\hline $\begin{array}{l}\text { Associate's } \\
\text { Degree }\end{array}$ & B & Std. Error & Wald & $\mathrm{df}$ & Sig. & $\operatorname{Exp}(B)$ \\
\hline $\begin{array}{l}\text { Household } \\
\text { Income }\end{array}$ & .000 & .000 & 22.244 & 1 & .000 & 1.000 \\
\hline Female & -.617 & .188 & 10.769 & 1 & .001 & 1.852 \\
\hline $\begin{array}{l}\text { Mothers } \\
\text { with a High } \\
\text { School } \\
\text { Education }\end{array}$ & -.685 & .259 & 6.995 & 1 & .008 & 1.984 \\
\hline $\begin{array}{l}\text { Mothers } \\
\text { with a } \\
\text { College } \\
\text { Education }\end{array}$ & -.927 & .296 & 9.825 & 1 & .002 & 2.597 \\
\hline $\begin{array}{l}\text { Fathers } \\
\text { with a High } \\
\text { School } \\
\text { Education }\end{array}$ & -.953 & .255 & 13.948 & 1 & .000 & 3.367 \\
\hline $\begin{array}{l}\text { Fathers } \\
\text { with a } \\
\text { College } \\
\text { Education }\end{array}$ & -1.214 & .299 & 16.515 & 1 & .000 & .297 \\
\hline Black & .660 & .249 & 6.996 & 1 & .008 & .517 \\
\hline Hispanic & -.101 & .263 & .147 & 1 & .701 & .904 \\
\hline $\begin{array}{l}\text { College } \\
\text { Preparatory }\end{array}$ & -1.652 & .265 & 38.800 & 1 & .000 & 5.076 \\
\hline CTE & -.716 & .387 & 3.418 & 1 & .064 & .489 \\
\hline Dual & -1.450 & .414 & 12.281 & 1 & .000 & 5.208 \\
\hline
\end{tabular}




\begin{tabular}{|c|c|c|c|c|c|c|}
\hline $\begin{array}{l}\text { Bachelor's } \\
\text { Degree }\end{array}$ & B & Std. Error & Wald & $\mathrm{df}$ & Sig. & $\operatorname{Exp}(B)$ \\
\hline $\begin{array}{l}\text { Household } \\
\text { Income }\end{array}$ & .000 & .000 & 57.586 & 1 & .000 & 1.000 \\
\hline Female & -.961 & .161 & 35.452 & 1 & .000 & 2.618 \\
\hline $\begin{array}{l}\text { Mothers } \\
\text { with a High } \\
\text { School } \\
\text { Education }\end{array}$ & -.947 & .251 & 14.233 & 1 & .000 & 2.577 \\
\hline $\begin{array}{l}\text { Mothers } \\
\text { with a } \\
\text { College } \\
\text { Education }\end{array}$ & -1.763 & .276 & 40.689 & 1 & .000 & 5.814 \\
\hline $\begin{array}{l}\text { Fathers } \\
\text { with a High } \\
\text { School } \\
\text { Education }\end{array}$ & -1.482 & .254 & 34.038 & 1 & .000 & 4.405 \\
\hline $\begin{array}{l}\text { Fathers } \\
\text { with a } \\
\text { College } \\
\text { Education }\end{array}$ & -2.279 & .285 & 63.863 & 1 & .000 & 9.804 \\
\hline Black & .644 & .210 & 9.397 & 1 & .002 & .525 \\
\hline Hispanic & .044 & .232 & .037 & 1 & .848 & 1.045 \\
\hline $\begin{array}{l}\text { College } \\
\text { Preparatory }\end{array}$ & -2.294 & .240 & 91.714 & 1 & .000 & 9.901 \\
\hline CTE & .353 & .440 & .642 & 1 & .423 & 1.423 \\
\hline Dual & -.441 & .433 & 1.033 & 1 & .309 & .644 \\
\hline
\end{tabular}




\begin{tabular}{|c|c|c|c|c|c|c|}
\hline $\begin{array}{l}\text { Graduate } \\
\text { Degree }\end{array}$ & B & Std. Error & Wald & $\mathrm{df}$ & Sig. & $\operatorname{Exp}(B)$ \\
\hline $\begin{array}{l}\text { Household } \\
\text { Income }\end{array}$ & .000 & .000 & 37.554 & 1 & .000 & 1.000 \\
\hline Female & -1.570 & .465 & 11.403 & 1 & .001 & 4.808 \\
\hline $\begin{array}{l}\text { Mothers } \\
\text { with a High } \\
\text { School } \\
\text { Education }\end{array}$ & -.393 & .916 & .184 & 1 & .668 & .675 \\
\hline $\begin{array}{l}\text { Mothers } \\
\text { with a } \\
\text { College } \\
\text { Education }\end{array}$ & -1.917 & .853 & 5.045 & 1 & .025 & 6.803 \\
\hline $\begin{array}{l}\text { Fathers } \\
\text { with a High } \\
\text { School } \\
\text { Education }\end{array}$ & .156 & .722 & .047 & 1 & .829 & 1.169 \\
\hline $\begin{array}{l}\text { Fathers } \\
\text { with a } \\
\text { College } \\
\text { Education }\end{array}$ & -.769 & .681 & 1.275 & 1 & .259 & .464 \\
\hline Black & -.023 & .524 & .002 & 1 & .965 & .977 \\
\hline Hispanic & .299 & .800 & .140 & 1 & .709 & 1.349 \\
\hline $\begin{array}{l}\text { College } \\
\text { Preparatory }\end{array}$ & -2.465 & .496 & 24.715 & 1 & .000 & 11.765 \\
\hline CTE & -1.039 & 1.107 & .882 & 1 & .348 & .354 \\
\hline Dual & -2.375 & .769 & 9.533 & 1 & .002 & 10.753 \\
\hline
\end{tabular}




\section{APPENDIX D}

Histogram of Residuals and Normal Probability Plot 


\section{Histogram}

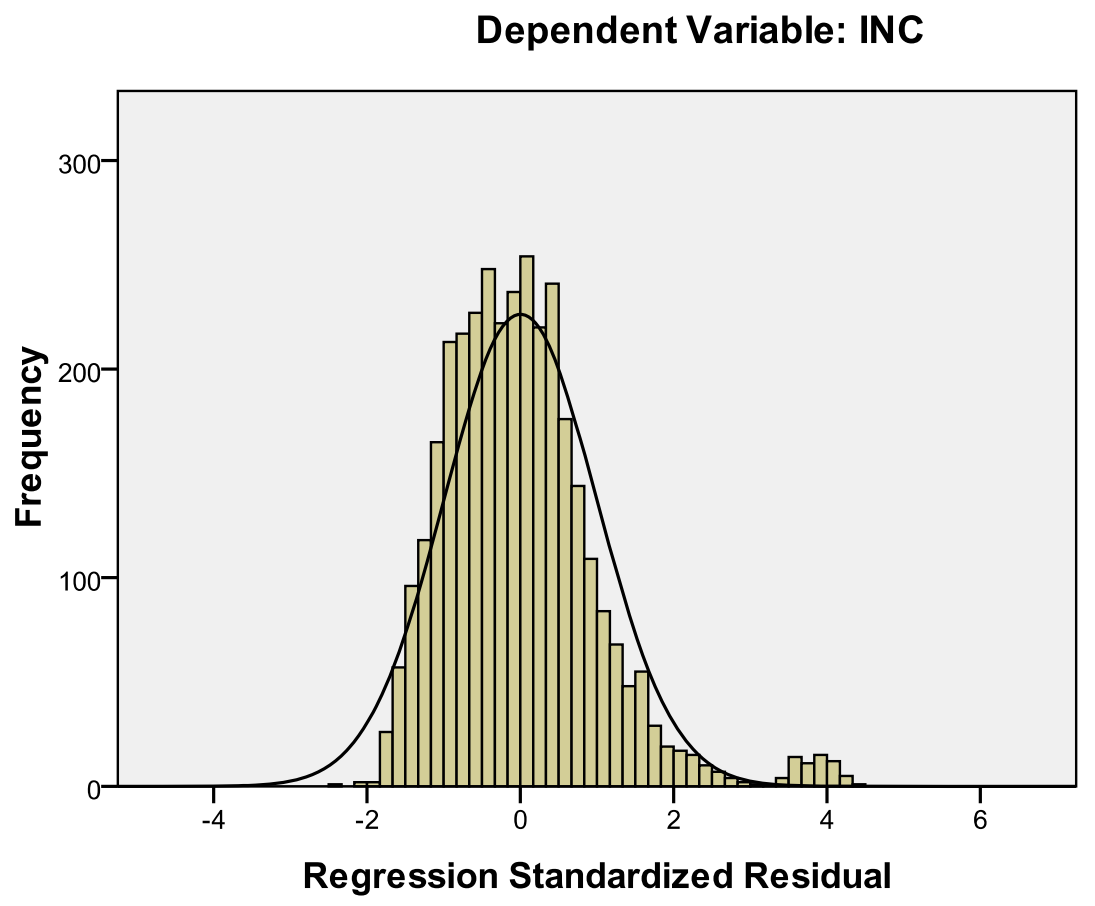

Mean $=-1.41 \mathrm{E}-18$

Std. Dev. $=0.998$

$\mathrm{N}=3,397$ 
APPENDIX E

Plot of Residuals and Predicted Y 
Normal P-P Plot of Regression Standardized Residual

Dependent Variable: INC

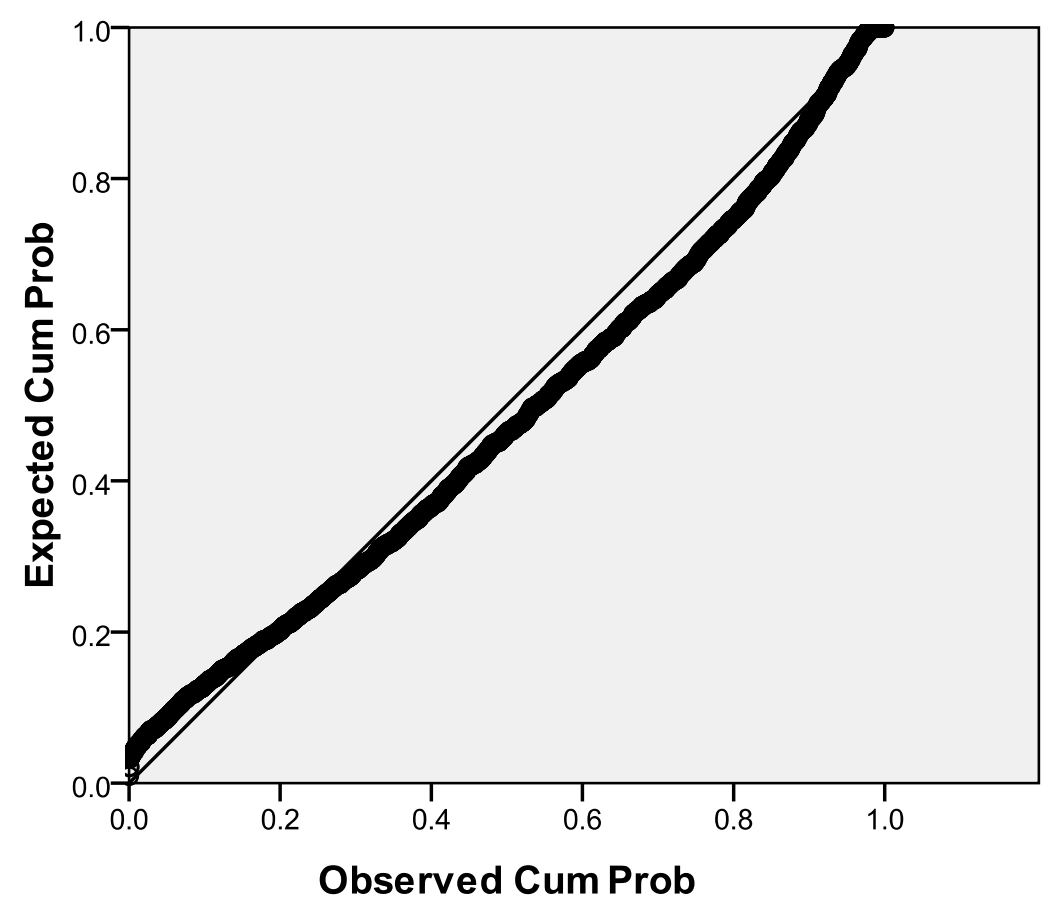


APPENDIX F

Predictors of Occupational Earnings 


\begin{tabular}{|c|c|c|c|c|c|}
\hline $\begin{array}{c}\text { Predictors of } \\
\text { Occupational } \\
\text { Earnings } \\
\end{array}$ & B & Std. Error & $\underline{b}$ & $\underline{\mathrm{t}}$ & $\mathrm{p}$ \\
\hline Gender & -6053.414 & 572.981 & -.200 & -10.523 & .000 \\
\hline Black & -2861.966 & 774.806 & -.074 & -3.694 & .000 \\
\hline Hispanic & 122.338 & 825.290 & .003 & .148 & .882 \\
\hline $\begin{array}{l}\text { Mothers } \\
\text { with a high } \\
\text { school } \\
\text { education }\end{array}$ & 877.886 & 911.485 & .028 & .963 & .336 \\
\hline $\begin{array}{l}\text { Mothers } \\
\text { with a } \\
\text { college } \\
\text { education }\end{array}$ & -1803.744 & 956.291 & -.060 & -1.886 & .059 \\
\hline $\begin{array}{l}\text { Fathers with } \\
\text { a high school } \\
\text { education }\end{array}$ & 409.425 & 865.144 & .013 & .473 & .636 \\
\hline $\begin{array}{c}\text { Fathers with } \\
\text { a college } \\
\text { education }\end{array}$ & 377.944 & 946.496 & .012 & .400 & .689 \\
\hline $\begin{array}{l}\text { Household } \\
\text { income }\end{array}$ & .025 & .008 & .070 & 3.5250 & .001 \\
\hline GED & -598.082 & 1590.851 & -.010 & -.376 & .707 \\
\hline $\begin{array}{l}\text { High School } \\
\text { Diploma }\end{array}$ & 2337.291 & 1256.407 & .077 & 1.860 & .063 \\
\hline $\begin{array}{l}\text { Associate's } \\
\text { Degree }\end{array}$ & 6856.878 & 1614.807 & .116 & 4.246 & .000 \\
\hline $\begin{array}{l}\text { Bachelor's } \\
\text { Degree }\end{array}$ & 5658.810 & 1418.535 & .159 & 3.989 & .000 \\
\hline $\begin{array}{l}\text { Graduate } \\
\text { Degree }\end{array}$ & 12903.845 & 3279.312 & .080 & 3.935 & .000 \\
\hline $\begin{array}{c}\text { College } \\
\text { preparatory }\end{array}$ & 1385.594 & 645.825 & .044 & 2.145 & .032 \\
\hline CTE & 3278.949 & 1313.253 & .048 & 2.497 & .013 \\
\hline Dual & 2753.545 & 1229.904 & .043 & 2.239 & .025 \\
\hline
\end{tabular}

$\mathrm{R}^{2}=.082$

Adjusted $\mathrm{R}^{2}=.077$

For model: $\mathrm{F}=14.72 ; \mathrm{p}<.001$ 